\title{
AVALIAÇÃO DO MODELO DE PENMAN-MONTEITH. PADRÃO FAO, PARA ESTIMAR A EVAPOTRANSPIRAÇÃO DE REFÊRENCIA NAS CONDIÇÕES CLIMÁTICAS DO ESTADO DE SÃO PAULO
}

\author{
JOSE GEANINI PERES \\ Engenheiro Agrónomo
}

\begin{abstract}
Orientador: Prof. Dr. JOSE ANTONIO FRIZZONE Co-orientador: Prof. Dr. ANTONIO ROBERTO PEREIRA
\end{abstract}

Tese apresentada a Escola Superior de Agricultura "Luiz de Queiroz", da Universidade de São Paulo, para obtenção do titulo de Doutor em Agronomia, Ärea de Concentração: Irrigação e Drenagem.

\author{
$P I R A C I C A B A$ \\ Estado de São Paulo - Brasil \\ Janeiro - 1994
}


Ficha catalografica preparada pela Seça de Livros da Divisao de Eiblioteca e Documentafá - PCLR/USP

Peres, José Geanini

F437a Avaliaço do modelo de Fenman-Monteith, padrao

FAO, para estimar a evapotranspiraço de referencia nas condiçBes climaticas do Estado de Sao Paulo. Piracicata, 1994 .

$116 p$.

TESE - ESALQ

Bibliogratia.

1. Cimatologia agrfcola 2. Evapotranspiraça 3. No delo de Fenman-Monteith i. Escola Superior de Agricultura Lliz de Gueiroz, Piracicaba 


\section{AVALIAÇÃO DO MODELO DE PENMAN-MONTEITH, PADRÃO FAO, PARA ESTIMAR A EVAPOTRANSPIRAÇÃO DE REFÊRENCIA NAS CONDIÇÕES CLIMÁTICAS DO ESTADO DE SÃO PAULO}

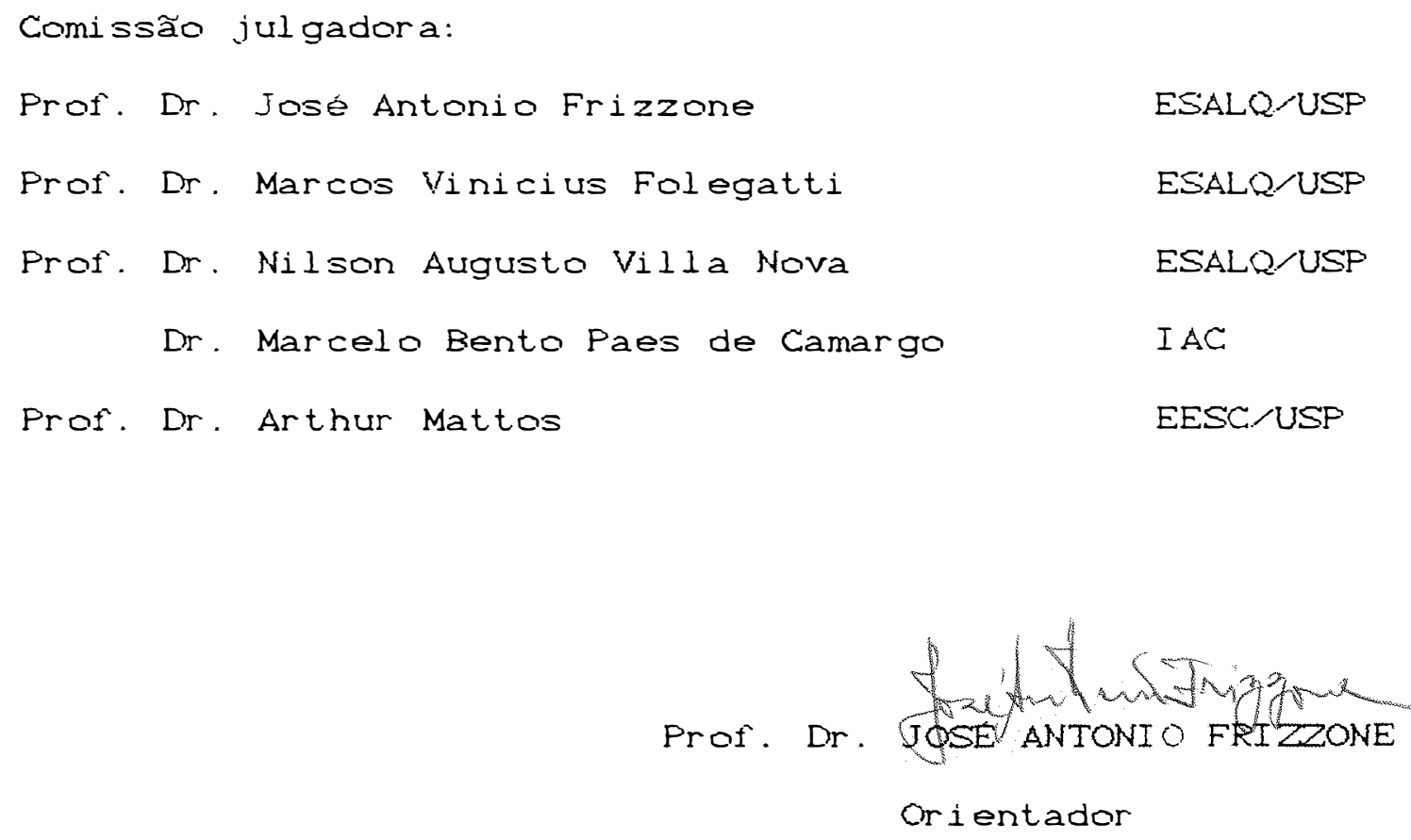


Ao meu filho Caio, meu paciente mestre nas artes e segredos da computação, pela participação decisiva na feitura deste trabalho.

Ao mestre Ángelo Paes de Camargo, pelo conjunto de sua obra em prol da ciencia brasileira.

OFEREÇO

A minha mulher Cátia e ao meu filho Danilo, pelo estimulo e confiança demonstrados 
Na realização deste trabalho, contei com a colaboração e estimulo permanentes dos Professores Antonio Roberto Pereira, José Antonio Frizzone e Nilson Augusto Villa Nova. A eles e a todos aqueles que de alguma forma contribuíram nesta empreitada 
LISTA DE FIGURAS. ..................... vii

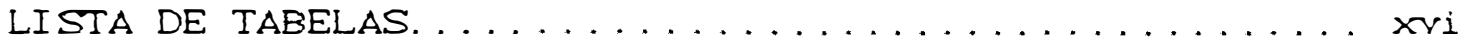

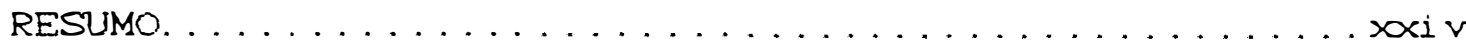

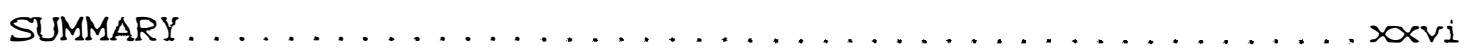

1. INTRODUÇRO ........................ 1

2. REVISTOO DA LI TERATURA.................... 7

3. MATERIAL E METODOS. .................... 26

3.1. Material....................... 26

3.1.1. Evapotranspiração de referência medida

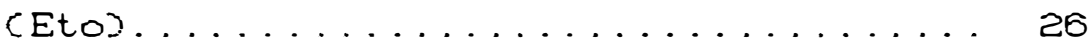

3.1.2. Obtenção dos dados climáticos........ 29

3.2. Metodos...................... 29

3.2.1. Cálculo dos parâmetros climáticos..... 29

3.2.1.1. Calor latente de vaporização. 30

3.2.1.2. Tangente à curva de pressão de satur ação do vapor d'água. 30

3.2.1.3. Pressão atmosférica........ 31

3.2.1.4. Constante psicrométrica..... 32 3.2.1.4.1. Constante psicrometrica modificada... 33

3.2.1.5. Massa especifica do ar...... 34 
vi.

3.2.1.6. Pressão de saturação do vapor d'agua............... 35

3.2.1.7. Pressão atual do vapor d'água. 36

3.2.1.8. Velocidade do vento........ 36

3. 2.1. 9. Radi ação sol ar 11quida....... 37

3.2.2. Estimativa da resistência aerodinâmica e do dossel................. 38

3.2.2.1. Resistência aerodinâmica..... 38

3.2.2.2. Resisténcia do dossel....... 41

3.2.3. Estimativa da evapotranspiração de referencia pelo modelo de Penman-Monteith 42

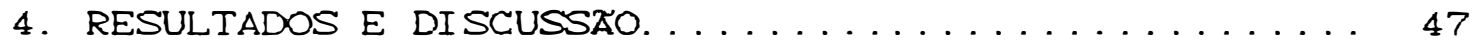

4.1. Relativos à evapotranspiração de referéncia estimada pelo modelo de Penman-Monteith (ETOM), padr ฐ̃o FAO. ............... 47

4.1.1. Periodicidade decadiária...........447

4.1.2. Periodicidade mensal............ 51

4.2. Relativos à sensibilidade do modelo de PenmanMonteith a variaçỡes da altura da vegetação e da resistência do dossel.............. s6

4. 3. Relativos à resistencia do dossel.......... 78

5. CONCLUSOES. ........................ 83

REFERENCIA BI BLI OGRAFICA. . . . . . . . . . . . 85

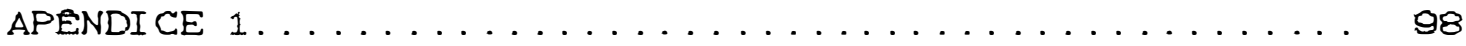

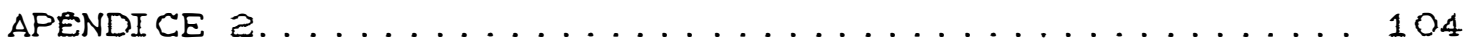


1: Evapotranspiração de referencia decadiaria estimada pelo modelo de Penman-Monteith (ETOM) versus a medida em evapotranspirometros de drenagem (ETo) em relação à reta 1:1. Campinas-SP. Per 10do de 1956 a 1959.....

2: Evapotranspiração de referencia decadiária estimada pelo modelo de Penman-Monteith CETOM versus a medida em evapotranspirómetios de drenagem (ETo) em relação à reta 1:1. Ribeirão Preto-SP. Período de 1956 a

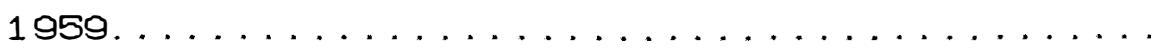

3: Evapotranspiração de referencia decadiária estimada pelo modelo de Penman-Monteith CETOM versus a medida em evapotranspirometros de drenagem (ETo) em relação à reta 1:1. Pindamonhangaba-SP. Periodo de 1954 a

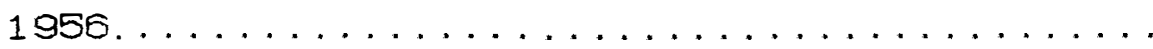


viii.

4: Evapotranspiração de referencia mensal estimada pelo modelo de Penman-Monteith (ETOM) versus a medida em evapotranspirómetros de drenagem (ETo) em relação à reta $1: 1$. Campinas-SP. Per 1 odo de 1956 a $1959 \ldots . . .53$

5: Evapotranspiração de referência mensal estimada pelo modelo de Penman-Monteith (ETOM) versus a medida em evapotranspirómetros de drenagem (ETo) em relação à reta 1:1. Ribeirão Preto-SP. Período de 1956 a

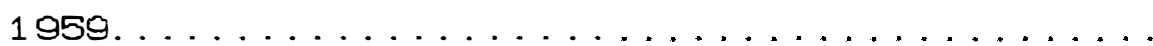

6: Evapotranspiração de referéncia mensal estimada pelo modelo de Penman-Monteith (ETOM versus a medida em evapotranspirómetros de drenagem (ETO) em relação à reta 1:1. Pindamonhangaba-SP. Período de 1954 a

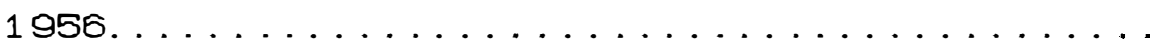

7: Evapotranspiração de referéncia decadiária estimada pelo modelo de Penman-Monteith (ETOM $\left.{ }_{0600}\right)^{2}$ versus a medida em evapotranspirómetros de drenagem (ETo) em relação à reta 1:1. Campinas-SP. Período de 1956 a

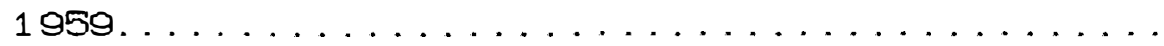


$i x$.

8: Evapotranspiração de referéncia decadiária estimada pelo modelo de Penman-Monteith CETOM $_{\text {oc20 }}$ ' versus a medida em evapotranspirómetros de drenagem (ETo) em relação à reta 1:1. Campinas-SP. Periodo de 1956 a

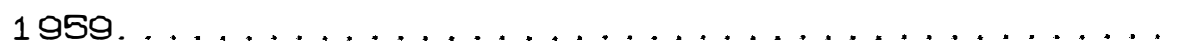

9: Evapotranspiração de referéncia decadiária estimada pelo modelo de Penman-Monteith CETOM $0040^{2}$ versus a medida em evapotranspirómetros de drenagem (ETo) em relação à reta 1:1. Campinas-SP. Periodo de 1956 a $1959 . \ldots \ldots \ldots \ldots \ldots \ldots \ldots \ldots \ldots \ldots . \ldots \ldots \ldots$

10: Evapotranspiração de referencia decadiária estimada pelo modelo de Penman-Monteith CETOM ${ }_{0000}{ }^{3}$ versus a medida em evapotranspirómetros de drenagem (ETo) em relação à reta 1:1. Campinas-SP. Periodo de 1956 a

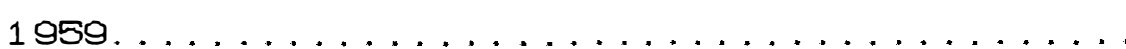

11: Evapotranspiração de referéncia decadiária estimada pelo modelo de Penman-Monteith CETOM ${ }_{0600}$ ? versus a medida em evapotranspirómetros de drenagem (ETo) em relação à reta 1:1. Campinas-SP. Periodo de 1956 a

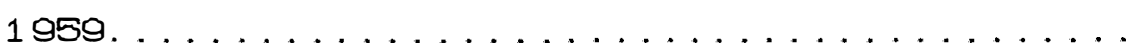


12: Evapotranspiração de referência decadiária estimada pelo modelo de Penman-Monteith (ETOM $_{\text {oovR }}$ ) versus a medida em evapotranspirómetros de drenagem (ETO) em relação à reta 1:1. Campinas-SP. Período de 1956 a

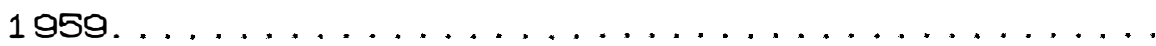

13: Evapotranspiração de referência decadiária estimada pelo modelo de Penman-Monteith $\left(\text { ETOM }_{\mathbf{1 2 0 0}}\right)^{2}$ versus a medida em evapotranspirómet.ros de drenagem (ETO) em relação à reta 1:1. Campinas-SP. Período de 1956 a

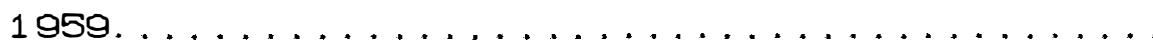

14: Evapotranspiração de referência decadiária estimada pelo modelo de Penman-Monteith (ETOM $_{1220}{ }^{3}$ versus a medida em evapotranspirómetros de drenagem (ETO) em relação à reta 1:1. Campinas-SP. Período de 1956 a

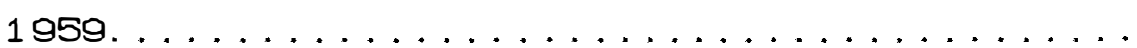

15: Evapotranspiração de referência decadiária estimada pelo modelo de Penman-Monteith CETOM $\left._{1240}\right)^{2}$ versus a medida em evapotranspirómetros de drenagem (ETo) em relação à reta 1:1. Campinas-SP. Período de 1956 a

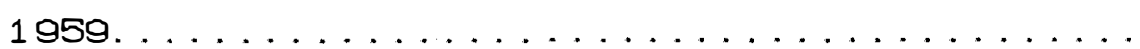


16: Evapotranspiração de referencia decadiária estimada pelo modelo de Penman-Monteith (ETOM $\left.{ }_{1200}\right)^{2}$ versus a medida em evapotranspirómetros de drenagem (ETo) em relação à reta 1:1. Campinas-SP. Período de 1956 a

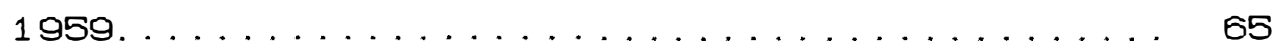

17: Evapotranspiração de referência decadiária estimada pelo modelo de Penman-Monteith (ETOM $\left._{1280}\right)^{2}$ versus a medida em evapotranspirómetros de drenagem (ETo) em relação à reta 1:1. Campinas-SP. Período de 1956 a

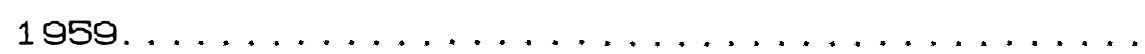

66

18: Evapotranspiração de referéncia decadiária estimada pelo modelo de Penman-Monteith CETOM $_{12 V_{R}}{ }^{2}$ versus a medida em evapotranspirómetros de drenagem (ETo) em relação à reta 1:1. Campinas-SP. Período de 1956 a

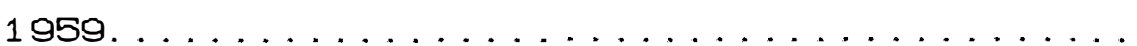

66

19: Evapotranspiração de referencia mensal estimada pelo modelo de Penman-Monteith (ETOM 0000 ' versus a medida em evapotranspirómetros de drenagem (ETo) em relação à reta 1:1. Campinas-SP. Período de 1956 a

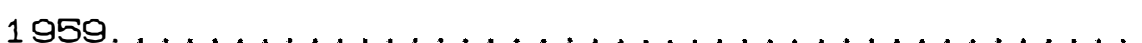


20: Evapotranspiração de referencia mensal estimada pelo modelo de Penman-Monteith (ETOM $\left._{0020}\right)^{2}$ versus a medida em evapotranspirómetros de drenagem (ETo) em relação à reta 1:1. Campinas-SP. Período de 1956 a

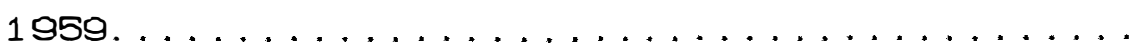

21: Evapotranspiração de referencia mensal estimada pelo modelo de Penman-Monteith

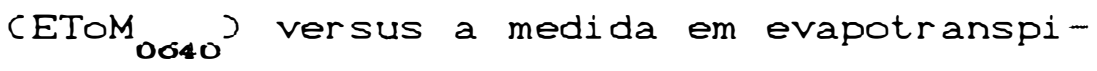
rómetros de drenagem (ETo) em relação à reta 1:1. Campinas-SP. Período de 1956 a

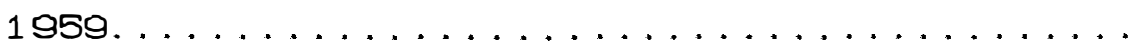

22: Evapotranspiração de referéncia mensal estimada pelo modelo de Penman-Monteith (ETOM $\left._{\text {o600 }}\right)^{2}$ versus a medida em evapotranspirómetros de drenagem (ETo) em relação à reta 1:1. Campinas-SP. Período de 1956 a

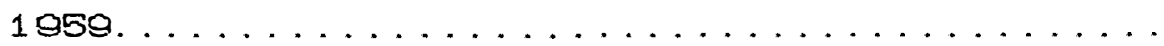

23: Evapotranspiração de referencia mensal estimada pelo modelo de Penman-Monteith (ETOM ${ }_{\text {ocao }}$ ) versus a medida em evapotranspirómetros de drenagem (ETo) em relação à reta 1:1. Campinas-SP. Período de 1956 a

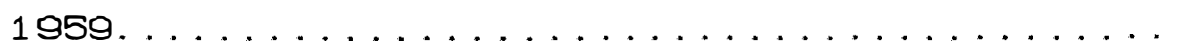


24: Evapotranspiração de referéncia mensal estimada pelo modelo de Penman-Monteith (ETOM DOVR' versus a medida em evapotranspirómetros de drenagem (ETo) em relação à reta 1:1. Campinas-SP. Periodo de 1956 a

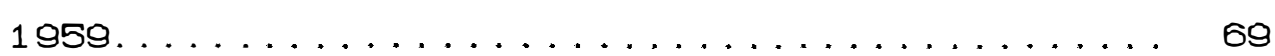

25: Evapotranspiração de referéncia mensal estimada pelo modelo de Penman-Monteith CETOM $_{1200}{ }^{2}$ versus a medida em evapotranspirómetros de drenagem (ETo) em relação à reta 1:1. Campinas-SP. Periodo de 1956 a

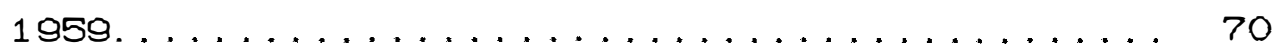

26: Evapotranspiração de referéncia mensal estimada pelo modelo de Penman-Monteith CETOM $_{1220}$ ' versus a medida em evapotranspirómetros de drenagem (ETo) em relação à reta 1:1. Campinas-SP. Periodo de 1956 a

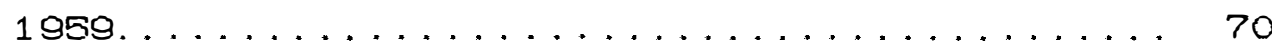

27: Evapotranspiração de referéncia mensal estimada pelo modelo de Penman-Monteith (ETOM $\left._{1240}\right)^{3}$ versus a medida em evapotranspirómetros de drenagem (ETo) em relação à reta 1:1. Campinas-SP. Periodo de 1956 a

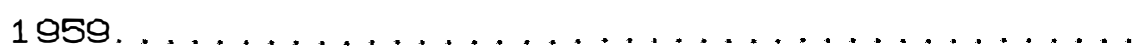


28: Evapotranspiração de referencia mensal estimada pelo modelo de Penman-Monteith

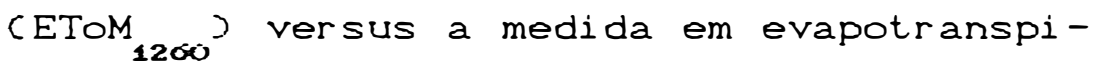
rómetros de drenagem (ETo) em relação à reta 1:1. Campinas-SP. Período de 1956 a

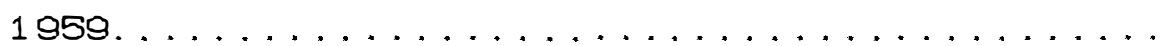

29: Evapotranspiração de referencia mensal estimada pelo modelo de Penman-Monteith

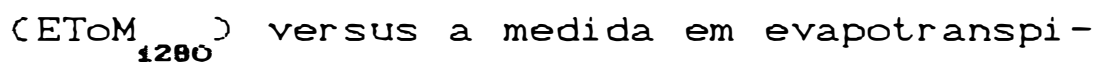
rómetros de drenagem (ETo) em relação à reta 1:1. Campinas-SP. Período de 1956 a

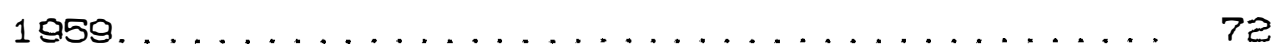

30: Evapotranspiração de referencia mensal estimada pelo modelo de Penman-Monteith (ETOM $_{12 V R}$ ) versus a medida em evapotranspirómetros de drenagem (ETo) em relação à reta 1:1. Campinas-SP. Período de 1956 a $1959 \ldots \ldots \ldots \ldots \ldots \ldots \ldots \ldots \ldots$

31: Variação temporal decadiária média da resistencia do dossel, considerando 0 è alturas de vegetação, obtida a partir da aplicação do modelo de Penman-Monteith aos valores medidos da evapotranspiração de refe- 
xV.

rencia coletados em Campinas-SP, no periodo

de $198 \mathrm{~g}$ a $1989 . \ldots \ldots \ldots . \ldots \ldots$

32: Variação temporal mensal media da resistencia do dossel, considerando oe alturas de vegetação, obtida a partir da aplicação do modelo de Penman-Monteith aos valores medidos da evapotranspiração de referencia coletados em Campinas-SP, no periodo de 1956

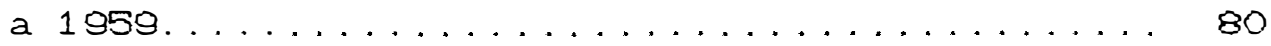


xvi.

\section{LISTA DE TABELAS}

Tabela $n \stackrel{0}{0}$

Página

1: Valores decadiários da evapotranspiração de referencia medida (ETO) e estimada pelo modelo de Penman-Monteith (ETOMD, em Campinas-SP. Período de 1956 a 1959 . Valores em $\mathrm{mm}$ de agua...................... 99

2: Valores decadiários da evapotranspiração de referencia medida (ETO) e estimada pelo modelo de Penman-Monteith CETOM, em Ribeirão Preto-SP. Periodo de 1956 a 1959. Valores em $m m$ de água....................100

3: Valores decadiários da evapotranspiração de referencia medida (ETO) e estimada pelo modelo de Penman-Monteith (ETOM), em Pindamonhangaba-SP. Periodo de 1954 a 1956 . VaLores em $\mathrm{mm}$ de água....................101

4: Número de observaçöes $(n)$, coeficiente 1 inear (a), coeficiente angular (b), erro padrão da estimativa (s) e coeficiente de 
xvi

determinação $\left(r^{2}\right)$ para as equaços de regressão linear simples entre os valores decadiarios da evapotranspiração de referéncia medida (ETO) e estimada pelo modelo de Penman-Monteith (ETOM), para CampinasSP, Ribeirão Preto-SP e Pindamonhagaba-SP.... 48

5: Valores mensais da evapotranspiração de referéncia medida (ETO) e estimada pelo modelo de Penman-Monteith (ETOM), em Campinas-SP. Periodo de 1956 a 1959. Valores em $m$ m de agua.................... 102

6: Valores mensais da evapotranspiração de referéncia medida (ETO) e estimada pelo modelo de Penman-Monteith (EToM), em Ribeirão Preto-SP. Periodo de 1950 a 1959. Valores em $m m$ de agua.................... 102

7: Valores mensais da evapotranspiração de referéncia medida (ETO) e estimada pelo modelo de Penman-Monteith (ETOMD, em Pindamonhangaba-SP. Periodo de 1954 a $1956 . \mathrm{Va}-$ Lores em $\mathrm{mm}$ de agua......................

8: Número de observaçôes $(n)$, coeficiente 1 inear (a), coeficiente angular (bj, erro 
xviii.

padrão da estimativa (s) e coeficiente de determinaçăo $\left(\mathrm{Cr}^{2} \mathrm{y}\right.$ para as equaçóes de regressão linear simples entre os valores mensais da evapotranspiração de referencia medida (ETO) e estimada pelo modelo de Penman-Monteith (ETOM), para Campinas-SP, Ribeir ̃o Preto-SP e Pindamonhagaba-SP....... 5e

9: Valores decadiários da evapotranspiração de referencia medida (ETO) e estimada pelo modelo de Penman-Monteith (ETOM), considerando diferentes resistencias do dossel e altura de vegetação igual a $0,06 \mathrm{~m}$, em Campinas-SP, ano de 1950. Valores em $\mathrm{mm}$ de agua............................ 105

10: Valores decadiários da evapotranspiração de referencia medida (ETO) e estimada pelo modelo de Penman-Monteith (EToM), considerando diferentes resistencias do dossel e altura de vegetação igual a $0.06 \mathrm{~m}$, em Campinas-SP, ano de 1957. Valores em $\mathrm{mm}$ de agua........................ 100

11: Valores decadiarios da evapotranspiração de referencia medida (ETo) e estimada pelo modelo de Penman-Monteith (ETOM), conside- 
rando diferentes resistennias do dossel e altura de vegetaçăo igual a 0,0 ôm, em Campinas-SF, ano de 1958. Vialores em $\mathrm{mm}$ de agua. . . . . . . . . . . . . . . . 107

12: Valores decadiarios da evapotranspiração de referencia medida (ETO) e estimada pelo modelo de Penman-Monteith (ETOM), considerando diferentes resistencias do dossel e altura de vegetaça igual a 0,05m, em Campinas-SP, ano de 1959 . Valores em $\mathrm{mm}$ de agua........................... 108

13: Valores decadiarios da evapotranspiração de referencia medida (ETo) e estimada pelo modelo de Penman-Monteith (ETOM), considerando diferentes resistências do dossel e altura de vegetação igual a $0,12 \mathrm{~m}$, em Campinas-SP, ano de 1956 . Valores em $\mathrm{mm}$ de água........................... 109

14: Valores decadiários da evapotranspiração de referencia medida (ETO) e estimada pelo modelo de Penman-Monteith (ETOM), considerando diferentes resistências do dossel e altura de vegetação iqual a $0,12 \mathrm{~m}$, em 
Campinas-SP, ano de 1957. Valores em $\mathrm{mm}$ de agua............................. 110

15: Valores decadiários da evapotranspiração de referencia medida (ETO) e estimada pelo modelo de Penman-Monteith (ETOM), considerando diferentes resistências do dossel e altura de vegetação igual a $0,1 \mathrm{zm}$, em Campinas-SP, ano de 1958. Valores em $\mathrm{mm}$ de gqua. . . . . . . . . . . . . . . . . . . . 111

16: Valores decadiarios da evapotranspiração de referencia medida (ETO) e estimada pelo modelo de Penman-Monteith (ETOM), considerando diferentes resistencias do dossel e altura de vegetação igual a $0.1 \mathrm{zm}$, em Campinas-SP, ano de 1959. Valores em $\mathrm{mm}$ de agua........................... 112

17: Número de observaçâes $(n)$, coeficiente linear (a), coeficiente angular (b), erro padrão da estimativa (s) e coeficiente de determinação $\left(r^{2}\right.$ ) para as equaçóes de regressão linear simples entre os valores decadiários da evapotranspiração de referencia medida (ETO) e estimada pelo modelo 
de Penman-Monteith (ETOM). Campinas-SP.

Periodo de 1950 a $1959 . \ldots \ldots \ldots \ldots \ldots$

59

18: Valores mensais da evapotranspiração de referéncia medida (ETO) e estimada pelo modelo de Penman-Monteith (ETOM), considerando diferentes resistencias do dossel e uma altura da vegetação de $0,06 \mathrm{~m}$, em Campinas-SF, ano de 1956. Valores em $\mathrm{mm}$ de agua........................... 113

19: Valores mensais da evapotranspiração de referéncia medida (ETO) e estimada pelo modelo de Penman-Monteith (EToM), considerando diferentes resistencias do dossel e uma altura da vegetação de $\bullet, 06 \mathrm{~m}$, em Campinas-SP, ano de 1957. Valores em $\mathrm{mm}$ de agua............................ 113

20: Valores mensais da evapotranspiração de referéncia medida (ETO) e estimada pelo modelo de Penman-Monteith (ETOM), considerando diferentes resisténcias do dossel e uma altura da vegetação de 0,06m, em Campinas-SP, ano de 1958. Valores em $\mathrm{mm}$ de agua........................... 114 
21: Valores mensais de evapotranspiração de referência medida (ETo) e estimada pelo modelo de Penman-Monteith (ETOM), considerando diferentes resistencias do dossel e uma altura da vegetação de $0.06 \mathrm{~m}$, em Campinas-SP, ano de 1959. Valores em $\mathrm{mm}$ de agua. . . . . . . . . . . . . . . . . .

22: Valores mensais de evapotranspiração de referencia medida (ETO) e estimada pelo modelo de Penman-Monteith (ETOM), considerando diferentes resistencias do dossel $e$ uma altura da vegetação de 0,1 $\mathrm{zm}$, em Campinas-SP, ano de 1956. Valores em $\mathrm{mm}$ de agua. . . . . . . . . . . . . . . . . . 115

23: Valores mensais de evapotranspiração de referencia medida (ETO) e estimada pelo modelo de Fenman-Monteith (ETOM), considerando diferentes resistencias do dossel e uma altura da vegetação de $0.12 \mathrm{~m}$, em Campinas-SP, ano de 1957. Valores em $\mathrm{mm}$ de agua........................... 115

24: Valores mensais de evapotranspiração de referencia medida (ETO) e estimada pelo modelo de Penman-Monteith (EToM), conside- 
xii i

rando difierentes resisténcias do dossel e uma altura da vegetação de $0,1 \mathrm{zm}$, em Campinas-SP, ano de 1958. Valores em $\mathrm{mm}$ de agua..............................

25: Valores mensais de evapotranspiração de referencia medida (ETO) e estimada pelo modelo de Penman-Monteith (ETOM), considerando diferentes resistencias do dossel e uma altura da vegetação de $0,1 \mathrm{zm}$, em Campinas-SP, ano de 1959. Valores em $\mathrm{mm}$ de agua.......................... 115

26: Número de observaçôes $(n)$, coeficiente linear (a), coeficiente angular (b), erro padrão da estimativa (s) e coeficiente de determinação $\left(r^{2}\right)$ para as equaçães de regressão linear simples entre os valores mensais da evapotranspiração de referéncia medida (ETO) e estimada pelo modelo de Penman-Monteith CETOMD. Campinas-SP. Periodo de 1956 a $1959 \ldots \ldots \ldots . \ldots \ldots 59 . \ldots \ldots$ 
xxiv.

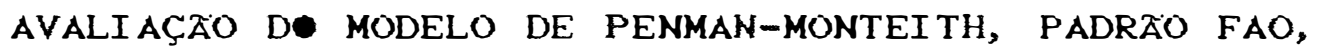
PARA ESTIMAR A EVAPOTRANSPIRAÇZ̃O DE REFERENCIA NAS CONDIÇOES CLIMATtCAS DO ESTADO DE SÃO PAULO.
\end{abstract}

Autor: JOSE GEANINI PERES

Orientador: Prof. Dr. JOSE ANTONIO FRIZZONE Co-orientador: Prof. Dr. ANTONIO ROBERTO PEREIRA

\title{
RESUMO
}

$$
\text { Avaliou-se o modelo de Penman-Monteith. }
$$
parametrizado pela FAO, na estimativa da evapotranspiração de referéncia (ETO), padrão grama, medida com evapotranspirómetros de drenagem, em trés locais do Estado de São Paulo. Com a padronização proposta pela FAO c vegetação com $0.12 \mathrm{~m}$ de altura; resitencia do dossel igual a $69 \mathrm{~s} \mathrm{~m}^{-1}$; albedo de $23 \%$, este modelo estimou ETo de forma consistente, tanto na escala decadiária quanto mensal. Nesta última, os valores estimados e medidos apresentaram correlação e concordáncia superiores àqueles da escala decadiária.

O modelo mostrou-se sensivel a variaçốes da altura da vegetação $\left(h_{c}\right)^{e}$ da resistencia do dossel ( $\mathrm{c}^{\text {J }}$. Assim, procuroutse a melhor combinação desses fatores para 
XXV.

as condiçöes dos experimentos, encont.rando-se $h_{e}=0,06 \mathrm{~m} e$ $r_{c}=80 \mathrm{~s} \mathrm{~m}^{-1}$, que são diferentes da recomendação da FAo. No entanto, a concordancia mais estreita entre valores estimados e medidos foi obtida quando se permitiu $r_{c}$ variar em função do saldo de radiação solar e do indice de área foliar.

Tomando-se a resistencia do dossel como incógnita do modelo, verificou-se que, para $h_{c}=0,06 \mathrm{~m}$, seu valor variou entre $300 \mathrm{~s} \mathrm{~m}^{-1}$, no outono-inverno, e eOe $s \mathrm{~m}^{-1}$, na primavera-veräo, enquanto que, para $h_{c}=0.1 \mathrm{~m}$, estes valores foram, respectivamente, 365 e $241 \mathrm{~s} \mathrm{~m}^{-1}$. Estes números, que são aplicáveis tanto à escala decadiaria quanto mensal, devem ser considerados como coeficientes empiricos, sem nenhum significado fisiológico. 
xori.

evaluation of the FaO PENMAN-MONTEITH MODEL TO ESTIMATE THE REFERENCE EVAPOTRANSPIRATION AT THE CLIMATIC CONDITIONS OF SÃO PAULO STATE, BRAZIL.

Author: JOSE GEANINI PERES

Adviser: Prof. Dr. JOSE ANTONIO FRIZZONE Co-adviser: Prof. Dr. ANTONIO ROBERTO PEREIRA

\section{SUMMARY}

An evaluation of the FAO Penman-Monteith model was performed using the grass reference evapotranspiration (ETO) measured with drainage evapotranspirometers, in three locations in the São Paulo State, Brazil. The model parameterized with the hypothetical crop conditions cfixed crop height $h_{c}=0.12$ $\mathrm{m}$; canopy resistance $r_{c}=60 \mathrm{~s} \mathrm{~m}^{-1}$; and $23 \%$ of albedos, estimated fairly well ETo both at the 10-day and at the monthly time scales. The agreement and correlation with the measured values was much better at the monthly time scale.

The model is sensitive to variations of vegetation height $\left(\mathrm{h}_{c}\right)$ and canopy resistance $\left(\mathrm{r}_{c}\right)$. The best combination found here, for such variables, was $h_{c}=$ 
xorvi

$0.06 \mathrm{~m}$ and $r_{c}=80 \mathrm{~s} \mathrm{~m}^{-1}$, which are different from the FAO recommendation. However, the best agreement resulted when canopy resistance was allowed to vary with the net solar radiation and the leaf area index.

Taking the canopy resistance as unknown of the model, at the vegetation height of $0.06 \mathrm{~m}$, its value varied between $300 \mathrm{~s} \mathrm{~m}^{-1}$, during the fall-winter season, and $202 \mathrm{~s} \mathrm{~m}^{-1}$ during the spring-summer period. For a vegetation height of $0.12 \mathrm{~m}$ these values are, respectively, 365 e $241 \mathrm{~s} \mathrm{~m}^{-1}$.

These numbers are applicable to both 10-day and the monthly scales and should be considered as an empirical coefficient without any physiological meaning. 


\section{INTRODUÇส̃O}

A evapotranspiração, em conjunto com a precipitação, constitui-se em um dos principais componentes do ciclo hidrológico. Por esta razão, o entendimento dos processos envolvidos e a capacidade de se estimar a sua ordem de grandeza são de fundamental importância no planejamento e utilização adequados dos recursos hídricos disponiveis na natureza.

Dentre os diferentes usos dos recursos hidricos, a irrigação destaca-se pela sua importância sócioeconómica, seja em regiỡes áridas e semi-áridas, onde é obrigatória ou, então, em areas onde ela é praticada de fórma a complementar à precipitação no atendimento das necessidades hidricas das culturas.

A quantificação precisa da água evapotranspirada pelo sistema solo-planta-atmosfera e de fundamental importância no planejamento, dimensionamento e manejo de sistemas de irrigação. Apesar dos custos envolvidos nos estudos de determinação das necessidades de água dos projetos serem despreziveis quando comparados com os seus 
custos totais, são muitos os projetos que se mostraram tecnica-economicamente inviaveis, devido a estimativas inadequadas da evapotranspiração.

Sistemas de irrigação, adequadamente projetados e operados, fornecem agua às culturas na quantidade, qualidade e momentos adequados. Quando a irrigaça se faz em quantidade de água inferior às reais necessidades dos cultivos, estes respondem produzindo abaixo de sua capacidade potencial. O mesmo ocorre se a dosagem aplicada for excessiva, devido à 1 ixiviação de nutrientes essenciais e, principalmente, pela aeração deficiente do sistema radicu$1 \mathrm{ar}$

A evapotranspiração pode ser determinada por meio de medidas diretas ou a partir de modelos baseados na utilização de dados climáticos. No primeiro grupo estão os diferentes tipos de lisimetros e o metodo do balanço de água no solo, enquanto no segundo, colocam-se os modelos meteorológicos, teóricos e empiricos.

Os métodos diretos, embora forneçam as meIhores estimativas da evapotranspiração, são de realização demorada, dispendiosos e de dificil execução nas condiçơes de campo, razões pelas quais são normalmente utilizados para calibrar os metodos do segundo grupo. Estas dificuldades restrigem a sua utilização às instituições de pesquisa, sendo de uso muito limitado nas condições cotidianas da irrigação. 
Visando superar estas dificuldades, muitos métodos teoricos e empiricos for am desenvolvidos para estimativa da evapotranspiração. Alguns são bastante simples, como o de THORNTHWAITE (1948), que utiliza apenas a temperatura do ar como variável climática. Outros, como o de PENMAN (1948), possuem um desenvolvimento teórico mais refinado, porém demandam um número maior de variáveis climáticas para a sua utilização. Entre estes dois extremos, encontra-se uma multidão de outros métodos.

o grande número de métodos teóricos e empiricos disponiveis constitui-se em uma facilidade aparente aos pesquisadores e projetistas. Estes, muitas vezes, tem que se decidir pelo uso um método, sem pleno conhecimento de sua génese, e acabam obtendo resultados nem sempre $f i-$ dedignos. Métodos empiricos, por exemplo, são excelentes para as condiçớes em que foram desenvolvidos, porém demandam cuidados nas extrapolaçช̃es para outras condiçช̃es edafocli máticas.

Procurando sistematizar o uso desses métodos, alguns autores e agéncias de desenvolvimento trouxeram ao conhecimento público, contribuiçôes técnicas muito importantes no estudo do consumo de agua pelas plantas.

JENSEN (1973) apresentou uma extensa compilação dos principais métodos utilizados na determinação da evapotranspiração, comparando-os em bases mensais. Os resultados obtidos são dificeis de serem interpretados, 
uma vez que não se fez uma distinção clara de qual seja a cultura de referéncia utilizada: alfafa ou grama.

Nesta mesma linha, porém com resultados práticos muito superiores, DOORENBOS \& PRUITT (1975), muito contribuiram na sistematizaçăo do cálculo das necessidades de água das culturas a partir dos conceitos de evapotranspiração de referéncia e coeficiente de cultura. Esta publicação, que no nosso meio passou a ser conhecida como o BOLETIM 24 da FAO, tornou-se uma referência mundial, sendo amplamente utilizada por engenheiros, agronomos e hidrologistas. O sucesso desta publicação deveu-se à clareza de sua metodologia e, também, ao grande número de tabelas e exemplos de aplicação apresentados pelos autores.

A partir de 1975, verificou-se um desenvolvimento acelerado dos recursos computacionais e de instrumentação. facilitando sobremaneira a coleta e o processamento das informaçơes climáticas. A popularização do computador fez com que facilidades como tabelas e abacos se tornassem obsoletas, quando comparadas com as vantagens apresentadas pelo processamento de algoritmos. Paralelamente a este desenvolvimento, novas pesquisas for am conduzidas na área das relaçôes solo-planta-água, tornando disponiveis informaçōes técnicas adicionais.

Com base nesta nova realidade, a food and Agriculture Organization (FAO) decidiu-se por uma ampla revisão da metodologia proposta por DOORENBOS \& PRUITI 
(1975). Os objetivos e procedimentos a serem adotados nesta revisão estão apresentados em SMI TH (1991).

A proposta da FAO é ambiciosa e deverá ser implementada em duas fases. Na primeira, sera martida a atual sistemática de se estimar a evapotranspiração da cultura a partir da evapotranspiração de referencia e coeficientes de cultura. A inovação nesta etapa está na adoção do modelo de Penman-Monteith (MONTEITH, 1965$)$ como método padrão para estimativa da evapotranspiração de referéncia. Na segunda fase, que deverá ser implementada nos próximos 10 anos, serão abandonados os conceitos de evapotranspiração de referéncia e coeficientes de cultura, passando a evapotranspiração da cultura a ser estimada diretamente pelo modelo de Penman-Monteith, atraves da incorporação de valores adequados para a resisténcia aerodinâmica e para a resisténcia do dossel, especificas para cada cultura.

A adoção do modelo de Penman-Monteith implicará no desenvolvimento de pesquisas adicionais com vistas a testar a sua validade em diferentes condiçres climáticas CSMITH, 1991). Nesta linha de atuação, o presente trabalho se propore a:

a) avaliar o modelo de Penman-Monteith, padrão FAO, como estimador da evapotranspiração de referéncia para grama, nas condiçơes climáticas do Estado de São Pau10; 
b) testar a sensibilidade do modelo a variações das caracteristicas da cultura de referéncia: altura e resistência do dossel. 


\section{REVISÃO DA LITERATURA}

THORNTHWAITE (1948) introduziu na literatu-

ra especializada o termo evapotranspiração potencial (ETP), definindo-a como sendo a quantidade máxima de água utilizada por uma extensa área vegetada, em crescimento ativo, sob condiçశ̃es ótimas de umidade do solo.

Quando as condiçర̃es de contorno acima não forem verificadas, tem-se a evapotranspiração real (ETa). que é aquela que ocorre em uma superficie vegetada, independente de sua área e das condiçớes de umidade do solo CTHORNTHWAITE, 1948; SEDIYAMA, 1987 ; VILLA NOVA \& REICHARDT, 1989 ; PEREIRA, 19923.

o conceito evapotranspiração da cultura (ETC) foi introduzido por DOORENBOS \& PRUITT (1975), caracterizando-a como sendo a evapotranspiração de uma cul tura agronómica, livre de doenças, desenvol vendo-se em uma área cultivada de um ou mais hectares, sob condiçớ otimizadas de solo, incluindo água e fertilidade.

Encontram-se na literatura duas definiçơes mais comuns para evapotranspiração de referência: uma re- 
8.

lacionada com a cultura de referencia grama (ETO) e outra com a cultura de referencia alfafa (ETr). DOORENBOS \& PRUITT (1975) definiram ETo como sendo a evapotranspiração que ocorre em uma extensa superficie de grama, com porte de 8 a $15 \mathrm{~cm}$, em crescimento ativo, cobrindo totalmente o solo e sem restrição de água. Por sua vez. JENSEN (1973) definiu ETr como sendo a evapotranspiração que se verifica em uma cultura de alfafa, com 30 a $50 \mathrm{~cm}$ de altura, e bordadura mínima de $100 \mathrm{~m}$, cultivada sem deficiencia hidrica.

Embora se reconheça que a alfafa possua caracteristicas aerodinâmicas mais representativas da maioria das culturas agronómicas do que a grama, esta última é mais utilizada pelo simples fato de a grande maioria das estaçōes agrometeorológicas serem gramadas CJENSEN, 1973; SMITH 1991). Outro ponto favorável à grama é que ela se adapta mais facilmente a diferentes condiçóes climáticas do que a alfafa.

Apesar desta preferencia pela grama, autores como JENSEN (1973) e WRIGTH (1982) têm desenvolvido intensa experimentação tomando a alfafa como cultura de referéncia. BURMAN et al. (1983) e CUENCA (1989) alertam para a necessidade de não se confundir as metodologias de cálculo utilizadas, uma vez que os coeficientes de cultura e a cultura de referencia mantém estreita relação funcional.

Procurando superar estas dificuldades, SMI TH (1991) propós que se adote uma definição padronizada 
9.

para a evapotranspiração de referéncia, com vistas, principalmente, à utilização do modelo de Penman-Monteith. A evapotranspiração de referéncia seria aquela que ocorre em uma cultura hipotética, apresentando as seguintes caracteristicas fixas: altura de $12 \mathrm{~cm}$, resistencia do dossel de $69 \mathrm{~s} \mathrm{~m}^{-1}$ e poder refletor (albedo) de $23 \%$

Esta definição é basicamente a proposta por DOORENBOS \& PRUITT (1975), com a vantagem de não apresentar ambiguidades quanto à umidade do solo, dimensões da área-tampão e, principalmente, quanto à espécie vegetal de referência.

Pelas definições anteriores, depreende-se facilmente que tanto a evapotranspiração da cultura (ETC) quanto a de referéncia (ETo ou ETr), ocorrem na forma máxima ou potencial, como salientado por CUENCA (1989) e PEREIRA (1992).

* Um dos procedimentos mais utilizados na estimativa das necessidades de água dos cultivos envolve um processo que se desenrola em duas etapas. Na primeira, uma equação empirica ou semi-empirica é utilizada para estimar a evapotranspiração de uma cultura de referéncia, normalmente ETo ou ETr; na segunda, a evapotranspiração de cultura (ETc) é obtida pela multiplicação de ETo ou ETr por um coeficiente de cultura (KC) empirico (IENSEN, 1973; DOORENBOS \& PRUITT, 1975 ).

De acordo com SMI TH (1991), um enfoque alternativo mais vantajoso estaria em conduzir o processo de 
10.

estimativa de ETc em uma só etapa, descartando-se a utilização dos coeficientes de cultura. Para tanto, sugere que - modelo de Penman-Monteith seja adotado como padrão, mediante utilização de valores adequados de resistência aerodinâmica e de resistencia do dossel, especificas para cada cultura.

No entanto, a adoção imediata desta sistemática simplificadora esbarra nas dificuldades de se conseguir valores experimentais confiáveis para a resisténcia do dossel, considerando-se os diferentes estádios do ciclo vegetativo das culturas e as condiçôes de umidade do solo (SMITH, 1991). Apesar destas dificuldades, este autor propõe que a evapotranspiração de referência seja estimada pelo modelo de Penman-Monteith, considerado superior aos demais.

A evapotranspiração potencial pode ser determinada de diferentes maneiras. De acordo com BURMAN et al. (1983), ela pode ser estimada a partir de medidas diretas ou de informações climáticas. No primeiro grupo, entre outros, estão incluldos os diferentes tipos de lisimetro e o balanço de água no solo; enquanto no segundo, estão enquadrados os modelos teóricos e empiricos, como os de PENMAN (1948), THORNTHWAITE (1948), BLANEY \& CRIDDLE (1950), JENSEN \& HAISE (1963), PRIESTLEY \& TAYLOR (1972), HARGREAVES (1977) entre outros e, também, evaporimetros como o tanque cilasse A. 
Estes métodos, embora estimem a evapotranspiraçăo potencial, necessariamente não estimam a mesma coisa. Assim, de acordo com BURMAN (1985), o modelo de Jensen-Haise estima a evapotranspiração de referencia para alfafa (ETr), enquanto o método de Hargreaves faz o mesmo para a grama (ETO).

Procurando sistematizar os procedimentos para estimativa da evapotranspiração de referência para grama ETO), DOORENBOS \& PRUITI (1975) selecionaram os métodos de Penman, de Blaney-Criddle, da radiação e do tanque Classe A, calibrando-os com os valores medidos da evapotranspiração de grama, coletados em lisimetros, nos mais diferentes climas e regiões. Segundo estes pesquisadores, - método de Penman é o que melhor estima ETo, seguido do tanque Classe A.

o método de Penman é amplamente utilizado porque facilita o entendimento dos processos fisicos da evaporação de superficies naturais e, tambem, porque se utiliza de informações meteorológicas coletadas em um unico nivel acima da superficie evaporante CTHOM \& OLIVER, 1977; BRUTSAERT, 1982; LUCHIARI Jr. , 1988).

Nas condiçôes brasileiras este modelø, nas suas diferentes versơes, tem sido muito utilizado para determinação de ETo, como pode ser visto em CAMARGo (1966), ORTOLANI et al. (1966), VILLA NOVA (1967), VILLA NOVA \& OMETTO (1981), EAREIERI (1981), SEDIYAMA (1987), SILVA (1989), PERES \& SCARDUA (1991) e LIMA (1991). 
A formula original de Penman foi desenvolvida para estimar os valores médios mensais da evaporação de uma superficie de água livre (EO), a partir de registros climatológicos padronizados como radiação solar, velocidade do vento, temperatura e umidade, coletados em um único nível. Para relacionar Eo à evaporação verificada em uma "vegetação verde, de porte baixo, cobrindo totalmente o solo e sem qualquer restrição hidrica", ou seja, ETo, PENMAN (1949) determinou fatores empiricos $(f)$ da seguinte ordem de grandeza: $f=0,80$ para 0 verão; $f=0,50$ para 0 inverno e $f=0,75$ como valor médio anual, que permitem transformar Eo em ETo atraves da expressão: $E_{0}=f \cdot E_{0}$. Apesar do modelo original de Penman apresentar formidável desenvolvimento teorico e ser basicamente físico, o mesmo não deixa de ser empirico, visto que incorpora em sua estrutura a função velocidade do vento, relativa ao termo aerodinâmico da equação CMONTEITH, 1985). Como a função velocidade do vento original aplicase a uma superficie de agua livre, DOORENBOS \& PRUITT (1975), a partir de medidas realizadas em lisimetros nas mais diferentes condiçöes geograficas e climaticas, calibraram-na para grama, tornando-a de uso universal para estimativa de ETo. A maioria das versöes conhecidas da equação original de Penman resulta de alteraçöes feitas na sua função velocidade do vento.

Para aplicação do modelo original de Penman, duas condiçöes devem ser assumidas. Primeira, que as 
fontes e sumidouros de calor sensivel e latente ocorram em um mesmo plano, a lâmina de uma folha por exemplo. Segunda, que a pressão do vapor d'água na superficie evaporante seja igual à pressão de saturação do vapor d'água à temperatura desta superficie.

Segundo THOM (1975), o fluxo de calor sensivel é originado a partir da superficie das folhas, enquanto o fluxo de calor latente tem sua origem na evaporação da água liquida existente nos espaços intercelulares da folha. De acordo com OKE (1992), a segunda condição de aplicação do modelo dificilmente é encontrada na maioria das superficies evaporantes.

Pelo exposto, verifica-se que o modelo original de Penman não $e$ um caso geral para estimativa da evapotranspiração, ' mas sim um caso muito particular aplicado a superficies de água livre, como um lago ou tanque Classe A, ou a superficies molhadas, como uma vegetação após uma chuva ou irrigação por aspersão CMONTEITH, 1965 ; THOM, 1975; MONTEITH, 1980; BRUTSAERT, 1982; MONTEITH, 1985; OKE, 1992). A expressão "superficie molhada" significa que a superficie está coberta por um camada infinitesimal de água (van BAVEL, 1967; MONTEITH \& UNSWORTH, 19903.

Muitos pesquisadores procuraram superar esta falta de generalidade da fórmula de Penman, cabendo a MONTEITH (1965) a obtenção de uma equação geral válida para qualquer tipo de vegetação, sob qualquer condição de 
estresse hidrico. Ele generalizou o modelo de Penman através de uma analogia com a Lei de Ohm para os circuitos elétricos, introduzindo no termo aerodinâmico duas resistências à transferéncia do vapor d'água: a resistência do dossel $(r)_{c}$ e a resistência aerodinâmica $(r)_{a}$. A primeira, como descritora das caracteristicas fisiológicas da planta e a segunda, do papel da turbuléncia atmosférica no processo de transporte do vapor d'água (OKE, 1992). O modelo assim desenvolvido passou a ser denominado de PenmanMonteith.

A superioridade do modelo de PenmanMonteith em relação às demais formas derivadas da equação original de Penman está em que ele leva em conta, além da resistência aerodinâmica à difusão turbulenta do calor sensivel e do vapor d’água, a resisténcia estomática ao transporte do vapor d'água (ALLEN et al, 1992). Segundo BRUIN \& HOLTSLAG (1982), este modelo constitui-se na mais completa expressão teórica para partição da radiação $11-$ quida disponivel em uma superficie vegetada, em termos de calor sensivel e latente.

No aspecto operacional, este modelo leva vantagens sobre os demais por ser o único que permite estimar, além da evapotranspiração potencial, a evapotranspiração real bastando, para tanto, se contar com uma relação funcional entre a resistência do dossel e o potencial de água no solo CGRANT, 1975; MONTEITH, 1980; HATFIELD, 1988; BEN-ASHER et al., 1989 ). 
15.

Um dos desafios do inicio dos anos 60 era desenvolver um método que considerasse os processos de transferencia em um est.omato e na atmosfera interna do dossel, ou seja, que superasse a distância de conhecimento cientifico entre o comportamento de uma folha e o dossel de uma planta. A solução foi a encontrada por MONTEITH (1965), que assumiu que as trocas de calor sensivel e latente (vapor d'água) entre o dossel e a atmosfera ocorrem em uma superficie plana arbitrária, localizada no mesmo nivel do sumidouro do fluxo de momento, isto e, o nivel $d+z_{e}$, onde $d=$ deslocamento do plano zero do perfil do vento e $z_{0}=$ comprimento de rugosidade da vegetaçăo.

Este modelo e frequientemente denominado de "modelo da folha grande", porque a superficie virtual anterior é considerada como possuidora das propriedades fisiológicas de todas as folhas do dossel CLHOMME, 1991; KROON \& BRUIN, 1993). De acordo com KROON \& BRUIN (1993), nenhum processo no interior do dossel é levado em consideração.

TANNER (1968) apresentou objeçöes teoricas ao "modelo da folha grande", argumentando que as fontes e sumidouros para calor sensivel, latente e fluxo de momento podem não estar a um mesmo nivel de referencia, ou seja, o modelo não leva em consideração a distribuição espacial destes fluxos. Acrescentou, ainda, que as boas correlaçöes entre a resistencia estomática e a resistencia do dossel derivadas por MONTEITH (1965) são apenas fortuit.as. 
O modelo de Penman-Monteith, embora tenha uma formulação teórica rigorosamente fisica, ser de fácil entendimento e demandar para a sua utilização de informações climatológicas padronizadas, normalmente coletadas em estaçơes meteorológicas padrơes, tem sua aplicação pratica limitada pelas dificuldades de se obter valores confiáveis e representativos para a resistencia do dossel, conforme relatado por NORMAN \& CAMPBELL (1983), MONTEITH (1985), LUCHIARI Jr. (1988), HATFIELD (1988), VILLA NOVA \& REICHARDT (1989), LUCHIARI Jr. \& RIHA (1991) e OKE (1992). Autores como BEN-ASHER et al. (1989) afirmam que o modelo de Penman-Monteith será de pouco valor prático, a não ser que a resistencia do dossel venha a ser parametrizada a partir de propriedades conhecidas e de fácil mensur ação da planta, do solo e da atmosfera.

Esta dificuldade operacional faz com que este modelo seja utilizado principalmente como uma ferramenta para estimativa da resistencia do dossel, quando a evapotranspiração é conhecida e não, como seria desejável, a situação inversa CRUSSELL, 1980; JACKSON et al., 1981; JOHNS et al., 1983; MONTEITH, 1985; ZHANG \& LEMEUR, 1992 ).

As dificuldades para se estimar a resistencia do dossel decorrem do fato dela ser uma função composta de muitos fatores ambientais e biologicos, tais como radiação solar, déficit de saturação de vapor d'água, disponibilidade de água no solo, indice de area foliar (IAF), 
idade da planta, entre outros, cujos efeitos individuais não são fáceis de serem isolados (MONTEI TH, 1985 ).

A estimativa da resistencia do dossel pode ser feita a partir de medidas diretas da resistencia estomática média, através de porómetros de difusão, e do indice de área foliar da planta, estimado por amostragem. No entanto, esta e uma tarefa ardua e trabalhosa e, por esta razão, dentro dos limites dos erros experimentais, a resistência do dossel pode ser determinada como resíduo da aplicação do modelo de Penman-Monteith, desde que se conheça a evapotranspiração (lisimetros, razão de Bowen...) e as variáveis climáticas envolvidas no processo, assegurando-se, ainda, que a evaporação do solo seja desprezivel. CMONTEITH, 1980; SHARMA, 1983; MONTEITH, 1985; LUCHI ARI Jr., 1988; LUCHI ARI Jr. \& RIHA, 1991; OKE, 1992$).$ Segundo ALLEN (1986) e ALLEN et al. (1989), a resisténcia do dossel para uma cultura bem irrigada pode ser obtida dividindo-se a resistência estomatica mínima, medida em folhas individuais por meio de porómetros de difusão, pela metade do indice de área foliar (IAF). De acordo eles, este ajustamento do IAF serve para levar em conta o fato de somente a parte superior de uma cultura densa ser ativa no transporte de calor sensivel e vapor d'água e na absor ção da radiação solar. MONTEI TH (1981) e SHARMA (1983) sugerem que a resisténcia estomática mínima é da ordem de $100 \mathrm{~s} \mathrm{~m}^{-1}$. Segundo MONTEITH (1985), os valores da resistência do dossel assim obtidos são equivalen- 
tes aos estimados pelo método residual, através da aplicação do modelo de Penman-Monteith.

Evidências experimentais têm mostrado que ocorre melhoria nas estimativas da evapotranspiração pelo modelo de Penman-Monteith, quando se adota valores da resistência do dossel variáveis com a radiação liquida disponível. Esta variação leva em consideração os efeitos de intensidade da luz solar e o comprimento do dia CALLEN, 19863.

O modelo de Penman-Monteith torna-se seme1 hante ao original de Penman, quando se $\mathrm{faz}_{\mathrm{c}}=0 \mathrm{~s} \mathrm{~m}^{-1} \mathrm{e}$ se substitui a função velocidade do vento pelo inverso da resistência aerodinâmica. Neste caso, ele serve para estimar a evaporação de uma superficie de água livre, que não e o caso da evapotranspiração potencial das culturas. Estas, mesmo sob condiçr̃es ótimas de umidade, apresentam uma resistência do dossel mensurável, diferente de zero, sendo naturalmente denominada de resistência do dossel à evapotranspiração potencial CJACKSON et al., 1981; JACKSON, 1983; MONTEITH, 1985)

Contrariament.e a esta afirmação, van BAVEL (1967) observou que até um potencial matricial de 4 bar a evapotranspiração da alfafa ocorreu à taxa potencial, indicando não haver controle do consumo de água pelos estômatos da planta, implicando em que $r_{c} \cong 0 \mathrm{~s} \mathrm{~m}^{-1}$. Esta evidéncia experimental foi ratificada por van BAVEL \& EHRLER (1968) e JOHNS et al. (1983). SLABBERS (1977) utilizou 
19.

$r_{c}=0 s \mathrm{~m}^{-1}$ para estimar a evapotranspiração potencial de várias culturas agrícolas, obtendo boa correlação com os valores medidos em lisimetros de drenagem.

Os valores conhecidos de $r_{c}$ para as difierentes culturas estão ao redor de $20 \mathrm{~s} \mathrm{~m}^{-1}$ para solos próximos à capacidadede campo, aumentando à medida que a umidade do solo diminui. Este fato evidencia a necessidade de se pesquisar o comportamento desta resisténcia em função da disponibilidade de água no solo. Esta parametrização de $r_{c}$, para condiçớes otimas e de restrição de água no solo, permitirá que se estime a evapotranspiração real diretamente a partir do modelo de Penman-Monteith CHATFIELD, 19883.

MONTEITH (1985) sugere que se adote $r_{c}=50$ $s \mathrm{~m}^{-1}$ para a determinação da evapotranspiração potencial das plantas cultivadas. Este valor concorda com os apresentados por OKE (1992), listados a seguir: grama 70 $s \mathrm{~m}^{-1}$, culturas agricolas $50 \mathrm{~s} \mathrm{~m}^{-1}$ e florestas 80 a 150 $s m^{-1}$.

Trabalhando com $\&$ culturas irrigadas, O' TOOLE \& REAL (1986) encontraram valores de $r_{c}$ variando de $14 \mathrm{~s} \mathrm{~m}^{-1}$ (arroz) ate $69 \mathrm{~s}^{-1}$ (figueira), sendo que 7 das culturas estudadas apresentaram $r_{c}$ entre 32 e $69 \mathrm{~s} \mathrm{~m}^{-1}$.

Para a cultura do trigo irrigado na região de Planaltina-DF, LUCHIARI Jr. \& RIHA (1991) encontraram que $r_{c}$ variou de 50 a $100 \mathrm{~s} \mathrm{~m}^{-1}$ no dia imediatamente ante- 
20.

rior à irrigação, enquanto a variação foi de 15 a $50 \mathrm{~s} \mathrm{~m}^{-1}$ um dia após. Em ambos os casos, $r_{c}$ cresceu rapidamente a partir do meio da tarde, chegando a valores superiores a $200 \mathrm{~s} \mathrm{~m}^{-1}$ após as 16 horas.

RUSSELL (1980), trabalhando com cevada e pastagem durante 3 anos, no verão, encontrou que $r_{c}$ teve grande variação nesse período, oscilando de 15 a 200 $\mathrm{s}^{-1}$, sendo maior nos anos mais secos e crescente à medida que as plantas amadureciam.

Também com cevada, GRANT (1975) observou que no inicio da implantação da cultura, quando esta não cobria totalmente o solo, $r_{c}$ foi da ordem de $100 \mathrm{~s} \mathrm{~m}^{-1}$. valor este também verificado quando a cultura entrou em fase de amadurecimento. No intervalo destas condições, quando a cultura cobria totalmente o solo, determinou-se $r_{c}=35 \mathrm{~s} \mathrm{~m}^{-1}$.

BRUIN \& HOLTSLAG (1982) determinaram a resistencia do dossel para grama em duas condições climáticas, normal e seca, e verificaram que $r_{c}$ variou consideravelmente na faixa de 20 a $280 \mathrm{~s} \mathrm{~m}^{-1}$. No periodo normal, $r_{c}$ teve um valor tipico de $60 \mathrm{~s} \mathrm{~m}^{-1}$, enquanto no seco esta variaçăo foi de 100 a $260 \mathrm{~s} \mathrm{~m}^{-1}$.

JOHNS et al. (1983), trabalhando com grama sob condiçães ambientais controladas e solo na capacidade de campo, encontrou que ETo foi mais influenciada pelas condiçơes ambientais do que pelas condiçơes fisiológicas da planta. Para grama com altura média de $5,0,6,5$ e 8,0 
$\mathrm{cm}$ os valores médios de $r_{c}$ foram, respectivamente, de 40 , 30 e $15 \mathrm{~s} \mathrm{~m}^{-1}$, ou seja, diminuiram à medida que a área foliar aumentou.

$$
\text { Numa cultura de soja, BAYLEY \& DAVIES }
$$

(1981) observaram que $r_{c}$ variou exponencialmente com a radiação global. Sob condiçơes não restritivas de água no solo, eles encontraram valores de $r_{c}$ entre 25 e $50 \mathrm{~s} \mathrm{~m}^{-1}$, até quando a radiação global foi igual ou superior a 200 $\left.w \mathrm{~m}^{-2} \mathrm{c} \cong 400 \mathrm{cal} \mathrm{cm}^{-2} \mathrm{dia}^{-1}\right)$. Abaixo deste valor, $\mathrm{r}_{c}$ cresceu exponencialmente com a diminuição da disponibilidade de energia.

HATFIELD (1985) observou que a resisténcia do dossel para trigo diminui exponencialmente com o aumentoda radiação global incidente. Para valores de radiação global entre 500 e $200 \mathrm{cal} \mathrm{cm}^{-2} \mathrm{dia}^{-1} \mathrm{C} \cong 250$ a $100 \mathrm{~W} \mathrm{~m}^{-2}$ ), $r_{c}$ variou de 74 a $132 \mathrm{~s} \mathrm{~m}^{-1}$.

Uma vez bem estabelecido o valor da resistencia do dossel $\left(\mathrm{r}_{\mathrm{c}}\right.$ ), o modelo de Penman-Monteith tem se mostrado superior aos demais metodos combinados na estimativa da evapotranspiração potencial, para uma ampla variedade de climas e localidades CSLABBERS, 1977; van ZYL \& JAGER, 1987; ALLEN et al., 1989; SMITH, 1991; LUCHI ARI Jr. \& RIHA, 1991 J.

$$
\text { Adotando } r_{c}=0 \mathrm{~s} \mathrm{~m}^{-1} \text { para definir que a }
$$
evapotranspiração se dava à taxa máxima, SLABBERS (1977) estimou as necessidades de água da beterraba, girassol, alfafa e trigo pelo modelo de Penman-Monteith. Foi obtida 
boa correlação entre os valores estimados e os medidos em lisimetros de drenagem e pelo balanço de água no solo. o autor realça a importáncia de se considerar nos métodos combinados a rugosidade da cultura, especialmente para culturas relativamente altas.

LUCHIARI Ir. \& RIHA (1991) utilizaram este modelo para estimar a evapotranspiração do trigo nas condições edafoclimaticas do Planalto Central brasileiro, encontrando que os valores estimativos foram cerca de $6 \%$ superiores aos medidos pela razão de Bowen, com os quais foram altamente correlacionados, em termos horários e diários.

Uma função relacionando a resisténcia do dossel ao indice de área foliar e ao deficit de umidade no solo foi derivada por GRANT (1975). Utilizando esta relação funcional no modelo de Penman-Monteith, este autor obteve boa concordancia com os valores medidos diretamente em lisimetros de pesagem e pela razão de Bowen.

Treze metodos combinados for am testados por ALLEN (1985) na estimativa da evapotranspiração de referencia para grama (ETO) e alfafa (ETr), em duas localidades de climas opostos - árido e úmido - e comparados os resultados com leituras lisimetricas locais. O modelo de Penman, com a função velocidade do vento calibrada para as condiçశ̃es locais por WRIGHT (1982), apresentou desempenho ligeiramente superior ao de Penman-Monteith, no qual foi utilizada uma resistencia do dossel $r_{c}=50 \mathrm{~s} \mathrm{~m}^{-1}$. No en- 
tanto, ambos tiveram comportamento estimativo muito superior ao método de Penman com a função velocidade do vento calibrada por DOORENBOS \& PRUI IT (1975). Quando foi utilizada uma $r_{c}=0 \mathrm{~s} \mathrm{~m}^{-1}$ no modelo de Penman-Monteith os resultados obtidos não apresentaram boa correlação com os medidos.

Van ZYL \& JAGER (1987), conduzindo experimentação com trigo sob condiçôes ottimas de umidade e utilizando o modelo de Fenman-Monteith com $r_{c}=33 \mathrm{~s}^{-1}$ para estimativa da evapotranspiração potencial, obtiveram alta correlação com os valores medidos em lisimetros. Observaram, também, que o modelo foi insensivel à correção da estabilidade atmosférica, fato também observado por LUCHI ARI Jr. (1988).

ALLEN (1986) testou 10 variaçôes da equação de Penman, em três localidades de caracteristicas climáticas distintas, desde o árido ao úmido, nas quais estavam disponiveis 3 anos de regist.ros climatológicos e de evapotranspiração de referéncia (ETo e ETr) obtidos em lisimetros de pesagem de alta precisão. O modelo de PenmanMonteith, no qual foram utilizados para a resistencia do dossel valores variáveis em função da radiação solar liquida e do indice de área foliar, foi o que estimou ETo com maior precisão, em termos mensais e estacionais. Nesta situação, a resisténcia média do dossel foi de $70 \mathrm{~s} \mathrm{~m}^{-1}$, para um gramado com $12 \mathrm{~cm}$ de altura. Quando se adotou $r_{c}=s m^{-1}$ as estimativas fornecidas melo modelo, ape- 
24.

sar de boas, foram menos precisas que as anteriores. De qualquer forma, para todos os métodos analisados, as determinações mensais apresentaram maior variabilidade do que as estacionais.

ALLEN et al. (1989) investigaram 5 variantes da equação de Penman utilizando informações climatológicas e lisimétricas de 11 localidades diferentes situadas em latitudes variando de $56^{\circ} \mathrm{S}$ (Australia), passando por $0^{\circ} \mathrm{N}$ (Zaire), até $56^{\circ} \mathrm{N}$ (Dinamarca) e altitudes na fiaixa de -30 a $2770 \mathrm{~m}$, abrangendo diferentes condiçơes de clima, desde o árido até o úmido. O método de Penman-Monteith foi - que forneceu as estimativas mais consistentes de ETo $\left(r_{c}=69 \mathrm{~s} \mathrm{~m}^{-1}\right)$ e de $\operatorname{ETr}\left(r_{c}=45 \mathrm{~s}^{-1}\right)$, em termos diários e mensais, seguido pelo de Penman, com função velocidade do vento calibrada por WRIGHT (1982).

No geral, a incorporação dos efeitos da area foliar e da altura da vegetação, atraves da resistência aerodinâmica e resisténcia do dossel, no modelo de Penman-Monteith, faz com este modelo estime com maior precisão a evapotranspiração potencial para uma ampla variedade de climas e localidades. Outro aspecto que deve ser destacado é que os valores de resistencia do dossel calculados pelos algorítmos apresentados por ALLEN (1986) devem ser utilizados para perlodos iguais ou superiores ao diário. Saliente-se, também, que os valores estimados e medidos da evapotranspiração são muito sensiveis a altura do dossel (ALLEN et al., 1989; ALLEN et al., 1992 ). 
25.

Nas condiçơes brasileiras, a utilização do modelo de Penman-Monteith bastante restrita e recente, podendo ser destacados os trabalhos desenvolvidos por FOLEGATTI (1988); AGUIAR NETTO et al. (1993); AZEVEDO et al. (1993) e SANTOS et al. (1993). 
26.

\section{MATERIAL E METODOS}

3.1. Material

3.1.1. Evapotranspiração de referencia medida(ETo)

Esta pesquisa foi realizada a partir de dados experimentais coletados em evapotranspirómetros do tipo Thornthwaite instalados nas estaçôes experimentais do Instituto Agronómico de Campinas (IAC) localizadas em Cam-

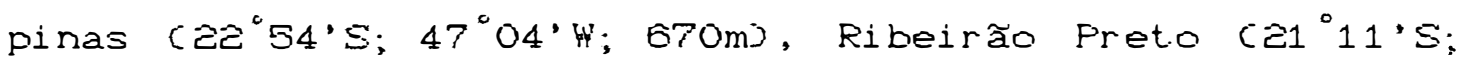
$47^{\circ} 48^{\prime} \mathrm{H} ; 620 \mathrm{~m}$ ) e Pindamonhangaba (2. ${ }^{\circ} 58^{\prime} \mathrm{S} ; 45^{\circ} 25^{\circ} \mathrm{H} ; 570 \mathrm{~m}$ ) (CAMARGO, 19663.

Segundo a classificação climática de Köppen, Campinas possui clima Cwa, subtropical com inverno seco; Ribeirão Preto tem clima Aw, tropical com inverno seco; e Pindamonhangaba apresenta clima do tipo Ciwb, temperado com inverno seco. 
De acordo com CAMARGO (1966), em cada localidade acima foi instalada uma bateria de 3 evapotranspirómetros, constituidos de caixas de cimento-amianto com $0,54 \mathrm{~m}^{2}$ de area livre e $0,50 \mathrm{~m}$ de profundidade. As caixas foram enterradas de forma a manter uma borda de $8 \mathrm{~cm}$ acima do nivel do terreno, evitando-se, assim, a entrada de água oriunda de escoamento superficial, seja das chuvas ou irrigaçöes. As caixas for am enchidas com a mesma terra das covas onde foram enterradas, mantendo-se a mesma or dem da camada superficial de $20 \mathrm{~cm}$. A terra de enchimento foi bem peneirada, visando a sua homogeneizaçăo e retirada de material grosseiro. Para facilitar o processo de drenagem, foi colocado em cada caixa uma camada de $8 \mathrm{~cm}$ de pedra britada e, sobre esta, uma fina camada de areia grossa. A agua drenada era coletada em um fosso próximo aos evaporimetros.

Tanto os lisimetros quanto as areas circunvizinhas foram vegetadas com grama batatais CPaspalum notatum flugges, mantida com altura adequada atraves de cortes periódicos. Uma bordadura com aproximadamente $10 \mathrm{~m}$ foi mantida de cada lado dos evapotranspirometros. e adequadamente irrigados de modo a propiciar condiçăes à obtenção da evapotranspiração potencial.

No inicio, os lisimetros eram irrigados diariamente pela superficie, sendo que, apos um período de adaptação, as irrigaçơes passaram a ser feitas em dias alternados, utilizando-se de um volume de agua suficiente 
28.

para promover uma pequena drenagem. Esta tecnica permitiu manter o solo com umidade próxima da capacidade de campo, - que era monitorado por meio de tensiómetros instalados a diferentes profundidades nas caixas.

Como pode ser concluido, as informaçôes coletadas nos evapotranspirometros representam, de fato, a evapotranspiração potencial de referencia (ETO), como definido por DOORENBOS \& PRUITT (1975). O calculo de ETo foi feito atraves da equação de conservação de massa:

$$
E T O=I+P-D \pm \Delta S
$$

onde: $I=$ irrigação; $P=$ precipitação $; D=$ drenagem; $e$ $\Delta S=$ variação do armazenamento de água. Como a irrigação era frequiente e o solo foi mantido praticamente na capacidade de campo, a variação do armazenamento pode ser considerada desprezivel, ou seja, $\Delta S \cong 0$.

A evapotranspiração foi coletada em bases decadiárias e, posteriormente, processada em termos mensais, visto o equipamento utilizado não possuir sensibilidade para obtenção de valores diários. Para os efeitos desta pesquisa, os dados originais foram submetidos a uma triagem, descartando-se aqueles considerados suspeitos.

Estas informaçơes experimentais já foram objeto de estudos desenvolvidos anteriormente por FERREIRA (1972), VILLA NOVA \& OMETTO (1981), PEREIRA \& CAMARGO (1989), PEREIRA (1990) e LIMA (1991). 
29.

3.1. 2. Obtenção dos dados climáticos

\begin{abstract}
As informações climáticas utilizadas neste trabalho foram coletadas (leituras às 7,14 e 21 horas) pela Seção de Climatologia Agrícola, do Instituto Agronômico de Campinas (IAC), nas localidades anteriormente descritas, e processadas de acordo com suas normas e procedimentos. Faz exceção, o cálculo da temperatura média diária, aqui definida como sendo a média entre as temperaturas máxima e minima diária.
\end{abstract}

3. 2. Métodos

3. 2.1. Cálculo dos parâmetros climáticos

A palavra padronização fundamental no processo de revisão da metodologia proposto pela FAO. Para se atingir a uniformização dos procedimentos de trabalho, foram desenvolvidos algoritmos para cálculo dos diferentes parâmetros climáticos, tomando-se como base sua aceitação geral e simplicidade de uso. Alguns parâmetros tiveram seu valor fixado com base em sua validade global. 
30 .

Os algoritmos a seguir, com exceção do utilizado para cálculo da radiação liquida, estão apresentados em SMI TH $(1991)$.

3.2.1.1. Calor latente de vaporização $(\lambda)$

- calor latente de vaporização da água é uma função linear da sua temperatura:

$$
\lambda=2,501-\left(2,361 \cdot 10^{-3}\right) \mathrm{T}
$$

onde: $\lambda=$ calor latente de vaporização $\left(M J \mathrm{~kg}^{-1}\right)$.

$T=$ temperatura do ar $C^{\circ} \mathrm{C}$.

Como o calor latente de vaporização varia muito pouco com a temperatura, será adotado um valor único, tomando-se $\mathrm{T}=20^{\circ} \mathrm{C}$ como padrão, $\lambda=2,45 \mathrm{MJ} \mathrm{kg}$.

3. ̇.1. ¿a. Tangente à curva da pressão de saturação do vapor d'água $c \Delta$

A tangente à curva da pressão de saturação do vapor d'água em função da temperatura pode ser 
31.

calculada pele expressão:

$$
\Delta=\frac{4098 e_{s}}{(T+237,3)^{2}}
$$

onde: $\Delta=$ tangente à curva de pressão de saturação do vapor d'água no ponto dado pela temperatura média do ar $\left(\mathrm{kPa}{ }^{\circ} \mathrm{C}^{-1}\right)$.

$T=$ temperatura média diária do ar $\left({ }^{\circ} \mathrm{C}\right.$.

$e_{s}=$ pressão de saturação do vapor d'água à temperatura média diária do ar (kPa).

3.2.1.3. Pressão atmosférica (P)

A pressão atmosferica pode ser obtida pela seguinte relação ter modi nâmica:

$$
P=P_{0}\left(\frac{T_{0}-\alpha Z}{T_{0}}\right)^{g / \alpha R}
$$

onde: $P=$ pressão atmosférica na altitude $\mathrm{Z}(\mathrm{kPa})$.

$$
\begin{aligned}
& P_{0}=\text { pressão atmosférica ao nivel do mar }\left(Z_{0}\right) \\
& \left(P_{0}=101.3 \mathrm{kPa}\right) . \\
& Z=\text { altitude do local }(\mathrm{m}) . \\
& g \quad \text { aceleração da gravidade terrestre } \\
& \mathrm{R}=\text { constante dos gases } \\
& \left.C R=287 \mathrm{~J} \mathrm{~kg} \mathrm{~s}^{-1} \mathrm{~K}^{-1}\right) .
\end{aligned}
$$


32.

$T_{0}=$ temperatura absoluta do ar em $Z_{0}$ (K). Utilizando-se a expressão $T_{0}=273,16+T$, onde $T=$ temperatura media do ar $C^{\circ} \omega$ e assumindo-se que $T=20^{\circ} \mathrm{C}$ em $Z_{0}$, obtem-se que $T_{0}=293,16 \mathrm{~K}$.

$\alpha=$ gradiente adiabatico do ar saturado $\left.c a=0,0065 \mathrm{~K} \mathrm{~m}^{-1}\right)$.

Para se evitar cálculos excessivos, tomouse um um valor medio $Z=620 \mathrm{~m}$ para a altitude das trés localidades.

Substituindo-se estes valores em (3) resulta que $\mathrm{P}=94,19 \mathrm{kPa}$.

3.2.1.4. Constante psicrométrica $(\gamma)$

A constante psicrometrica sem ventilação forçada foi calculada atraves da expressão:

$$
\gamma=10^{-9} \frac{c_{p} P}{\varepsilon \lambda}
$$

onde: $\gamma=$ constante psicrometrica $\left(\mathrm{kPa}^{\circ} \mathrm{C}^{-1}\right)$.

$$
\begin{aligned}
c_{p}= & \text { calor especifico do ar a pressão constante } \\
& \left.c_{c_{p}}=1.013 \mathrm{~kJ} \mathrm{~kg}^{-1} C^{-1}\right) . \\
P= & \text { pressão atmosférica }(P=94,19 \mathrm{kPa}) . \\
\varepsilon= & \text { razão entre o peso molecular do vapor d'água e } \\
& \text { do ar atmosférico seco }(\varepsilon=0,622) .
\end{aligned}
$$


33.

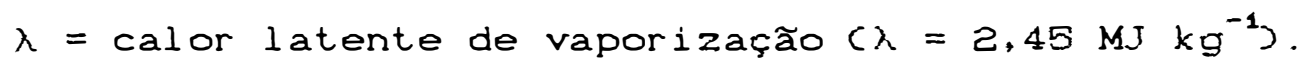

Substituindo-se estes valores na expressão (4) obtem-se $\gamma=0,0623 \mathrm{kPa}^{\circ} \mathrm{C}^{-1}$.

3.2.1.4.1. Constante psicrometrica modificada $\left(\gamma^{*}\right)$

Segundo MONTEITH (1965), a constante psicrometrica modificada pode ser calculada pela fómula:

$$
\gamma^{*}=r\left(1+\frac{r}{r_{a}}\right)
$$

onde: $\gamma^{*}=$ constante psicrometrica modificada (kPa $\left.{ }^{*} \mathrm{C}^{-1}\right)$.

$\gamma=$ constante psicrometrica $\left(\mathrm{kPa}^{\circ} \mathrm{C}^{-1}\right)$.

$r_{c}=$ resistencia do dossel $\left(s \mathrm{~m}^{-1}\right.$ ).

$r_{a}=$ resistência aerodinâmica $\left(s \mathrm{~m}^{-1}\right)$.

Substituindo-se na expressão (5) os valores

padronizados de $r_{c}=69 \mathrm{~s} \mathrm{~m}^{-1}$ (eq. 2a) e $r_{a}=\frac{208}{U_{2}}-\mathrm{s}^{-1}$ (eq. 20), para o padrão grama, se tem que:

$$
\gamma^{*}=\gamma\left(1+0,330 \mathrm{u}_{2}{ }^{3}\right.
$$

onde: $U_{2}=$ velocidade média diária do vento medida a $2 \mathrm{~m}$ de altura $\left(\mathrm{m} \mathrm{s}^{-1}\right)$. 
34.

3.2.1.5. Massa especifica do ar (p)

A massa especifica do ar atmosférico pode ser calculada atraves da equação dos gases ideais:

$$
\rho=\frac{P}{T_{V} R}
$$

onde: $\rho=$ massa especifica do ar $\left(\mathrm{kg} \mathrm{m} \mathrm{m}^{-3}\right)$.

$P=$ pressão atmosférica $(P=94,19 \mathrm{kPa})$.

$\mathrm{R}=$ constante universal dos gases $\left(R=0,287 \mathrm{~kJ} \mathrm{~kg}^{-1} \mathrm{~K}^{-1}\right)$.

$T_{v}=$ temperatura virtual do ar $(K)$.

Segundo SMITH (1991), a temperatura virtual pode ser aproximada pela seguinte expressão:

$$
T_{V}=T+275
$$

onde: $T=$ temperatura do ar $C^{\circ} \mathrm{C}$.

Substituindo-se os valores anteriores na equaçăo $(7)$, resulta em:

$$
\rho=\frac{328,2}{(T+2753} \mathrm{kg} \mathrm{m}^{-3}
$$


35.

3.Z.1.6. Pressão de saturação do vapor d'água $\left(e^{5}\right)$

A pressão de saturação do vapor d'água atmosférico pode ser estimada em função da temperatura pela equação:

$$
e_{s}=0.6108 \exp \left(\frac{17.27 T}{T+237.3}\right)
$$

onde: $e_{s}=$ pressão de saturação do vapor d'água $(k P a)$. $T=$ temperatura média diária do ar $\left.C^{\circ} \mathrm{C}\right)$.

3.2.1.7. Pressão atual do vapor d'água $\left(e_{a}\right)$

A pressão atual de vapor pode ser calculada conhecendo-se a temperatura e a umidade relativa do ar, ou seja:

$$
e_{a}=e_{s} \frac{U R}{100}
$$

onde: $e_{a}=$ pressão atual do vapor d'agua $(k \mathrm{~Pa})$.

UR= umidade relativa média diaria do ar $(\%)$. 
3.2.1.8. Velocidade do vento $\left(\mathrm{U}_{2}\right)$

O ajustamento da velocidade do vento obtida por instrumentos colocados a alturas diferentes da padrão $c z=2 \mathrm{~m}$ deve levar em consideração a rugosidade da superficie. Admitindo-se que o perfil vertical da velocidade do vento seja logaritmico, a velocidade a $2 \mathrm{~m}$ de altura pode ser calculada atraves da relação:

$$
U_{2}=U_{z} \frac{\operatorname{Ln}\left(\frac{z-d}{z_{o m}}\right)}{\operatorname{Ln}\left(\frac{z-d}{z_{o m}}\right)}
$$

onde: $U_{2}=$ velocidade do vento à altura padrão de $2 \mathrm{~m}$ $\left(\mathrm{m} \mathrm{s} \mathrm{s}^{-1}\right)$.

$U_{z}=$ velocidade do vento a altura $z\left(m s^{-1}\right)$.

$d=$ deslocamento do plano zero do perfil do vento $(m)$.

$z_{o m}=$ comprimento de rugosidade equivalente para transferencia de momento $(\mathrm{m})$.

$z=$ altura na qual o vento foi medido $(\mathrm{m})$

Os valores de de $z_{\text {om }}$ devem ser referenciados a rugosidade da grama, como pode ser visto nas equaçỡes (16) e (17) adiante. 
3.2.1.9. Radiação solar liquida ( $R_{n}$ )

A radiação solar liquida $\left(R_{n}\right)$ foi estimada atraves das equaçőes desenvolvidas por OMETTO (1981) para as condiçỡes do Estado de Săo Paulo. Foram consideradas duas épocas do ano: primavera-verão (PV), abrangendo os meses de outubro a março, e outono-inverno (OI), relativa aos meses de abril a setembro. Estas equaçס̃es foram obtidas atraves de análise de regressão linear simples, a partir de valores medidos da radiação solar liquida $\left(R_{n}\right)$ e da razão de insolação $(n / N)$, e valores tabelados da radiação solar global na auséncia da atmosfera $\left(Q_{0}\right)$.

. primavera-verão (PV)

$$
\begin{aligned}
& R_{n}=Q_{0}\left[0,17+0,2 e \frac{n}{N}\right] \\
& \text { outono-inverno (OI) } \\
& R_{n}=Q_{0}\left(0,15+0,12 \frac{n}{N}\right)
\end{aligned}
$$

onde: $R_{n}=$ radiação solar liquida na superficie do solo Ccal $\mathrm{cm}^{-2} \mathrm{dia}^{-1}$. $Q_{0}=$ radiação solar global na auséncia de atmosfera, obtida em tabelas astronómicas em função da época do ano e da latitude (cal $\mathrm{cm}^{-2} \mathrm{dia}^{-1}$ ). 
38.

$\mathrm{n}=$ número de horas de insol ação medida em heliografo $(h)$.

$N=$ número máximo de horas de insolação, obtido em tabelas astronómicas em função da época do ano e da latitude (h).

Para conversão dos valores de $R_{n}$ em cal $\mathrm{cm}^{-2}$ dia $a^{-1}$ para $M J \mathrm{~m}^{-2} \mathrm{dia}^{-1} \in \mathrm{mm}$ dia $\mathrm{a}^{-1}$ podem ser utilizadas as seguintes equivalencias de unidade:

$$
\begin{aligned}
& 1 \mathrm{cal} \mathrm{cm}^{-2} \mathrm{dia}^{-1}=0,041868 \mathrm{MJ} \mathrm{m}^{-2} \mathrm{dia}^{-1} \\
& .1 \mathrm{cal} \mathrm{cm}^{-2} \mathrm{dia}^{-1}=\frac{1}{59} \mathrm{~mm} \mathrm{dia}
\end{aligned}
$$

3. 2.2. Estimativa da resistencia aerodinâmica e do dossel

3.2.2.1. Resistência aerodinâmica (r $\left.{ }_{a}\right)$

Segundo ALLEN et al (1888) a resistencia aerodinâmica pode ser obtida a partir da seguinte expressão:

$$
r_{a}=\frac{L_{n}\left(\frac{z_{m}-d}{z_{o m}}\right) \cdot L_{n}\left(\frac{z_{h}-d}{z_{o h}}\right)}{k^{2} U_{z}}
$$


39.

onde: $r_{a}=$ resistência aerodinâmica à transferéncia de calor sensivel e vapor d'água $\left(s \mathrm{~m}^{-1}\right)$.

$z_{m}=$ altura de medição da velocidade do vento $(m)$.

$z_{h}=$ altura de medição da temperatura e da umidade do ar $(m)$.

$d=$ deslocamento do plano zero do perfil do vento $(m)$.

$z_{\text {om }}=$ comprimento de rugosidade equivalente para transferéncia de momento $(m)$.

$z_{\text {oh }}=$ comprimento de rugosidade equivalente para transferéncia de calor sensivel e latente $(\mathrm{m})$.

$K=$ constante de von $\operatorname{Karman}(K=0,41)$.

$U_{z}=$ velocidade do vento medida à altura $z\left(m s^{-1}\right)$.

De acordo com MONTEITH (1981) e BRUTSAERT (1982) o deslocamento do plano zero (d) pode ser obtido em função da altura média da vegetação,a partir da seguinte expressão:

$$
d=\frac{2}{3} h_{c}
$$

onde: $h_{c}=$ altura média da vegetação $(m)$.

BRUTSAERT (1982) sugere que o comprimento de rugosidade equivalente para transferencia de momento ( $z$ om ${ }^{)}$pode ser estimado em função da altura média da vegetação $\left(h_{c}\right)$ de acordo com a expressão:

$$
z_{\text {om }}=0.123 \mathrm{~h}_{\mathrm{c}}
$$


onde: $h_{c}=$ altura média da vegetação $(m)$

Quanto ao comprimento de rugosidade equivalente para transferencia de calor sensivel e vapor d'agua ( oh $^{2}$, MONTEITH (1981) e BRUTSAERT (1982) propïem sua estimativa a partir de:

$$
\begin{gathered}
z_{\text {oh }}=0,1 z_{\text {or }} \\
z_{\text {or }}=0,0123 \mathrm{~h}_{\mathrm{c}}
\end{gathered}
$$

Adotando-se uma altura média $\mathrm{h}_{c}=0,1 \mathrm{z} \mathrm{m}$ para a grama, como sugerido por ALLEN et al. (1989) e SMITH (1991), são obtidas as seguintes relaç̧es: $d=0,08 \mathrm{~m}, z_{o m}=0,01476 \mathrm{~m} e z_{o h}=0,001476 \mathrm{~m}$.

Padronizando-se a leitura da velocidade do vento, da temperatura e umidade para uma altura $z=2 m e$ substituindo-se os valores para $d, z_{o m} e z_{o h}$ em (15), a resisténcia aerodinâmica para a grama pode ser obtida pela seguinte expressão:

$$
r_{a}=\frac{208}{U_{2}}
$$


3.2.2.2. Resistência do dossel ( $\mathrm{C}_{c}$ )

ALLEN (1986) e ALLEN et al. (1989) sugerem que a resistência do dossel de uma vegetação de referência, sob condiçốes adequadas de umidade e em desenvolvimento vegetativo ativo, pode ser estimada a partir da resistencia estomática mínima de uma folha cestomatos abertos e do indice de área foliar da vegetação. A fórmula proposta é a seguinte:

$$
r_{c}=\frac{r_{l}}{0.5 \text { IAF }}
$$

onde: $r_{c}=$ resistência do dossel (s $\mathrm{m}^{-1}$ ).

$r_{l}=$ resistência estomática minima para uma folha. Segundo MONTEITH (1981) e SHARMA (1983) pode ser adotado um valor $r_{l}=100 \mathrm{~s} \mathrm{~m}^{-1}$.

IAF = indice de área foliar. Segundo ALLEN et al. (1989), quando a vegetação de referência é a grama, o IAF é dado pela expressão:

$$
I A F=24 h_{c}
$$

onde: $h_{c}=$ altura média da vegetação $(m)$

Adotando-se um valor médio $h_{c}=0,12 \mathrm{~m}$ para a grama tem-se $I A F=2,88$.

Substituindo-se os valores de $r_{i}=100 \mathrm{~s} \mathrm{~m}^{-1}$ e $I A F=2,88$ em (21), obtem-se o valor da resisténcia do dossel padronizado para grama. Assim, $r_{c}=69 \mathrm{~s} \mathrm{~m}^{-1}$. 
42.

Baseado em evidéncias experimentais, ALLEN (1986) sugere que a resistencia do dossel pode ser calculada como uma função da radiação solar liquida e do Indice de area foliar. Para tanto, apresentou a seguinte fórmula empirica:

$$
r_{c}=\frac{500-0,85 \mathrm{Rn}}{I \mathrm{AF}}
$$

onde: $r_{c}=$ resistencia do dossel $\left(s \mathrm{~m}^{-1}\right)$.

$$
\begin{aligned}
\mathrm{Rn}= & \operatorname{radiação~} 1 \text { iquida }\left(c a l \mathrm{~cm}^{-2} \mathrm{dia}^{-1}\right) . \\
\mathrm{IAF}= & \text { indice de área foliar, calculado segundo } \\
& \text { equação (2己). }
\end{aligned}
$$

Esta equação foi utilizada em complementação à equação (21), buscando a parametrização da resistencia do dossel a partir de um elemento climatico de fácil obtenção direta ou indiretamente por algoritmos.

3. 2.3. Estimativa da evapotranspiração de referencia pelo modelo de Penman-Monteith

O desenvolvimento teorico detalhado do modelo de Penman-Monteith pode ser encontrado em MONTEITH (1965, 1981, 1985) E VILLA NOVA \& REICHARDT (1989). A representação matemática original do modelo é a seguinte: 


$$
\lambda \text { ETO }=\frac{\Delta\left[R_{n}-G\right)+\rho c_{p}\left[e_{s}-e_{a}\right] r_{a}}{\Delta+\gamma\left[1+\frac{r_{c}}{r_{a}}\right]}
$$

onde: $\lambda E$ To = densidade de fluxo de calor latente, $R=$ radiação solar liquida na superficie evaporante; $G=f l u x o$ de calor no solo; $\lambda$ = calor latente de vaporização; $\Delta$ = tangente à curva de pressão de saturação do vapor d'água; $\gamma=$ constante psicrometrica; $p=$ massa especifica do ar atmosférico; $c_{p}=$ calor especifico à pressão constante do ar atmosférico; $e_{s}=$ pressão de saturação do vapor d'água; $e_{a}=$ pressão atual do vapor d'água; $r_{c}=$ resistência do dossel; $r_{a}=$ resistência aerodinâmica.

Uma forma para facilitar o desenvolvimento da equação anterior para cálculo da evapotranspiração de referéncia consiste em dividi-la em dois termos: da radiação ou energético e aerodinâmico. Assim:

$$
E T O M=E T_{\text {rad }}+E T_{\text {aero }}
$$

onde: $E T O M$ = evapotranspiração de referéncia para grama, segundo Penman-Monteith $\left(\mathrm{mm}\right.$ di $\left.\mathrm{a}^{-1}\right)$.

$E T_{\text {rad }}=$ termo da radiação ou energetico $\left(\mathrm{mm} \mathrm{di}^{-1}\right)$.

$\mathrm{ET}_{\text {aero }}=$ termo aerodinâmico $\left(\mathrm{mm}\right.$ di $\left.\mathrm{a}^{-1}\right)$.

- termo energético pode ser obtido pela aplicação da seguinte fórmula: 


$$
E T_{\mathrm{rad}}=\frac{1}{\lambda} \frac{\Delta}{\Delta+\gamma\left(1+\frac{c}{r}\right)}\left(R_{n}-G\right)
$$

onde: $E T_{\text {rad }}=$ termo energético $\left(\mathrm{mm}\right.$ dia $\left.\mathrm{a}^{-1}\right)$.

$\Delta=$ tangente à curva de pressão de saturaçăo do vapor d'água no ponto dado pela temperatura media diaria do ar $\left(\mathrm{kPa}^{\circ} \mathrm{C}^{-1}\right)$.

$\lambda=$ calor latente de vaporização (MJ $\mathrm{kg}^{-1}$ ).

$\gamma=$ constante psicrometrica $\left(k P a{ }^{\circ} \mathrm{C}^{-1}\right)$.

$r_{c}=$ resistencia do dossel is $\mathrm{m}^{-1}$.

$r_{a}=$ resistencia aerodinâmica (s $m^{-1}$ ).

$R_{n}=$ radiação solar liquida à superficie evaporante CMJ $\mathrm{m}^{-2} \mathrm{~d}^{-1} \mathrm{y}$.

$G=f l u x o$ de calor no solo $\left(M J \mathrm{~m}^{-2} \mathrm{~d}^{-1}\right)$.

A ordem de grandeza do fluxo diário de calor no solo, para periodos iguais ou superiores a 10 ou 20 dias, é suficientemente pequena, podendo ser desprezada nos cálculos (JENSEN, 1973; PEREIRA, 1990; SMITH, 1991 ).

$$
\begin{aligned}
& \text { Substituindo-se } \\
& \text { na equação } \\
& \lambda=2,45 \mathrm{MJ} \mathrm{kg}{ }^{-1}, \gamma^{*}=\gamma\left(1+\frac{r}{r} \frac{c}{a}\right) \text { e } G=0 \mathrm{MJ} \mathrm{m}^{-2} \mathrm{~d}^{-1} \text { : } \\
& E T_{\text {rad }}=0,408 \frac{\Delta}{\Delta+\gamma^{*}} R_{n}
\end{aligned}
$$

onde: $0,408=$ fator para conversão de unidades $\left(k g \mathrm{MJ}^{-1}\right)$.

- termo aerodinâmico pode ser calculado pela expressão: 


$$
E_{\text {aero }}=\frac{86400}{\lambda} \frac{1}{\Delta+\gamma\left(1+\frac{r_{c}}{r_{a}}\right]} \frac{\rho c_{p}\left(e_{s}-e_{a}\right)}{r_{a}}
$$

onde: $E T_{\text {aero }}=$ termo aerodinâmico $\left(\mathrm{mm} \mathrm{dia}^{-1}\right)$.

86400 = fator para converter a unidade de tempo segundo (s) em dia.

$\rho=$ massa especifica do ar atmosférico $\left(\mathrm{kg} \mathrm{m}^{-3}\right)$.

$c_{p}=c a l o r$ especifico do ar atmosferico a pressão constante CMJ kg-1 ${ }^{\circ} \mathrm{C}^{-1} \mathrm{~J}$.

$e_{s}=$ pressão de saturaçăo do vapor d'água à temperatura media diaria do ar (kPa).

$e_{a}=$ pressão atual do vapor d'água à temperatura média diaria do ar $(\mathrm{kPa})$.

Para os demais parâmetros, são vallidas as definições e unidades de medidas anteriormente descritas.

$$
\text { Substituindo-se } c_{p} \text { (eq. } 43, \gamma^{*} \text { (eq. } 5 \text { ) e } 0
$$

(eq. 9) na equação (29), resulta em:

$$
E T_{\text {aero }}=187340,4 \frac{\gamma}{\Delta+\gamma^{*}} \frac{\left(e_{s}-e_{a}\right)}{r_{a}(T+275)}
$$

Iransportando-se as equações (28) e (30) para a equação (26), e tomando-se como padrão a grama, cuja resistência aerodinâmica é dada por $r_{a}=-\frac{208}{U_{2}} s \mathrm{~m}^{-1}$, obtem-se a expressão final proposta por SMITH (1981):

$$
\text { ETOM }=0.408 \frac{\Delta}{\Delta+\gamma^{*}} R_{n}+\frac{900}{(T+275)} \frac{\gamma}{\Delta+\gamma^{*}}\left(e_{s}-e_{a}\right) U_{2}
$$


46.

- cujos parâmetros e respectivas unidades já foram definidos. 


\title{
4. RESULTADOS E DISCUSSÃO
}

\author{
4.1. Relativos à evapotranspiração de referencia esti- \\ mada pelo modelo de Penman-Monteith (EToM), padrão \\ FAO.
}

4.1.1. Periodicidade decadiária.

Nas Tabelas 1,2 e 3 (Apéndice 1 ) estão apresentados os valores decadiários da evapotranspiração de referéncia medida em lisimetro (ETO) e estimada pelo modelo de Penman-Monteith CETOM. Da Tabela 4 constam os parâmetros estatisticos relativos às equaçớs de regressão linear simples entre os valores medidos e estimados da evapotranspiração de referencia para as 03 localidades estudadas. Nas Figuras 1,2 , 3 estão as representações graficas das correlaçōes entre valores medidos e estimados, tomando-se como referencial a reta $1: 1$. 
48.

Tabela 4: Número de observações $(n)$, coeficiente linear (a), coeficiente angular (b), erro padrão da estimativa (S) e coeficiente de determinação $\left(r^{2}\right)$ para as equaçơes de regressão linear simples entre os valores decadiários da evapotranspiração de referéncia medida (ETO) e estimada pelo modelo de Penman-Monteith (ETOMD, em Campinas-SP, Ribeirão Preto-SP e Pindamonhagaba-SP.

\begin{tabular}{|c|c|c|c|c|c|}
\hline & \multicolumn{5}{|c|}{ ETOM $=a+b$ ETO } \\
\hline & $\mathrm{n}$ & a & $b$ & $s$ & $r^{2}$ \\
\hline Campinas & 142 & $13.03^{3}$ & $0.79^{3}$ & 6,36 & $0.66^{3}$ \\
\hline R. Preto & 138 & $18,27^{2}$ & $0,51^{3}$ & 8,72 & $0,38^{3}$ \\
\hline Pinda. & 99 & $10.15^{1}$ & $0,59^{3}$ & 6,65 & $0,54^{3}$ \\
\hline $\begin{array}{l}1=\text { nãos } \\
2=\text { signi } \\
3=\text { signi }\end{array}$ & $\begin{array}{l}\text { ificat } \\
\text { ativo } \\
\text { ativo }\end{array}$ & $\begin{array}{l}10 \text { a } 5 \% \\
5 \% \text { de pr } \\
1 \% \text { de pr }\end{array}$ & $\begin{array}{l}\text { orobabi } \\
\text { abilida } \\
\text { abilida }\end{array}$ & & \\
\hline
\end{tabular}

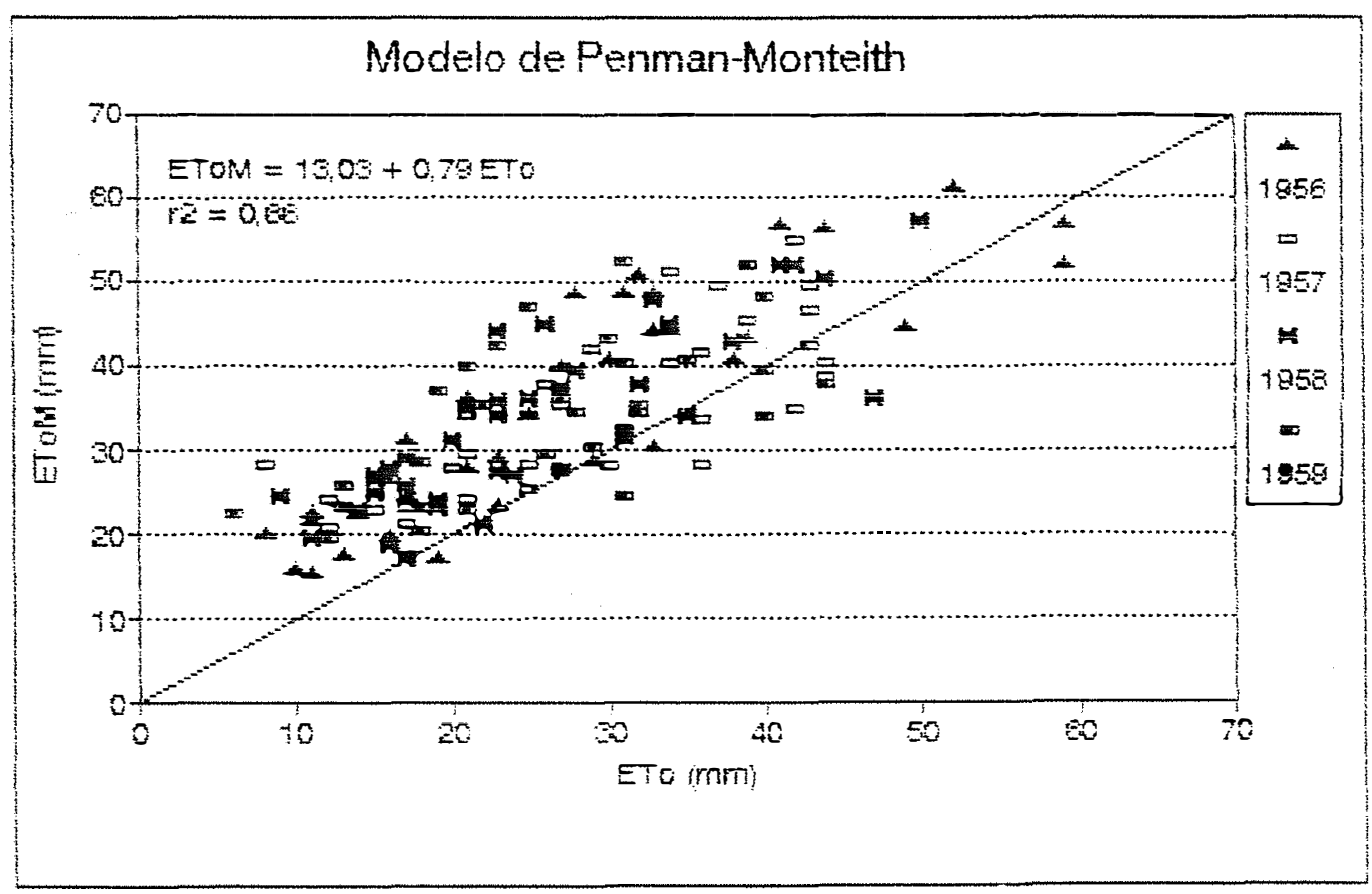

Figura 1: Evapotranspiração de referencia decadiária estimada pelo modelo de Penman-Monteith (ETOM) versus a medida em evapotranspirómetros de drenagem (ETo) em relação à reta 1:1. Campinas-SP. Período de 1956 a 1959. 
49.

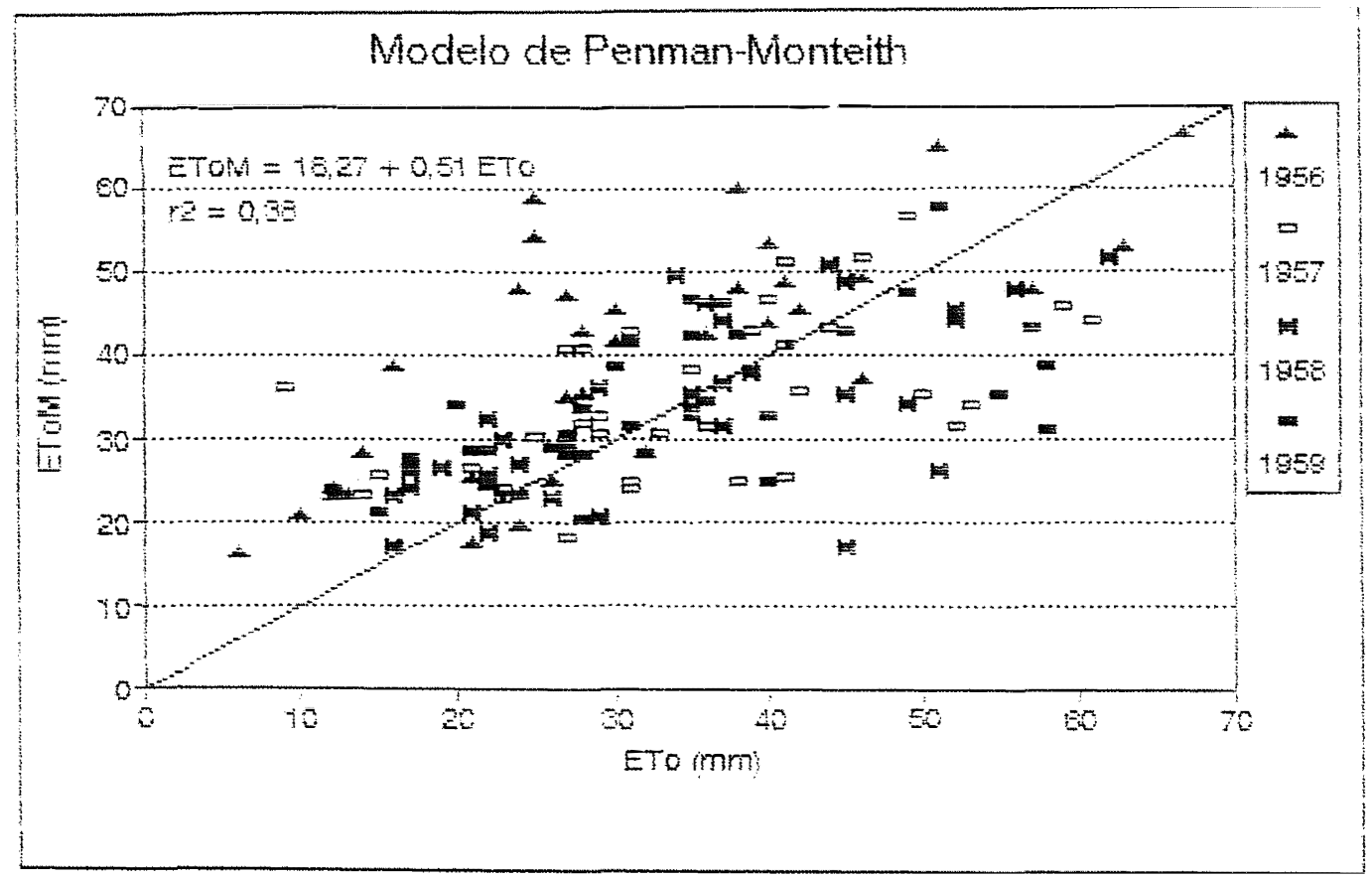

Figura e: Evapotranspiraçăo de referencia decadiária estimada pelo modelo de Penman-Monteith (ETOM) versus a medida em evapotranspirómetros de drenagem (ETO) em relação à reta 1:1. Ribeirão Preto-SP. Período de 1956 a 1959.

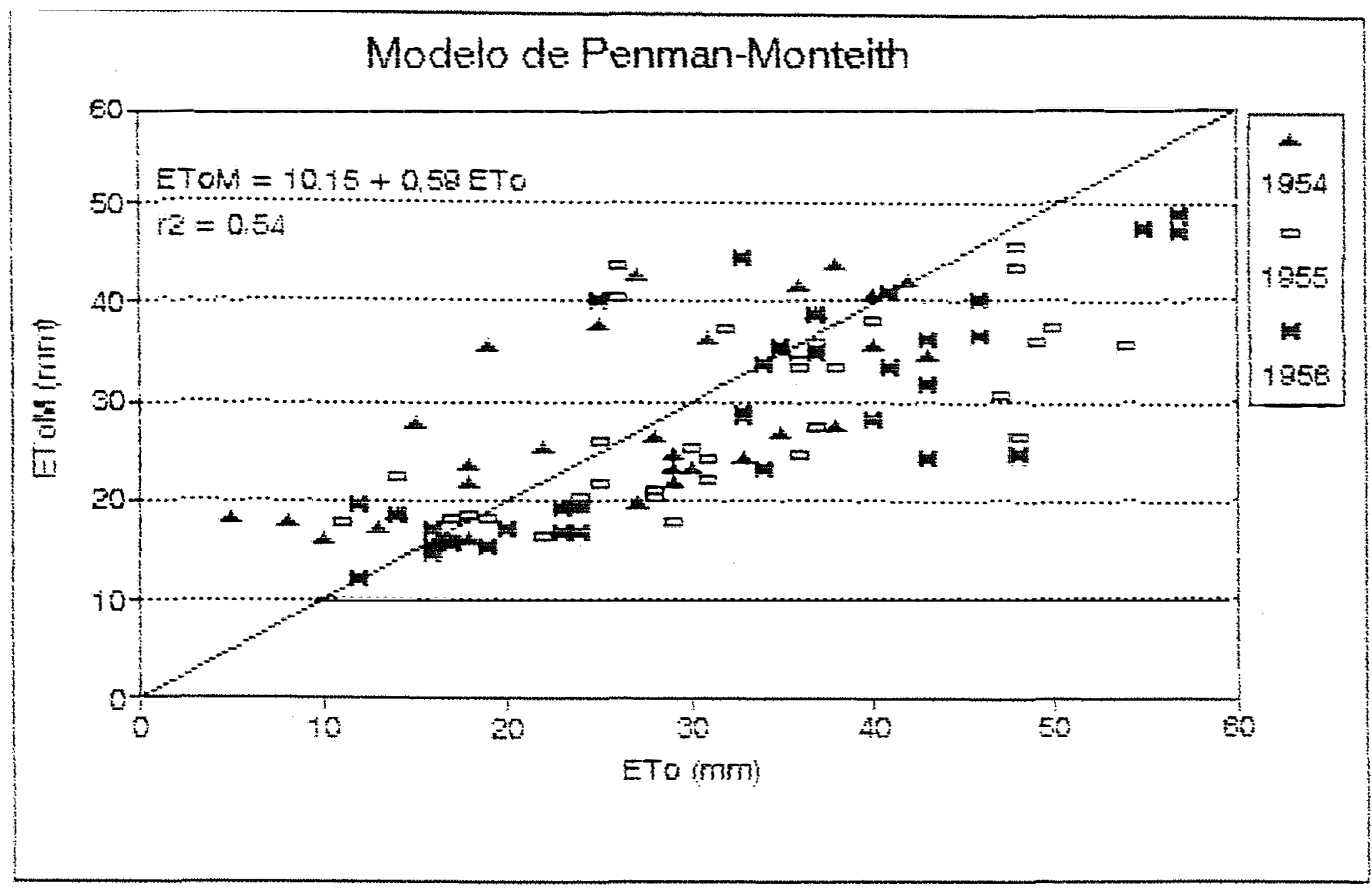

Figura 3: Evapotranspiração de referencia decadiária estimada pelo modelo de Penman-Monteith (ETOM versus a medida em evapotranspirsmetros de drenagem (ETo) em relação à reta 1:1. Pindamonhangaba-SP. Perlodo de 1954 a 1956. 
Da observação da Tabela 4 pode se verificar que as estimativas da evapotranspiração de referencia ajustaram-se com razoável precisão aos valores medidos, conforme pode ser conferido pelos coeficientes de determinação $\left(r^{2}\right)$ e pelos erros padróes da estimativa cs. Também deve ser observado que a correlação ent.re os valores est.imados e medidos em Campinas-SP mostrou-se bastante estreita, como indicado pelo coeficiente de correlação $C r=0,812$, bastante elevado e significativo ao nivel de $1 \%$ de probabilidade, o mesmo não ocorrendo em Pindamonhangaba-SP e Ribeirão Preto-SP.

o melhor ajuste verificado em Campinas-SP pode ser explicado, em parte, pelo fato dos evapotranspirometros ali instalados terem sido operados com maiores cuidados do que nas outras duas localidades CCAMARGO, 1966). Obs $\leadsto r v e-s e$ que em Ribeirão Preto-SP foi verificado - coeficiente de correlação mais baixo $\mathrm{cr}=0,62)$, porém significativo ao nivel de $1 \%$ de probabilidade, indicando que, apesar de ocorrer correlação direta positiva entre as variáveis envolvidas, o modelo de regressão linear simples obtido explica somente pequena parcela da variação total verificada. LIMA (1991) trabalhando com estes mesmos dados, na escala decadiaria, e utilizando uma variação da formula de Penman proposta por VILLA NOVA \& OMETTO (1981), obteve indice de correlação superior ao aqui citado. 
51.

As Figuras 1, 2 e 3 mostram que as estimativas da evapotranspiração de referência em Ribeirão Preto-SP e Pindamonhangaba-SP apresentaram maior dispersão do que aquelas obtidas em Campinas-SP, o que já era previsto pelos coeficientes de determinação e erros padröes da estimativa apresentados na Tabela 4. Observando-se as Figuras 1,2 e 3 verifica-se que o modelo superestimou a evapotranspiração de referéncia em Campinas-SP, enquanto que, apesar da maior dispersão verificada nas estimativas, em Pindamonhangaba-SP e Ribeirão Preto-SP, a maioria dos pontos plotados alinhou-se segundo a reta de isovalores, indicando existir um alto grau de concordância entre os valores estimados e medidos de ETo.

O fato do modelo de Penman-Monteith ter superestimado a evapotranspiração de referéncia medida em Campinas-SP pode ser explicado pela utilização nos cálculos de temperaturas anormalmente elevadas pelo processo de urbanização verificado junto à estação coletora deste parâmetro climático (CAMARGO, 1966 ).

\title{
4.1.2. Periodicidade mensal
}

\author{
Nas Tabelas 5,6 e 7 (Apéndice 1 ) estão \\ apresentados os valores mensais da evapotranspiração de \\ referéncia medida (ETO) e estimada pelos modelos de
}


52.

Penman-Monteith CETOM. Da Tabela 8 fazem parte os parâmetros estatisticos relativos às equações de regressão 1 inear simples entre os valores medidos e estimados da evapotranspiração de referéncia para as 03 localidades estudadas. Nas Figuras 4,5 e 6 estão as representaçőes gráficas das correlaçóes entre valores medidos e estimados, tomando-se como referencial a reta $1: 1$.

Tabela 8: Número de observações $(n)$, coeficiente linear (a), coeficiente angular (b), erro padrão da estimativa (S) e coeficiente de determinação $\left(r^{2}\right)$ para as equaçôes de regressão linear simples entre os valores mensais da evapotranspiração de referencia medida (ETo) e estimada pelo modelo de Penman-Monteith CETOMD, em CampinasSP, Ribeirão Preto-SP e Pindamonhagaba-SP.

\begin{tabular}{|c|c|c|c|c|c|}
\hline \multirow[b]{2}{*}{ Campinas } & \multicolumn{4}{|c|}{ ETOM $=a+b$ ETO } & $r^{2}$ \\
\hline & 48 & $30,58^{2}$ & $0.89^{3}$ & 12,08 & $0.83^{3}$ \\
\hline R. Preto & 48 & $35.10^{2}$ & $0.71^{3}$ & 17,39 & $0.64^{3}$ \\
\hline Pinda. & 34 & $11.56^{1}$ & $0.80^{3}$ & 13,50 & $0.77^{3}$ \\
\hline \multicolumn{6}{|c|}{$\begin{array}{l}1=\text { não significativo a } 5 \% \text { de probabilidade } \\
2=\text { significativo a } 5 \% \text { de probabilidade } \\
3=\text { significativo a } 1 \% \text { de probabilidade }\end{array}$} \\
\hline
\end{tabular}


53.

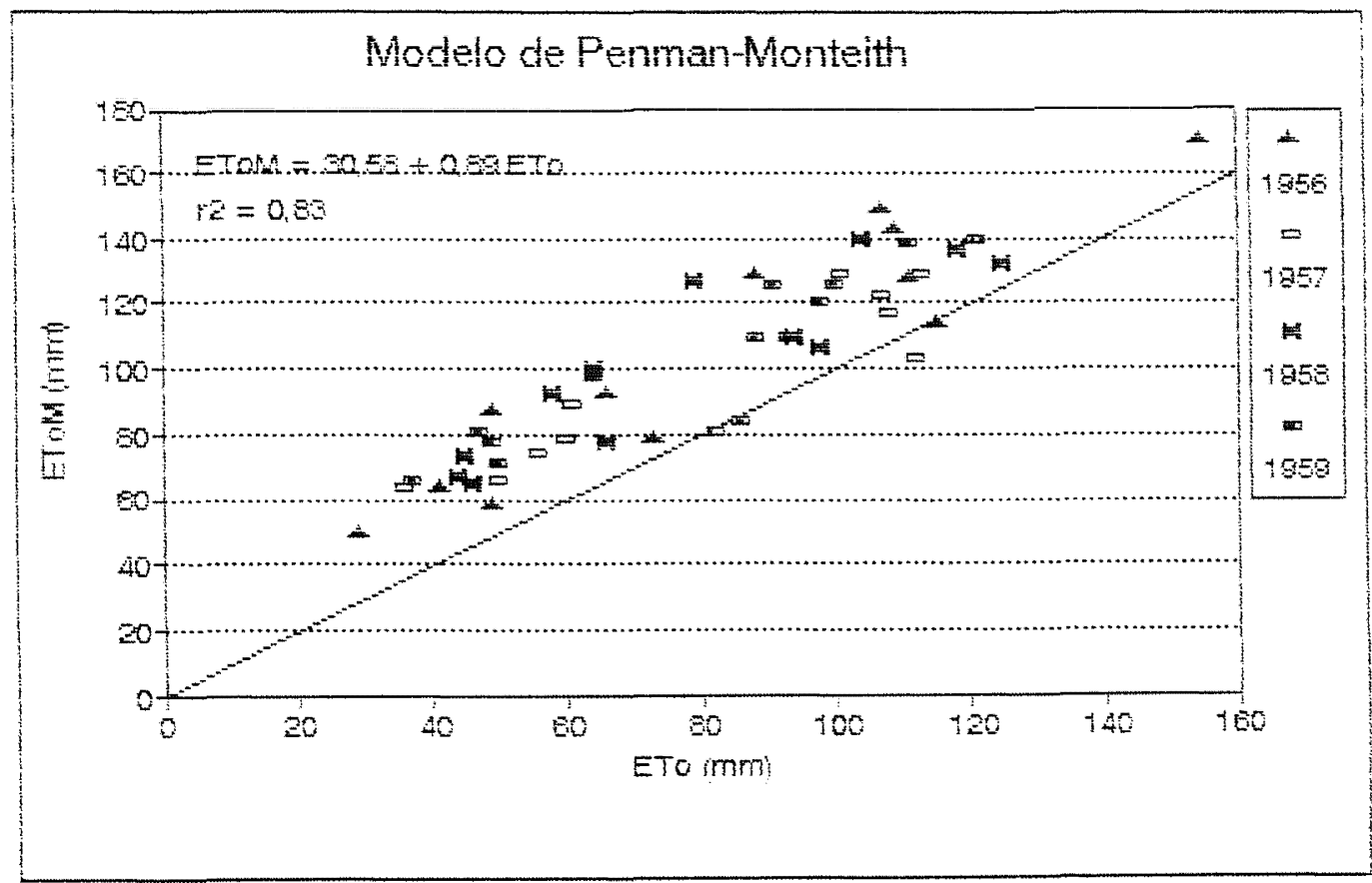

Figura 4: Evapotranspiração de referencia mensal estimada pelo modelo de Penman-Monteith CEToM versus a medida em evapotranspirómetros de drenagem (ETO) em relação à reta 1:1. Campinas-SP. Período de 1956 a 1959.

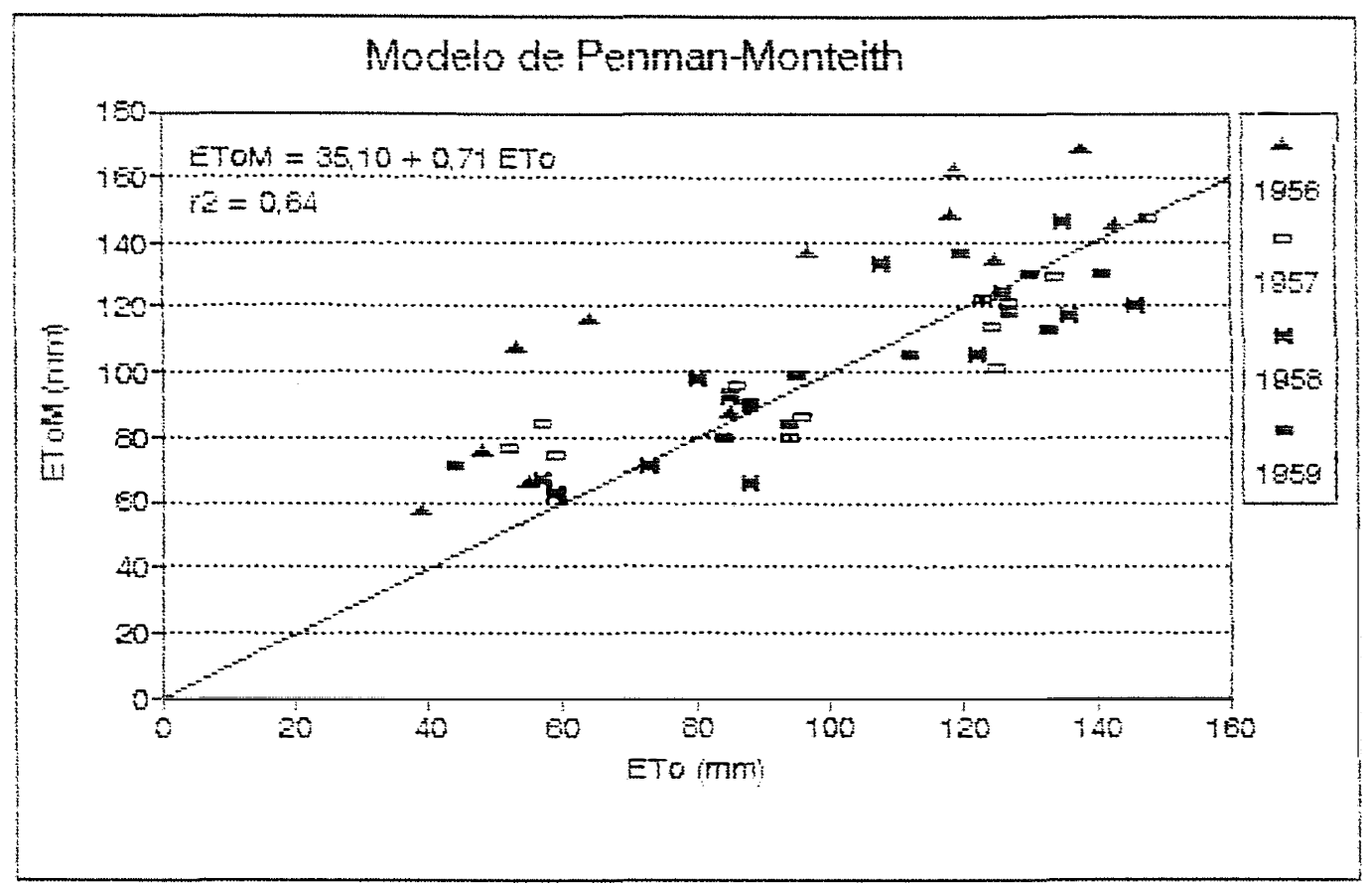

Figura 5: Evapotranspiração de referência mensal estimada pelo modelo de Penman-Monteith (EToM versus a medida em evapotranspirómetros de drenagem (ETO) em relaçăo à reta $1: 1$. Ribeirão Preto-SP. Periodo de 1956 a 1959. 
54.

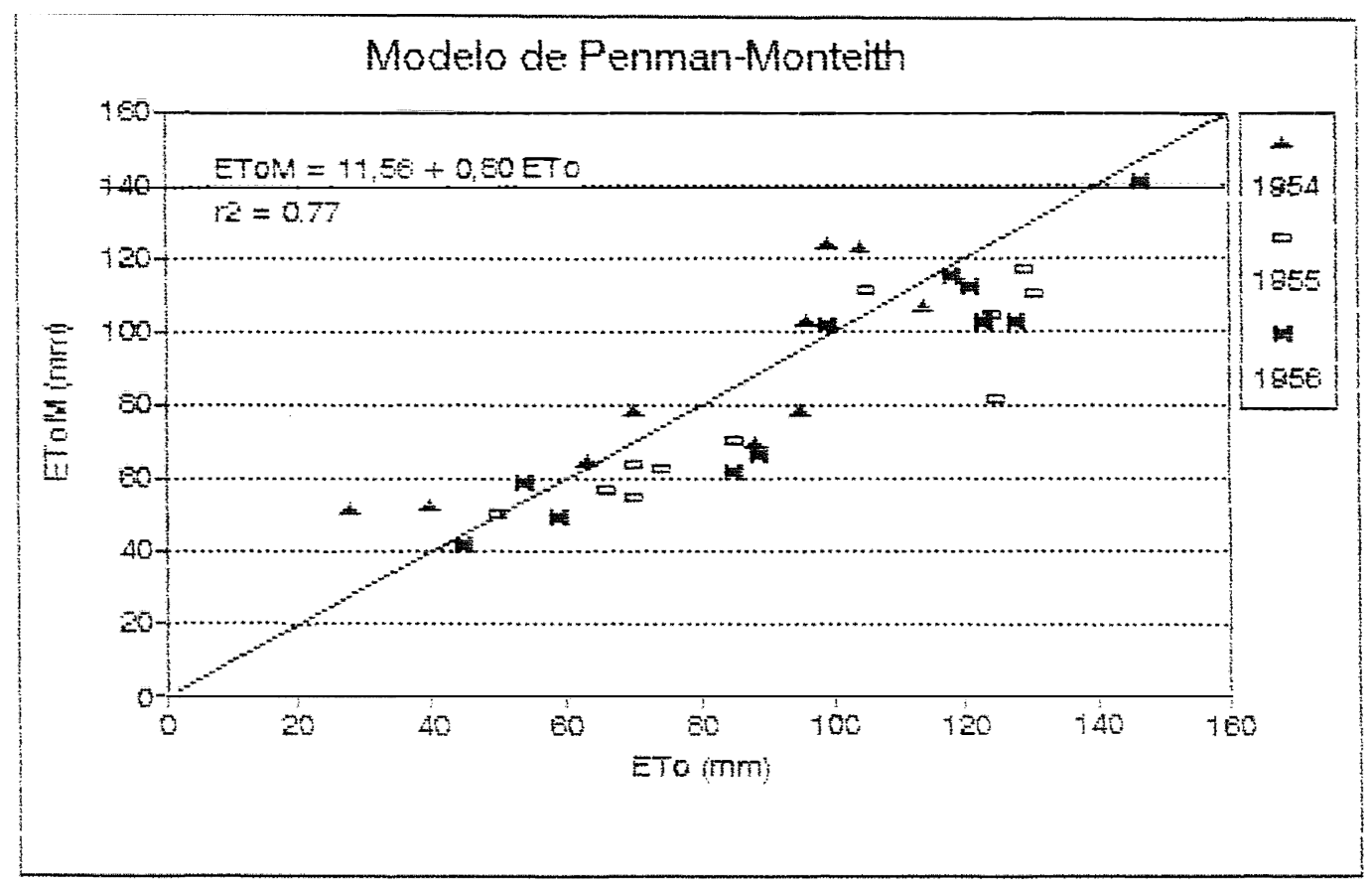

Figura 6: Evapotranspiração de referéncia mensal estimada pelo modelo de Penman-Monteith CETOMO versus a medida em evapotranspirómetros de drenagem (ETO) em relação à reta 1:1. Pindamonhangaba-SP. Periodo de 1954 a 1956.

Pelas informaçöes constantes da Tabela 8 ,

verifica-se que na periodicidade mensal houve uma melhoria substancial dos indicadores estatisticos que avaliam a correlação entre os valores estimados por Penman-Monteith e os medidos nos lisimetros. Assim, os coeficientes de correlação variaram de um minimo de 0,80 em Ribeirão Preto-SP até um valor máximo de 0,91 em Campinas-SP, ambos estatisticamente significativos ao nivel de $1 \%$ de probabiLidade.

Outro fato a ser destacado que o erro padrão da estimativa também diminuiu, passando de um valor 
55.

médio aproximado de $0,67 \mathrm{~mm}$ dia ${ }^{-1}$ na periodicidade decadiaria para $0,48 \mathrm{~mm}$ dia ${ }^{-1}$ na escala mensal. Estes numeros refletiram em uma menor dispersão dos pontos em relação à reta de isovalores.

Pela observação das Figuras 4,5 e 6 verifica-se que, em Campinas-SP, o modelo superestimou a evapotranspiração de referencia, enquanto que em Pindamonhangaba-SP ela foi subestimada, embora de forma menos acentuada. No caso de Ribeirão Preto-SP, apesar das estimativas apresentarem uma dispersão maior do que nas outras localidades, elas se alinharam ao longo da reta $1: 1$, indicando boa concordância entre os valores medidos e estimados.

Outro ponto a ser destacado, é a maior dispersão das estimativas verificada na escala decadiária em relação à mensal, traduzindo-se en coeficientes de determinação mais baixos e erros padróes de estimativa mais elevados. A explicação para esta ocorrencia está na inércia apresentada pelos evapotranspirómetros no que se refe re a sua drenagem, caracterizada por uma retenção tempor aria de agua livre, viciando os dados coletados. Esta situação torna-se mais acentuada se a precipitação, ou mesmo irrigação, ocorrer no final do período de análise. 
56.

4.2 Relativos à sensibilidade do modelo de PenmanMonteith a variações da altura da vegetação e da resistencia do dossel.

A maior dificuldade à aplicação prática do modelo de Penman-Monteith está na obtenção de valores confiáveis e representativos para a resistencia do dossel $(\mathrm{r})_{c}$. Na literatura especializada não se encontra uma definição clara acerca do valor de $r_{c}$ que, de fiato, represente as condiçớes de evapotranspiração potencial. No geral, são utilizados valores de $r_{c}$ na faixa de 0 a $80 \mathrm{~s} \mathrm{~m}^{-1}$.

Nesta simulação, foram utilizados valores constantes de $r_{c}$, aqueles normalmente citados na literatura, da ordem de $0,20,40,50$ e $80 \mathrm{~s} \mathrm{~m}^{-1}$, altem de um valor variável, em função da radiação solar liquida e do índice de área foliar da vegetação.

Outro aspecto importante considerado foi o valor utilizado para a altura da vegetação $\mathrm{Ch}_{c}{ }^{3}$, parâmetro fisiológico de fundamental importância à parametrizaçăo da resistencia aerodinâmica e do dossel. Neste estudo foram analisadas 02 alturas de vegetação, $h_{c}=0,12 \mathrm{~m}$ e $h_{c}=0,06$ m, a primeira representando o valor padronizado para grama proposto pela FAO (SMITH, 1991$)$ e segundo por ser mais adequado ao porte da grama batatais. 
57.

A combinação de 06 valores para resistência e de oz para a altura da vegetação resultou no estabelecimento de 12 formulaçơes alternativas, que permitiram testar a sensibilidade do modelo de Penman-Monteith a variaçơes numericas destes parâmetros fisiológicos, facilitando a escolha da alternativa que melhor se ajustou à evapotranspiração de referéncia medida.

Na realização desta análise de sensibilidade foram utilizadas as informações levantadas por CAMARGO (1966), em Campinas-SP, no periodo de 1956 a 1959.

A simbologia utilizada neste texto pode criar algum tipo de problema para seu entendimento e, desse modo, os exemplos a seguir procuram contornar as dificuldades porventura apresentadas pela notação.

- EToM 0000 : evapotranspiração de referéncia para grama estimada pelo modelo de Penman-Monteith, considerando uma altura de vegetação igual a $0,06 \mathrm{~m}$ (OS) e uma resisténcia do dossel igual a O $s \mathrm{~m}^{-1} \cos$.

- EToM ${ }_{1200}$ : evapotranspiração de referência para grama esti mada pelo modelo de Penman-Monteith, considerando uma altura de vegetação igual a $0,12 \mathrm{~m}$ (12) e uma resisténcia do dossel igual a 69 
58.

$s m^{-1}$ (69). Esta alternativa. que não faz parte das 12 anteriormente citadas, representa a formulação padronizada pela FAO (SMI TH, 1991), discutida anteriormente no item 4.1 sob denominação de EToM.

- EToM ${ }_{\text {12VR }}$ : evapotranspiração de referéncia para grama estimada pelo modelo de Penman-Monteith, considerando uma altura de vegetação igual a $0.12 \mathrm{~m}$ (12) e uma resistência do dossel variável (VR) de acordo com a equação 23 .

Nas Tabelas 9 a 16 (Apéndice 2 ) e 18 a 25 (Apéndice 2) estão apresentados, respectivamente, os valores decadiários e mensais da evapotranspiração de referência medida em lisimetro de drenagem (ETO) e a estimada pelo modelo de Penman-Monteith, considerando diferentes resistências do dossel e diferentes alturas da vegetação. Das Tabelas 17 e 26 fazem parte os parâmetros estatisticos relativos à análise de regressão linear simples entre os valores medidos e estimados de evapotranspiração de referência. As representaçơes gráficas das correlaçỡes entre as variáveis medidas e estimadas estão nas figuras 7 a 18 , 
escala decadiária, e Figuras 19 a 30 , relativas a escala mensal.

Tabela 17: Número de observaçós $(n)$, coeficiente linear (a), coeficiente angular (b), erro padrão da estimativa (S) e coeficiente de determinaçăo $\left(r^{2}\right)$ para as equaçōes de regressão il near simples entre os valores decadiarios da evapotranspiração de referéncia medida (ETo) e estimada pelo modelo de Penman-Monteith CETOM. CampinasSP. Perlodo de 1956 a 1959.

\begin{tabular}{|c|c|c|c|c|c|}
\hline Combi nação & $\mathrm{n}$ & $a$ & $b$ & $s$ & $r^{2}$ \\
\hline ETOM $_{0000}$ & 142 & $14,37^{1}$ & $0.88^{3}$ & 7,41 & $0,647^{3}$ \\
\hline ETOM $_{0020}$ & 142 & $13,54^{1}$ & $0.85^{3}$ & 6,94 & $0.660^{3}$ \\
\hline ETOM 0040 & 142 & $1 \mathrm{e}, 8 \mathrm{e}^{1}$ & $0.82^{3}$ & 6.56 & $0,670^{3}$ \\
\hline ETOM $_{0000}$ & 142 & $12,16^{1}$ & $0,80^{3}$ & 6,23 & $0.678^{9}$ \\
\hline ETOM $_{0<00}$ & 142 & $11.74^{1}$ & $0,77^{3}$ & 6,03 & $0.679^{3}$ \\
\hline ETOM $_{\text {OOVR }}$ & 142 & $5,50^{1}$ & $0.77^{3}$ & 5,85 & $0.690^{3}$ \\
\hline ETOM $_{1200}$ & 142 & $16,40^{2}$ & $0,91^{3}$ & 8,17 & $0.616^{3}$ \\
\hline ETOM $_{1220}$ & 142 & $15,25^{2}$ & $0.87^{3}$ & 7.50 & $0.635^{9}$ \\
\hline ETOM $_{1240}$ & 142 & $14,25^{2}$ & $0.84^{3}$ & 6,96 & $0,649^{3}$ \\
\hline ETOM $_{1200}$ & 142 & $13,38^{2}$ & $0.80^{3}$ & 6,53 & $0.660^{3}$ \\
\hline ETOM $_{1200}$ & 142 & $13,03^{2}$ & $0.79^{3}$ & 6.36 & $0.650^{3}$ \\
\hline ETOM $_{1280}$ & 142 & $12,60^{2}$ & $0,77^{3}$ & 6.17 & $0,668^{3}$ \\
\hline ETOM $_{12 V R}$ & 142 & $8,84^{1}$ & $0.84^{3}$ & 6,39 & $0.688^{3}$ \\
\hline $\begin{array}{l}1=\text { năo sig } \\
2=\text { signifi } \\
3=\text { signifi }\end{array}$ & $\begin{array}{l}\text { ficati } \\
\text { tivo a } \\
\text { tivo a }\end{array}$ & $\begin{array}{l}0 \text { a } 5 \% \text { d } \\
5 \% \text { de pr } \\
1 \% \text { de pr }\end{array}$ & $\begin{array}{l}\text { orobabi } \\
\text { abilida } \\
\text { abilida }\end{array}$ & dade & \\
\hline
\end{tabular}


60 .

Tabela a6: Numero de observaçes $(n)$, coeficiente linear (a), coeficiente angular (b), erro padrão da est.imativa (S) e coeficiente de determinação $\mathrm{Cr}^{2} \mathrm{j}$ para as equaçoes de regressão linear simples entre os valores mensais da evapotranspiração de referéncia medida (ETO) e estimada pelo modelo de Penman-Monteith CETOM. Campinas-SP. Periodo de 1956 a 1959.

\begin{tabular}{|c|c|c|c|c|c|}
\hline Combinação & $\mathrm{n}$ & a & $b$ & $s$ & $r^{2}$ \\
\hline ETOM $_{0000}$ & 48 & $32,9 e^{2}$ & $1.01^{3}$ & 14,15 & $0.82 \mathrm{e}^{3}$ \\
\hline ETOM $_{0020}$ & 48 & $30,80^{2}$ & $0,97^{3}$ & 13,19 & $0.832^{3}$ \\
\hline ETOM $_{0040}$ & 48 & $28.96^{2}$ & $0.94^{9}$ & 12,41 & $0,839^{3}$ \\
\hline ETOM 0000 & 48 & $27 \cdot 28^{2}$ & $0.91^{3}$ & 11,74 & $0,845^{3}$ \\
\hline ETOM $_{00000}$ & 48 & $26,2 e^{2}$ & $0.88^{9}$ & 11.47 & $0.843^{3}$ \\
\hline ETOM OAVR & 48 & $7,4 e^{1}$ & $0.88^{3}$ & 10,88 & $0.855^{3}$ \\
\hline ETOM $_{1200}$ & 48 & $39 \cdot 42^{2}$ & $1.03^{3}$ & 15,83 & $0.794^{9}$ \\
\hline ETOM $_{1220}$ & 48 & $36.39^{2}$ & $0.98^{9}$ & 14,44 & $0.809^{9}$ \\
\hline ETOM $_{1240}$ & 48 & $33,77^{2}$ & $0,94^{3}$ & 13,32 & $0.821^{9}$ \\
\hline ETOM $_{1200}$ & 48 & $31,48^{2}$ & $0,90^{3}$ & $1 \hat{\mathrm{E}}, 4 \mathrm{e}$ & $0.829^{9}$ \\
\hline ETOM $_{1200}$ & 48 & $30,58^{2}$ & $0.89^{3}$ & 12.08 & $0,830^{9}$ \\
\hline ETOM $_{1280}$ & 48 & $29,47^{2}$ & $0.87^{3}$ & 11,69 & $0.835^{3}$ \\
\hline ETOM $_{12 \mathrm{VR}}$ & 48 & $16.75^{1}$ & $0,95^{3}$ & 11,88 & $0.855^{3}$ \\
\hline $\begin{array}{l}1=\text { ño sig } \\
2=\operatorname{signifi} \\
3=\operatorname{sighifi}\end{array}$ & $\begin{array}{l}\text { icat } \\
\text { i vo } \\
\text { ivo }\end{array}$ & $\begin{array}{l}10 \text { a } 5 \% \\
5 \% \text { de } p \\
1 \% \text { de } p\end{array}$ & $\begin{array}{l}\text { probab } \\
\text { oabilid } \\
\text { oabilid }\end{array}$ & $\begin{array}{l}\text { I idade } \\
\text { de } \\
\text { de }\end{array}$ & \\
\hline
\end{tabular}


61.

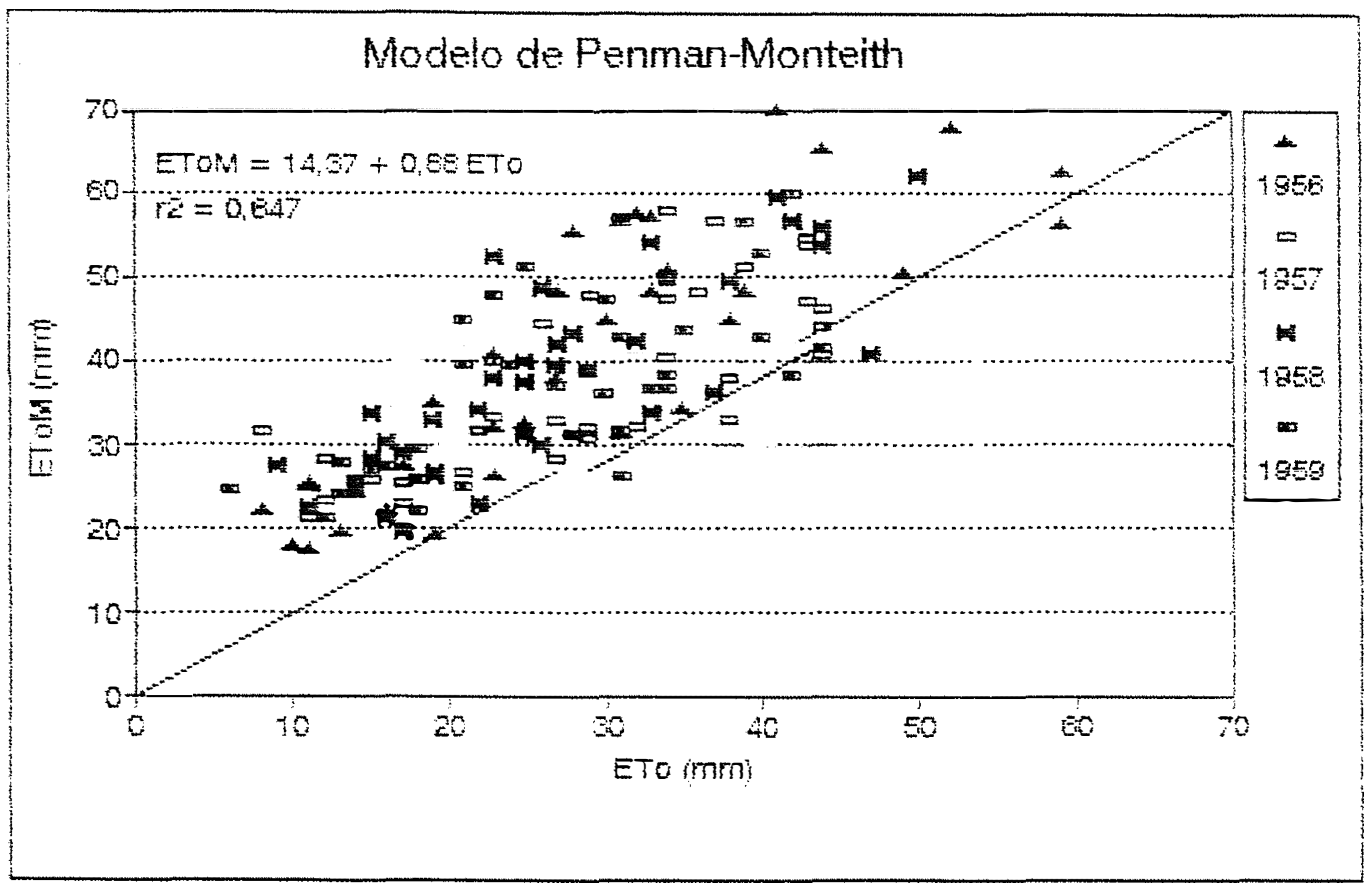

Figura 7: Evapotranspiração de referencia decadiaria estimada pelo modelo de Penman-Monteith (ETOM ${ }_{0000}$ ) versus a medida em evapotranspirometros de drenagem (ETo) em relação à reta 1:1. Campinas-SP. Periodo de 1956 a 1959.

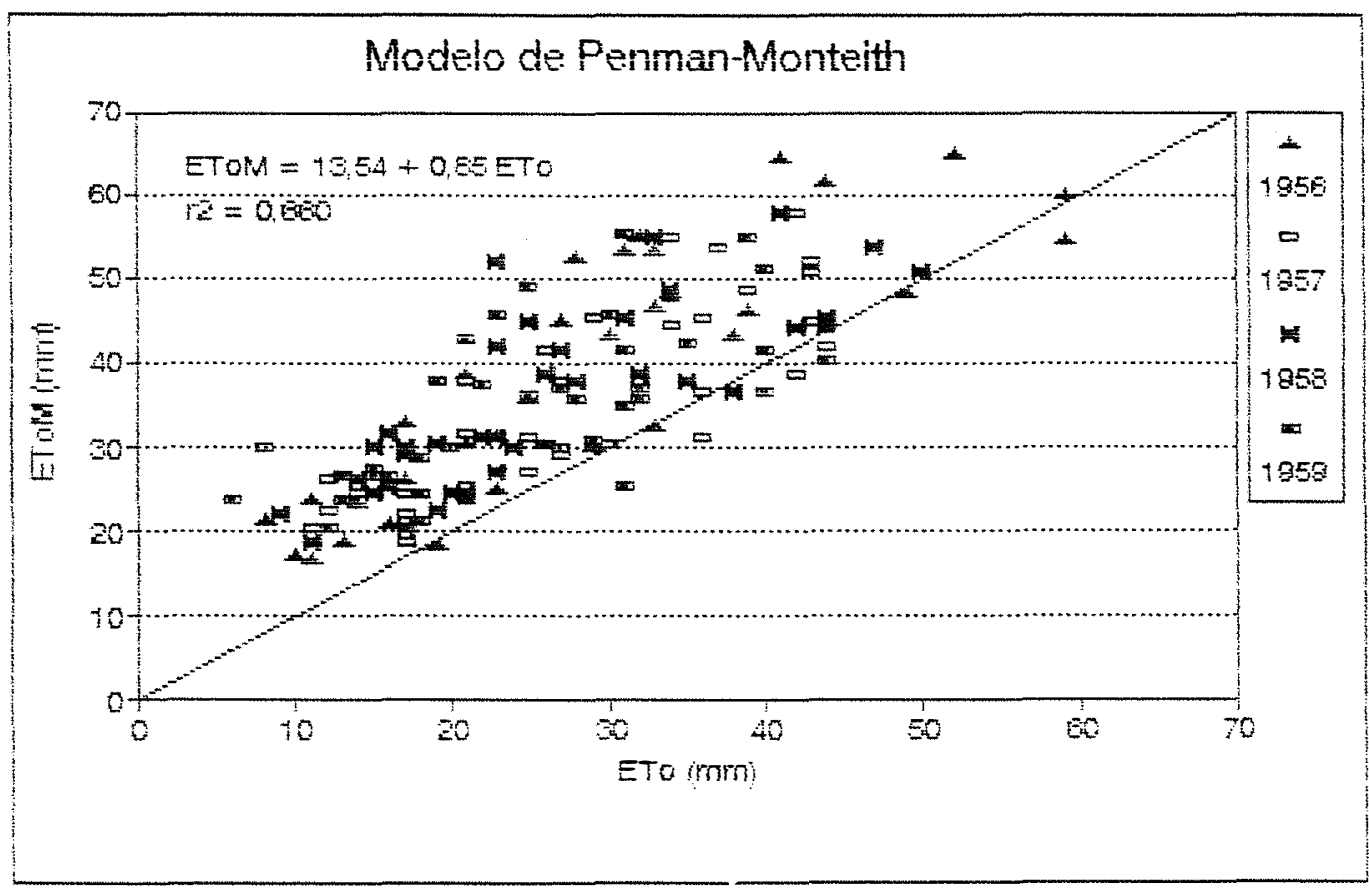

Figura 8: Evapotranspiração de referencia decadiária estimada pelo modelo de Penman-Monteith (EToM ooro' versus a medida em evapotranspirómetros de drenagem (ETO) em relação à reta 1:1. Campinas-SP. Periodo de 1956 a 1959. 
62.

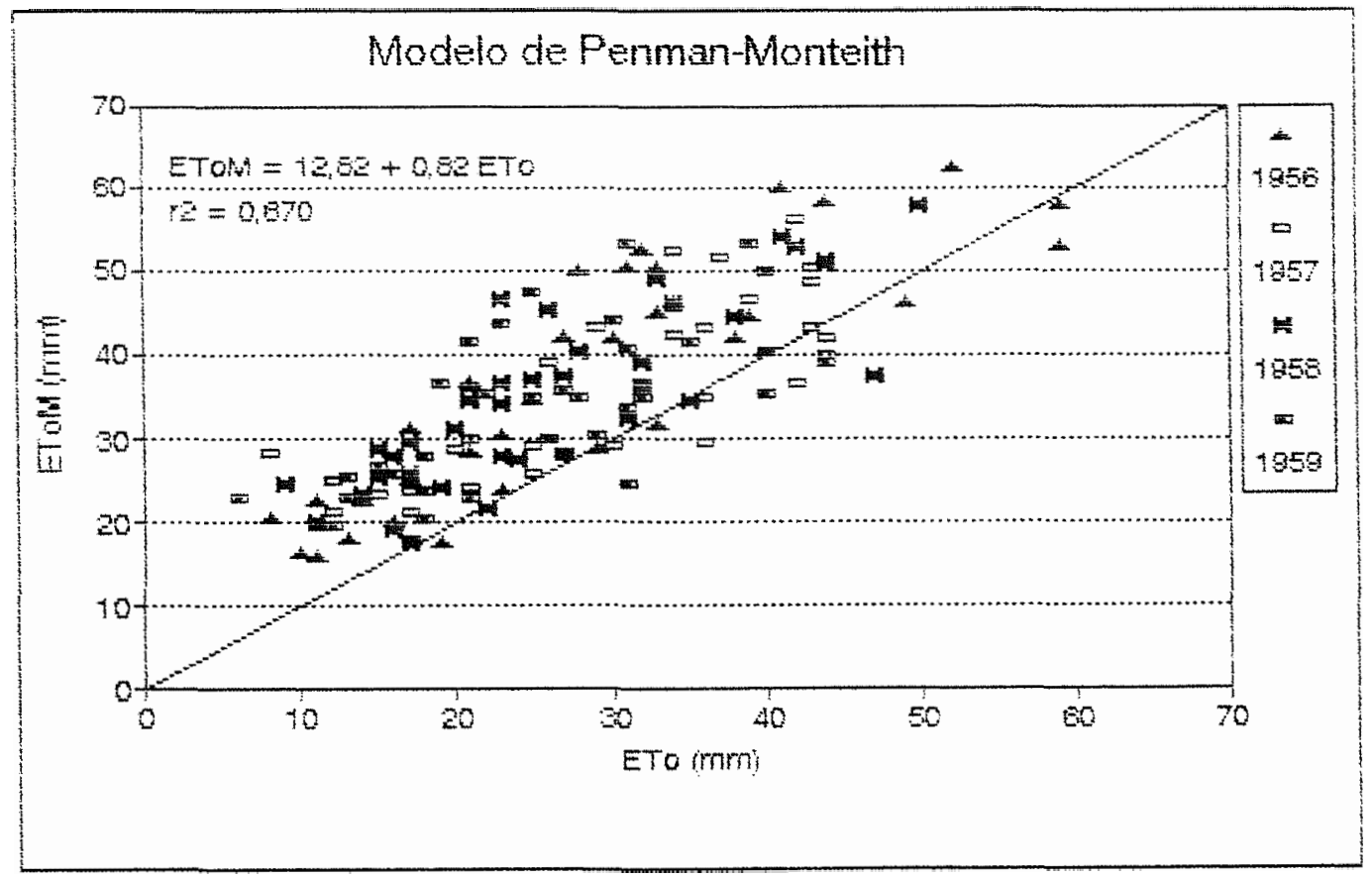

Figura 9: Evapotranspiração de referencia decadiária estimada pelo modelo de Penman-Monteith (EToM ${ }_{0040}$ ) versus a medida em evapotranspirometros de drenagem (ETO) em relação à reta $1: 1$. Campinas-SP. Periodo de 1956 a 1959.

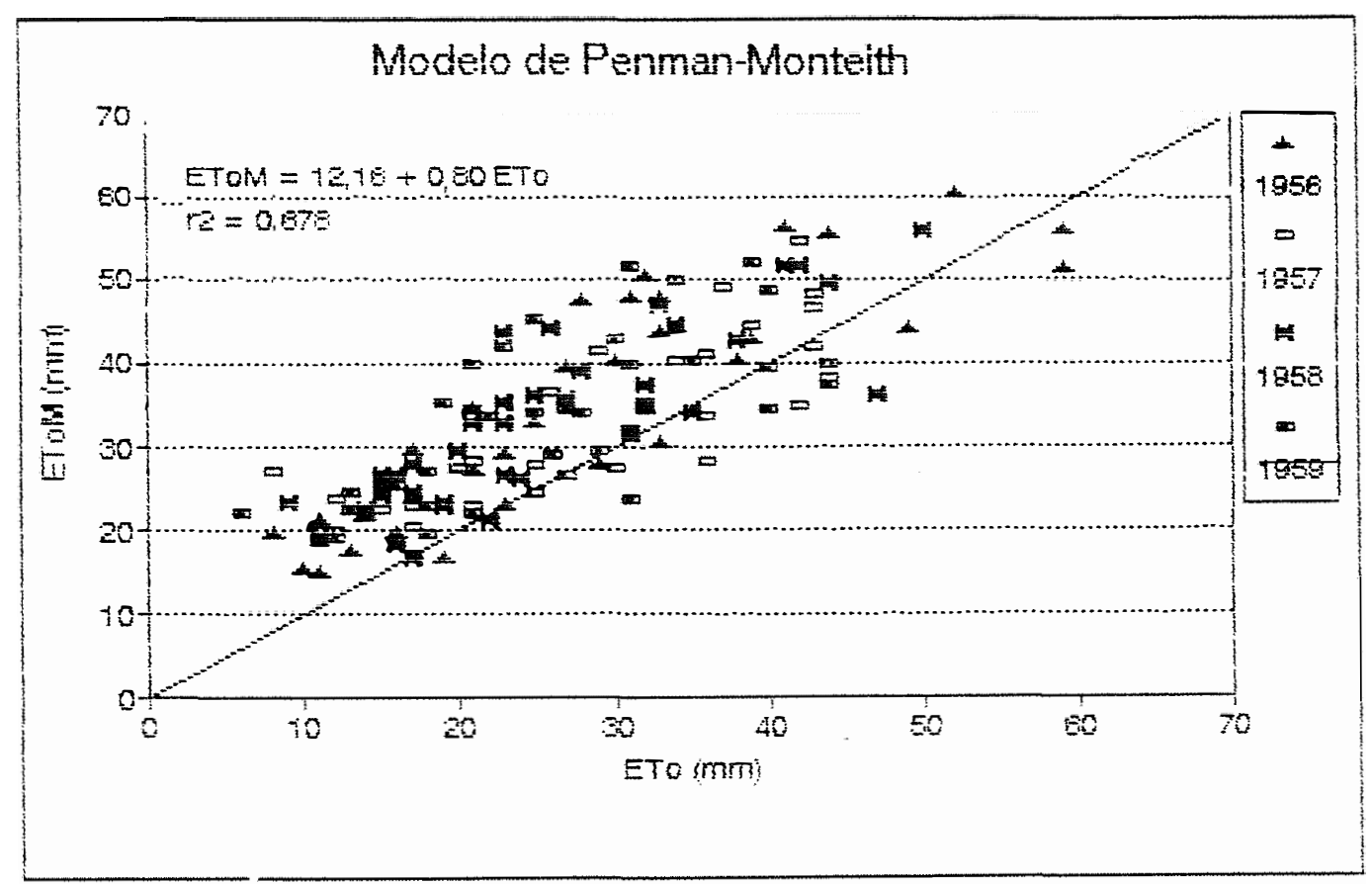

Figura 10: Evapotranspiração de referencia decadiaria estimada pelo modelo de Penman-Monteith (ETOM ${ }_{0<00}$ ) versus a medida em evapotranspirometros de drenagem (ETo) em relação à reta 1:1. Campinas-SP. Periodo de 1958 a 1959. 
63.

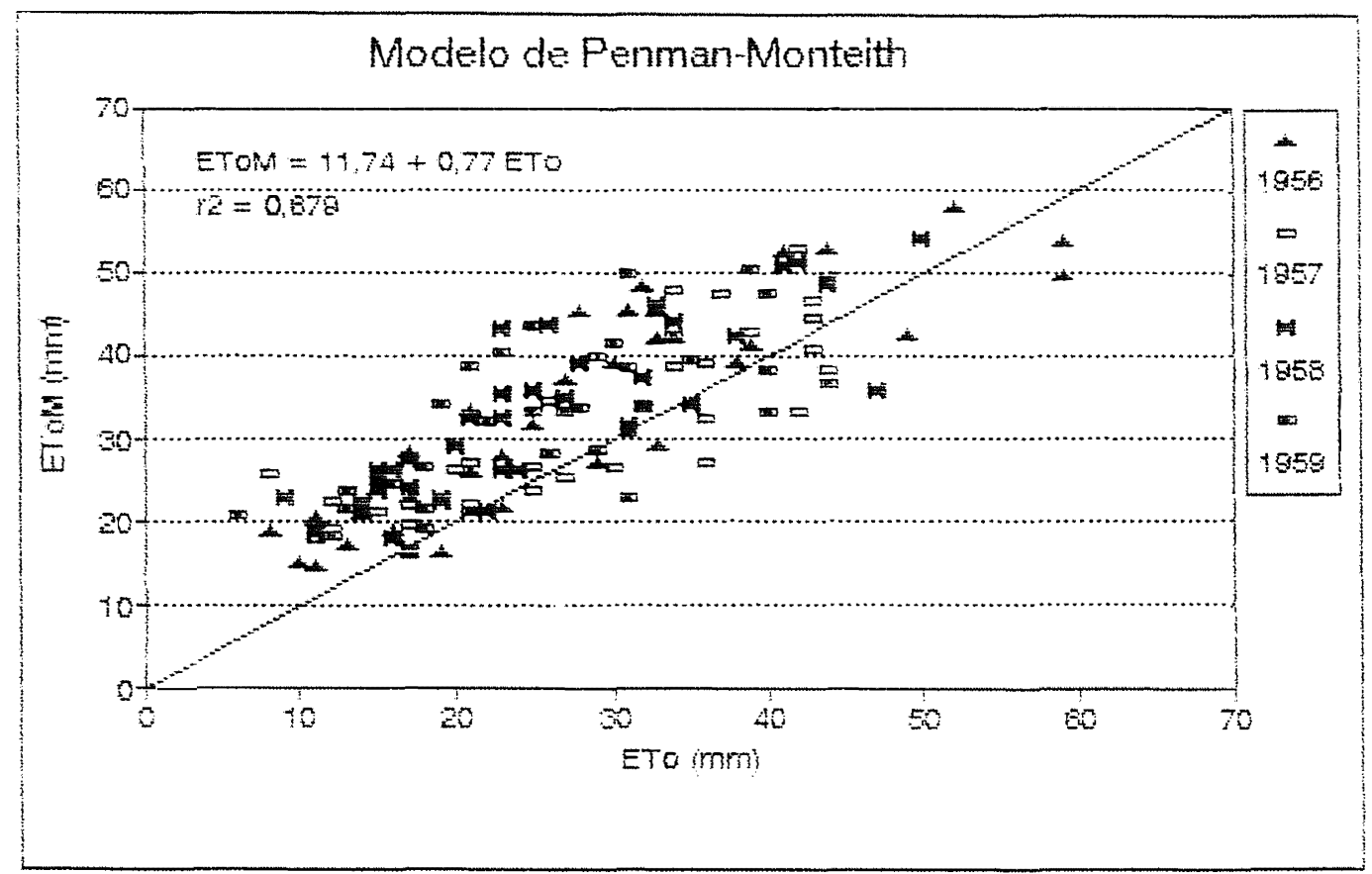

Figura 11: Evapotranspiração de referencia decadiária estimada pelo modelo de Penman-Monteith (ETOM ${ }_{0000}$ ) versus a medida em evapotranspirometros de drenagem (ETO) em relação à reta 1:1. Campinas-SP. Periodo de 1956 a 1959.

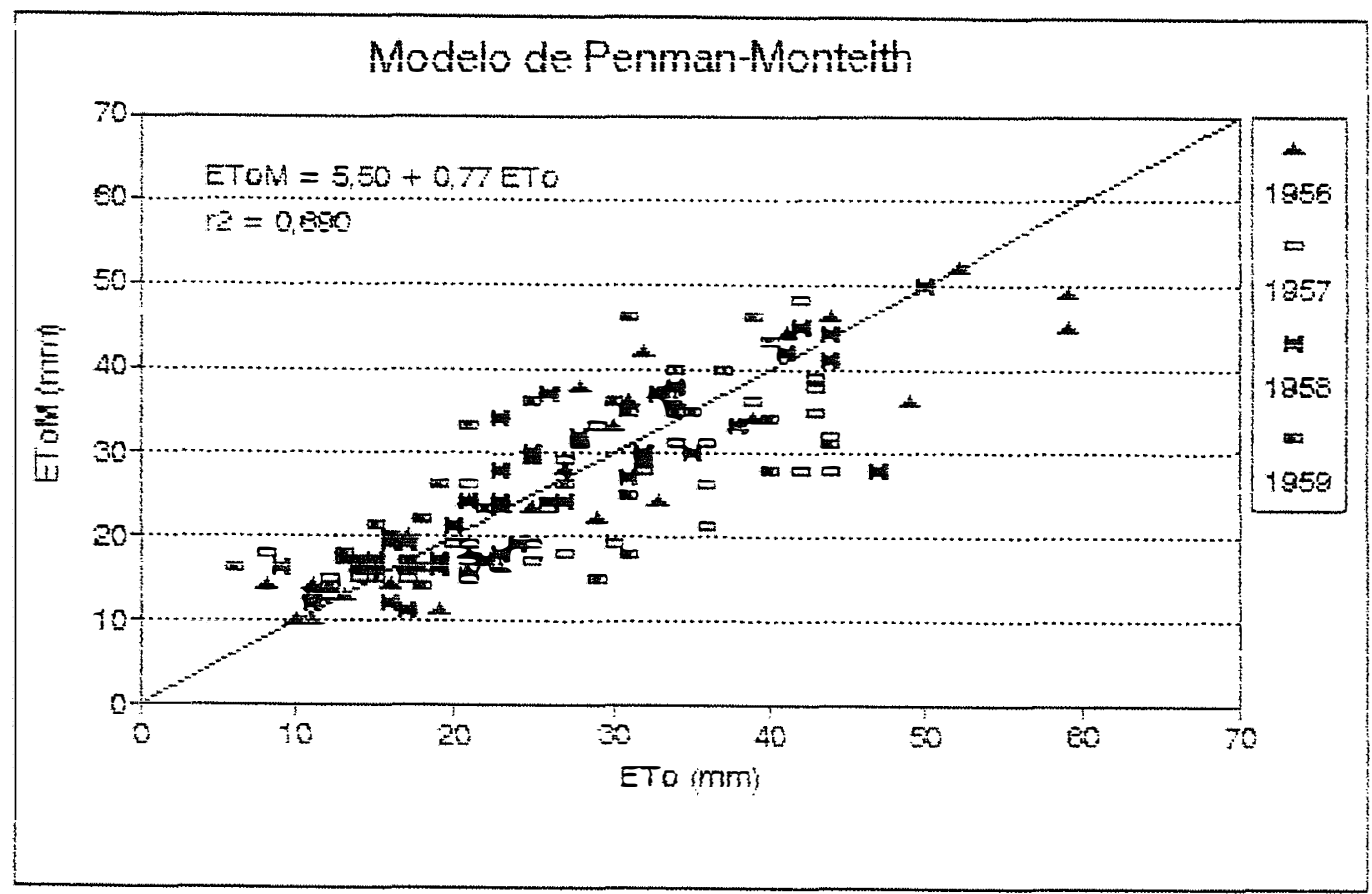

Figura 12: Evapotranspiração de referéncia decadiária estimada pelo modelo de Penman-Monteith (ETOM ${ }_{\text {OovR }}{ }^{3}$ versus a medida em evapotranspirómetros de drenagem (ETO) em relação à reta $1: 1$. Campinas-SP. Período de 1956 a 1959. 
64.

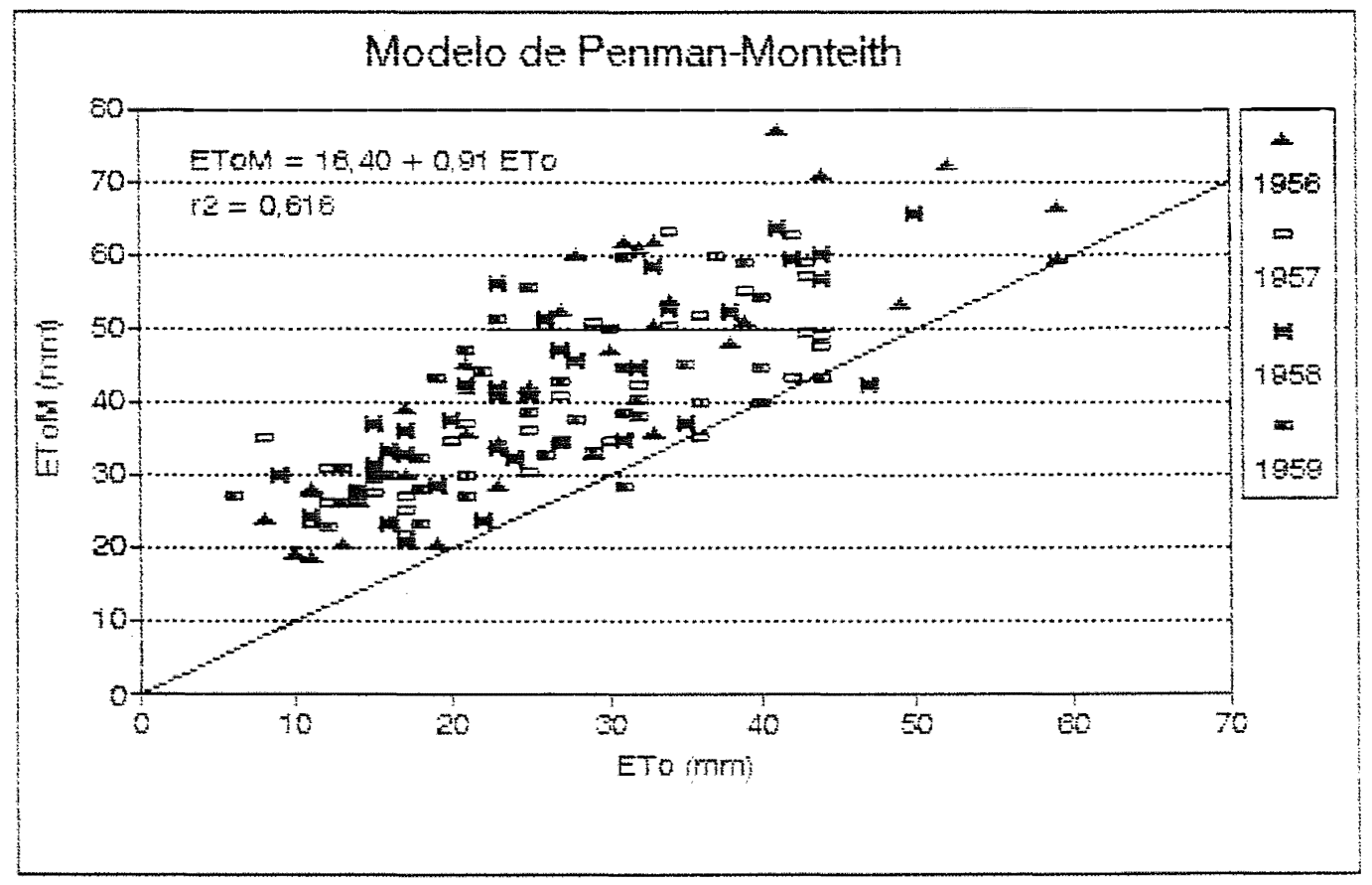

Figura 13: Evapotranspiração de referencia decadiária estimada pelo modelo de Penman-Monteith (ETOM ${ }_{1200}{ }^{3}$ versus a medida em evapotranspirometros de drenagem (ETO) em relação à reta $1: 1$. Campinas-SP. Período de 1956 a 1959.

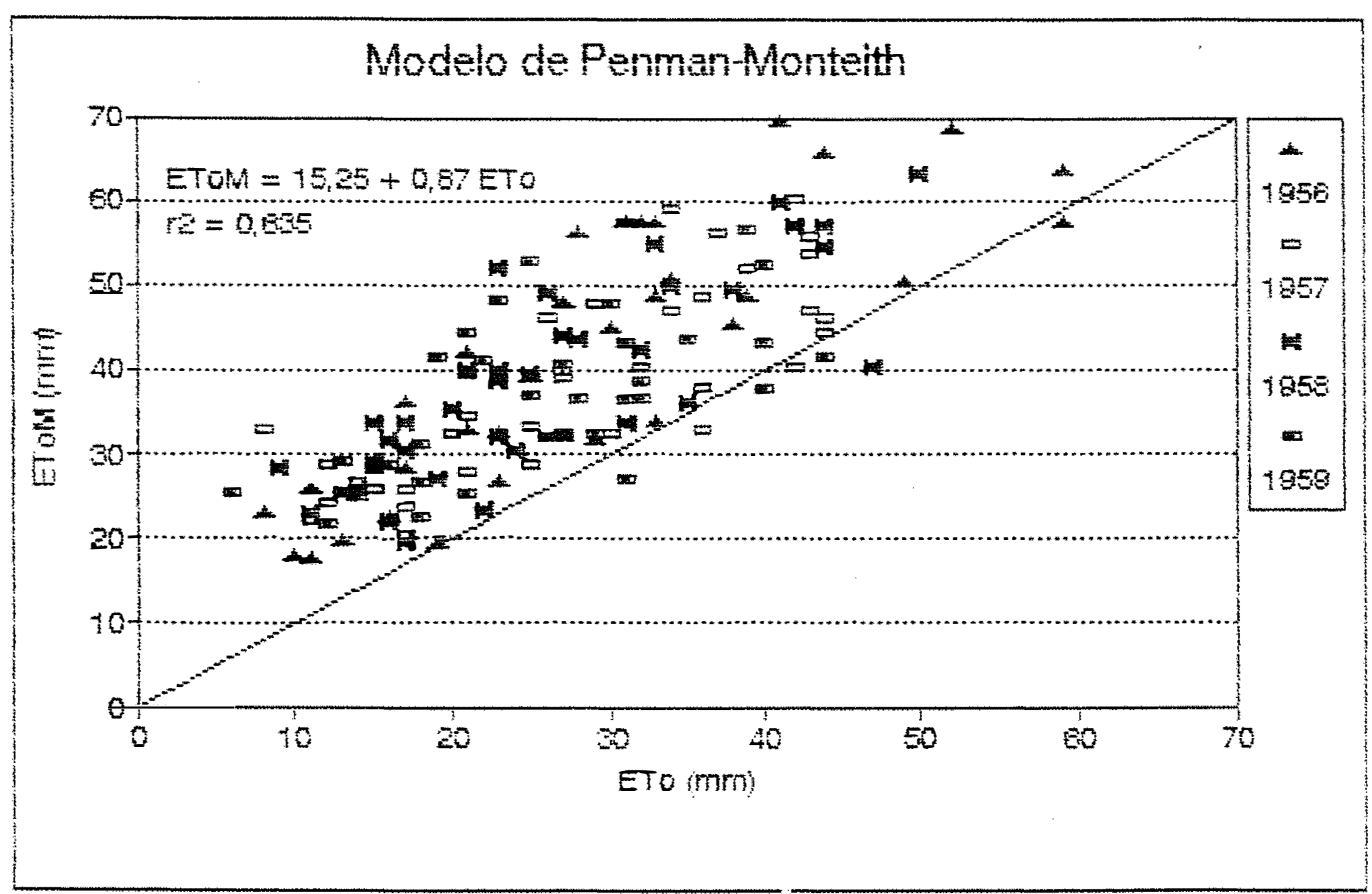

Figura 14: Evapotranspiração de referencia decadiária estimada pelo modelo de Penman-Monteith (ETOM ${ }_{1220}$ ) versus a medida em evapotranspirometros de drenagem (ETO) em relação à reta 1:1. Campinas-SP. Período de 1956 a 1959. 
65.

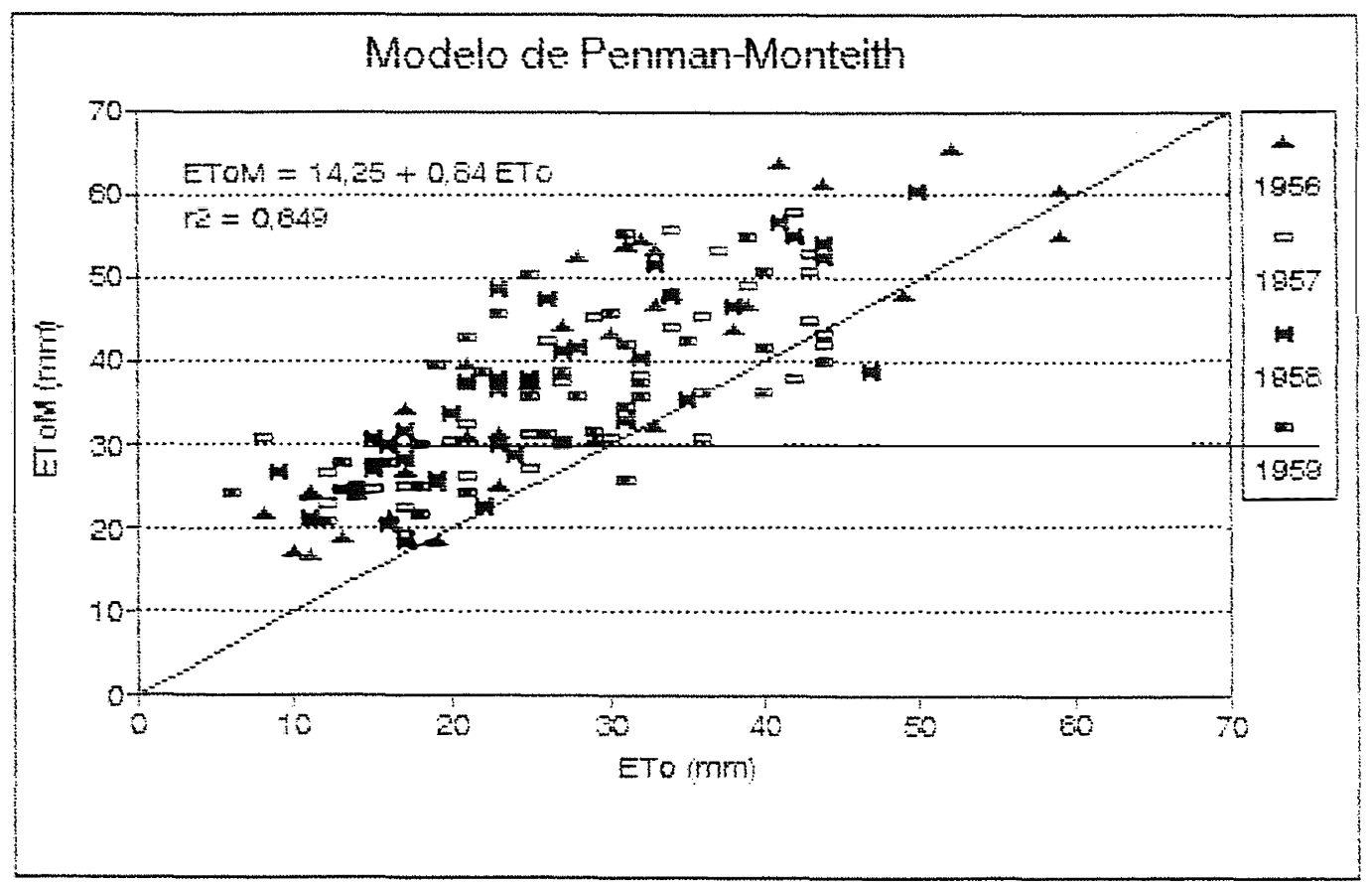

Figura 15: Evapotranspiração de referencia decadiaria estimada pelo modelo de Penman-Monteith (ETOM ${ }_{1240}{ }^{3}$ versus a medida em evapotranspirometros de drenagem (ETO) em relação à reta 1:1. Campinas-SP. Período de 1956 a 1959.

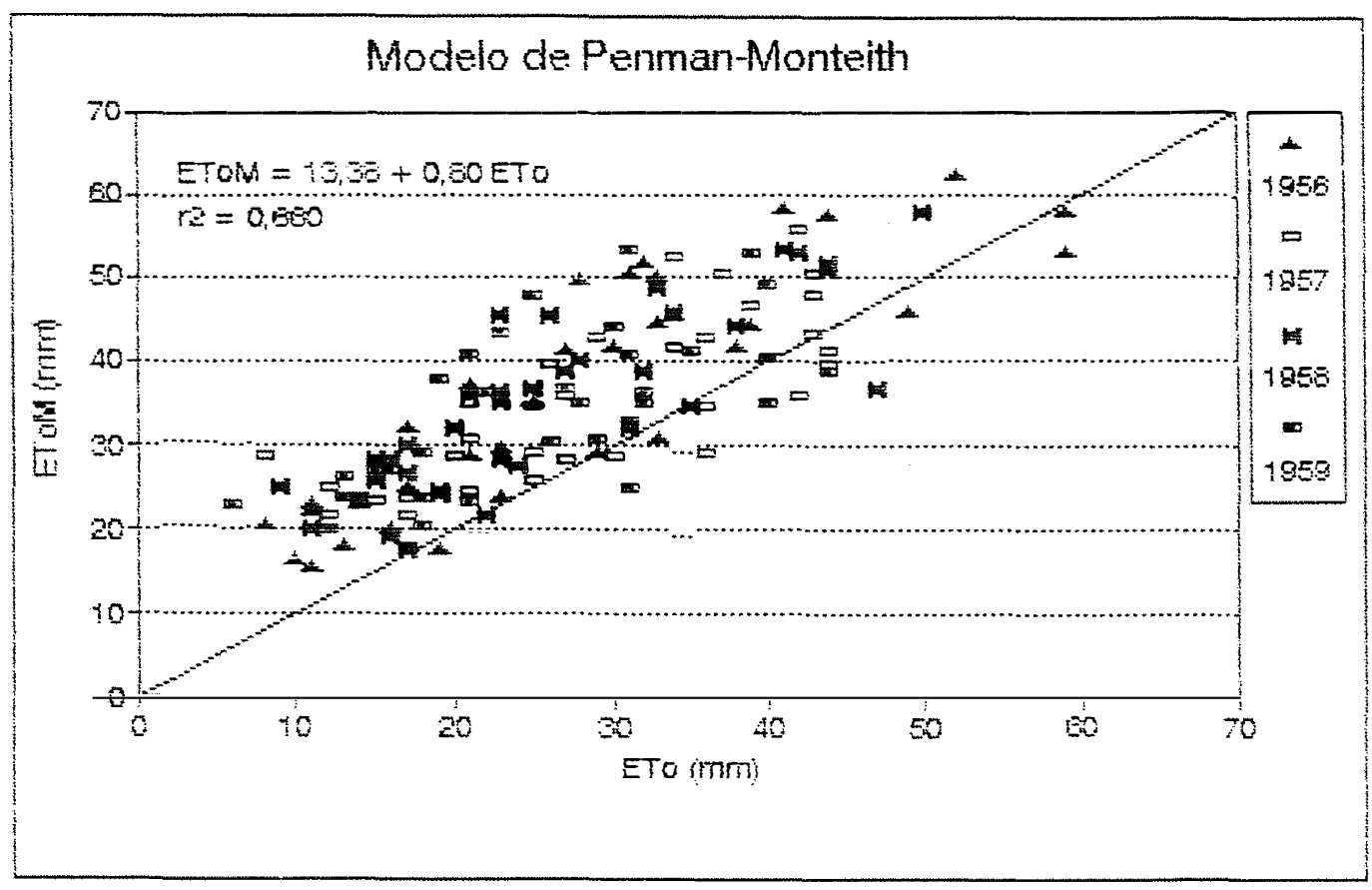

Figura 16: Evapotramspiração de referencia decadiaria estimada pelo modelo de Penman-Monteith (ETOM ${ }_{1200}$ ? versus a medida em evapotranspirometros de drenagem (ETO) em relação à reta $1: 1$. Campinas-SP. Periodo de 1956 a 1959. 
66.

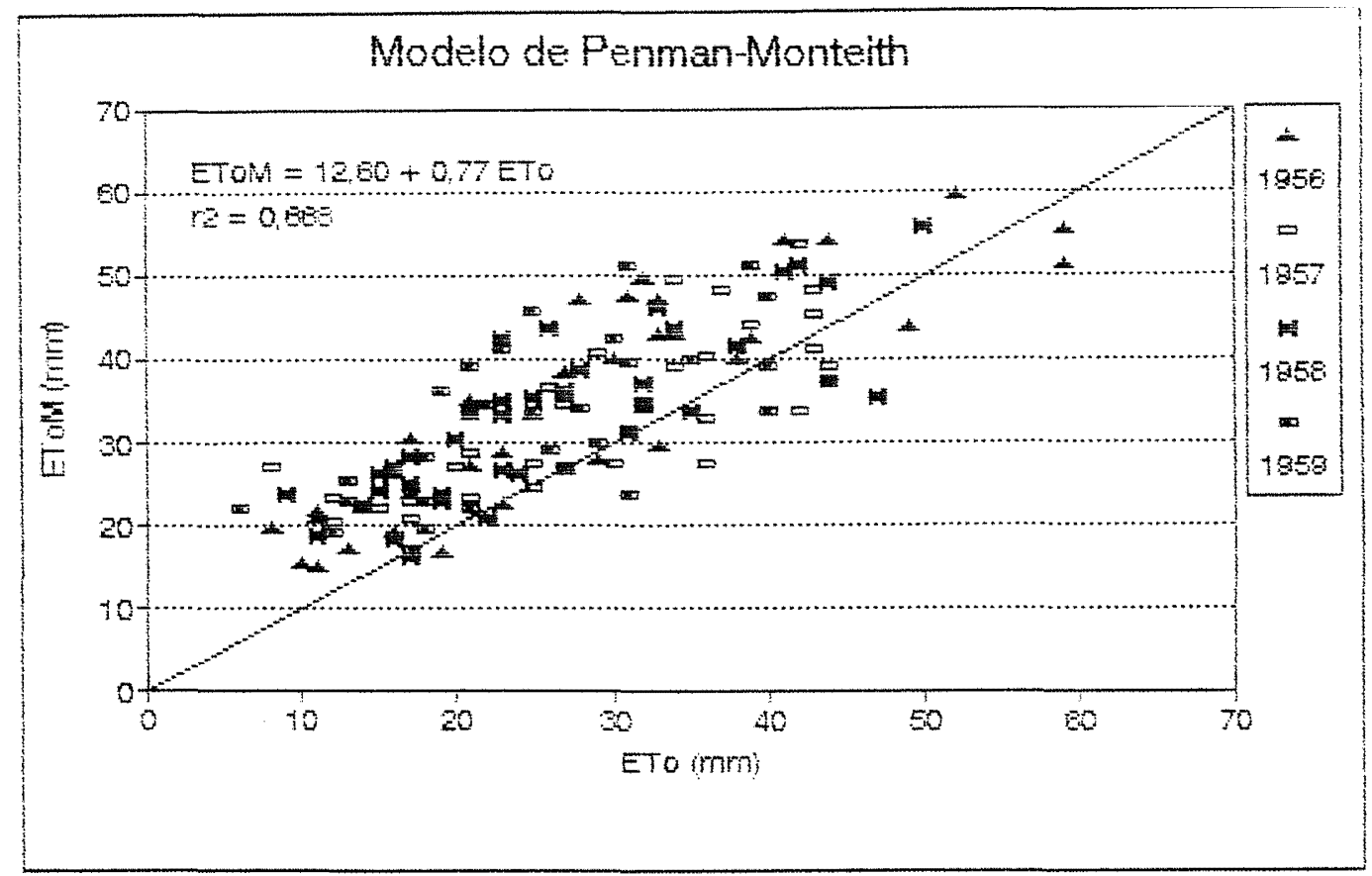

Figura 17: Evapotranspiração de referencia decadiaria est1mada pelo modelo de Penman-Monteith (EToM ${ }_{1280}$ ) versus a medida em evapotranspirómetros de drenagem (ETO) em relação à reta 1:1. Campinas-SP. Periodo de 1956 a 1959.

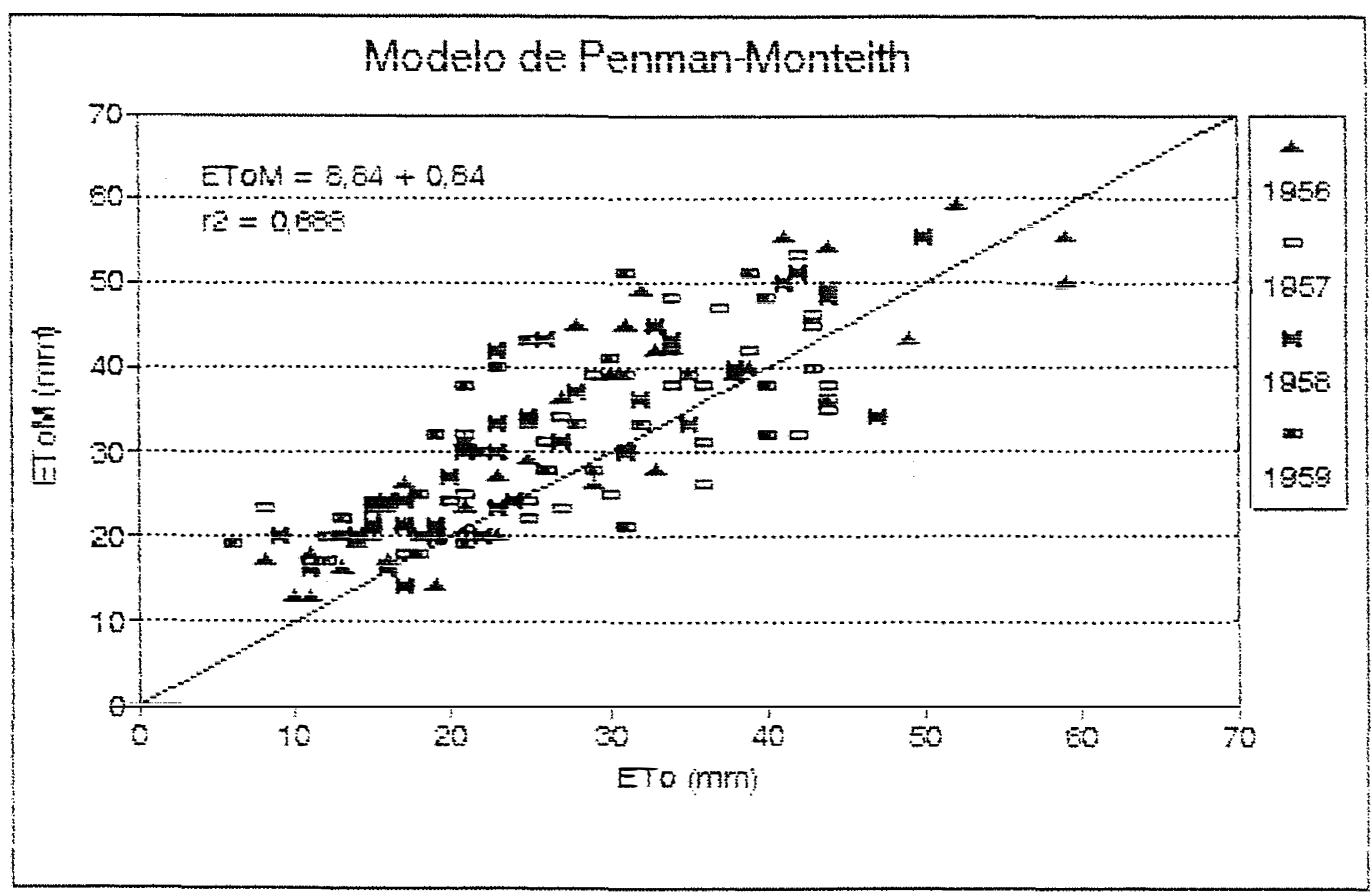

Figura 18: Evapotranspiraçăo de referencia decadiária estimada pelo modelo de Penman-Monteith (ETOM ${ }_{12 \mathrm{VR}}$ ' versus a medida em evapotranspirometros de drenagem (ETO) em relação à reta 1:1. Campinas-SP. Perído de 1956 a 1959. 
67.

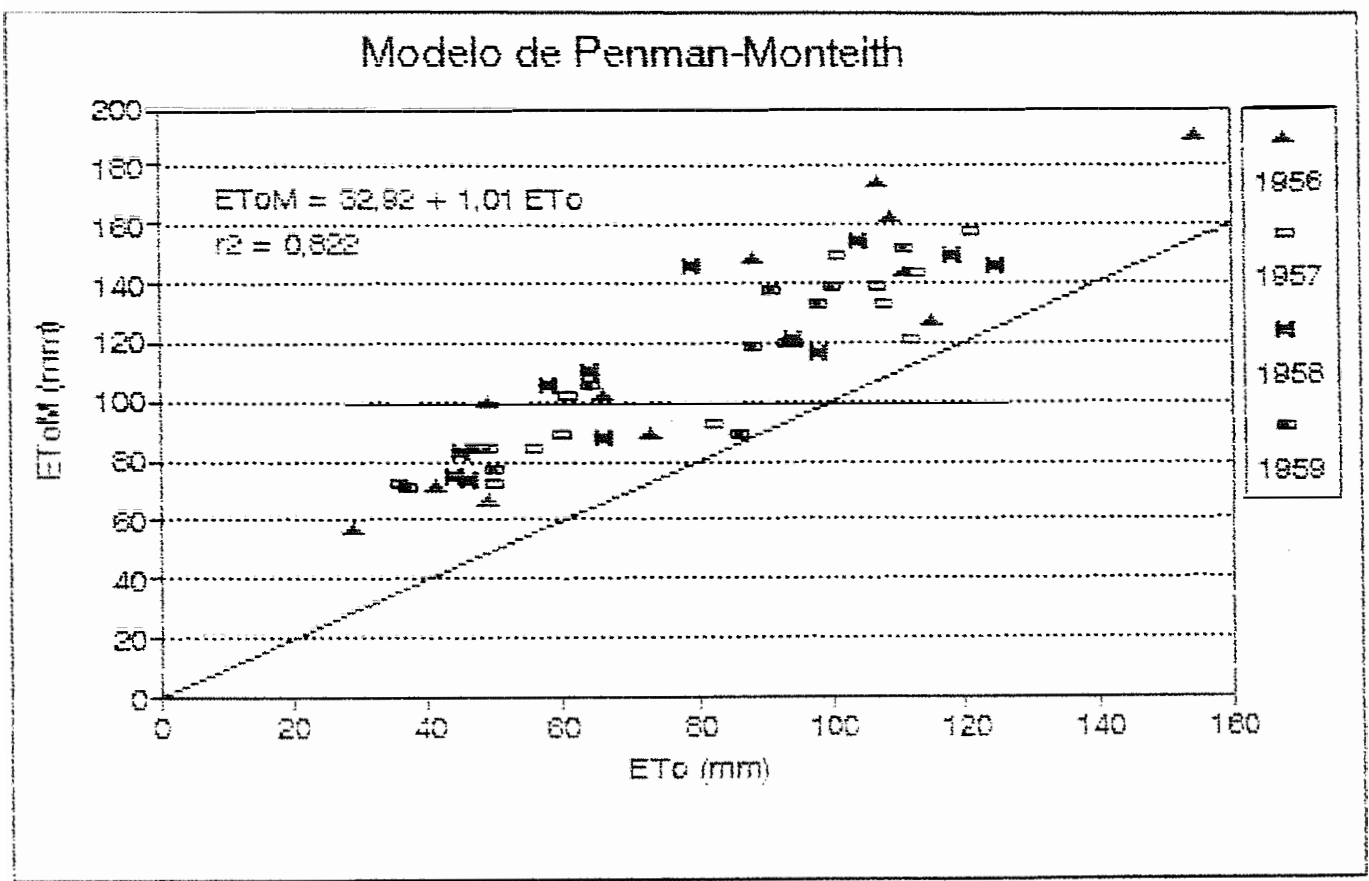

Figura 19: Evapotranspiração de referencia mensal estimada pelo modelo de Penman-Monteith (ETOM ${ }_{\text {ocoo }}$ ' versus a medida em evapotranspirómetros de drenagem (ETO) em relação à reta $1: 1$. Campinas-SP. Periodo de 1956 a 1959 .

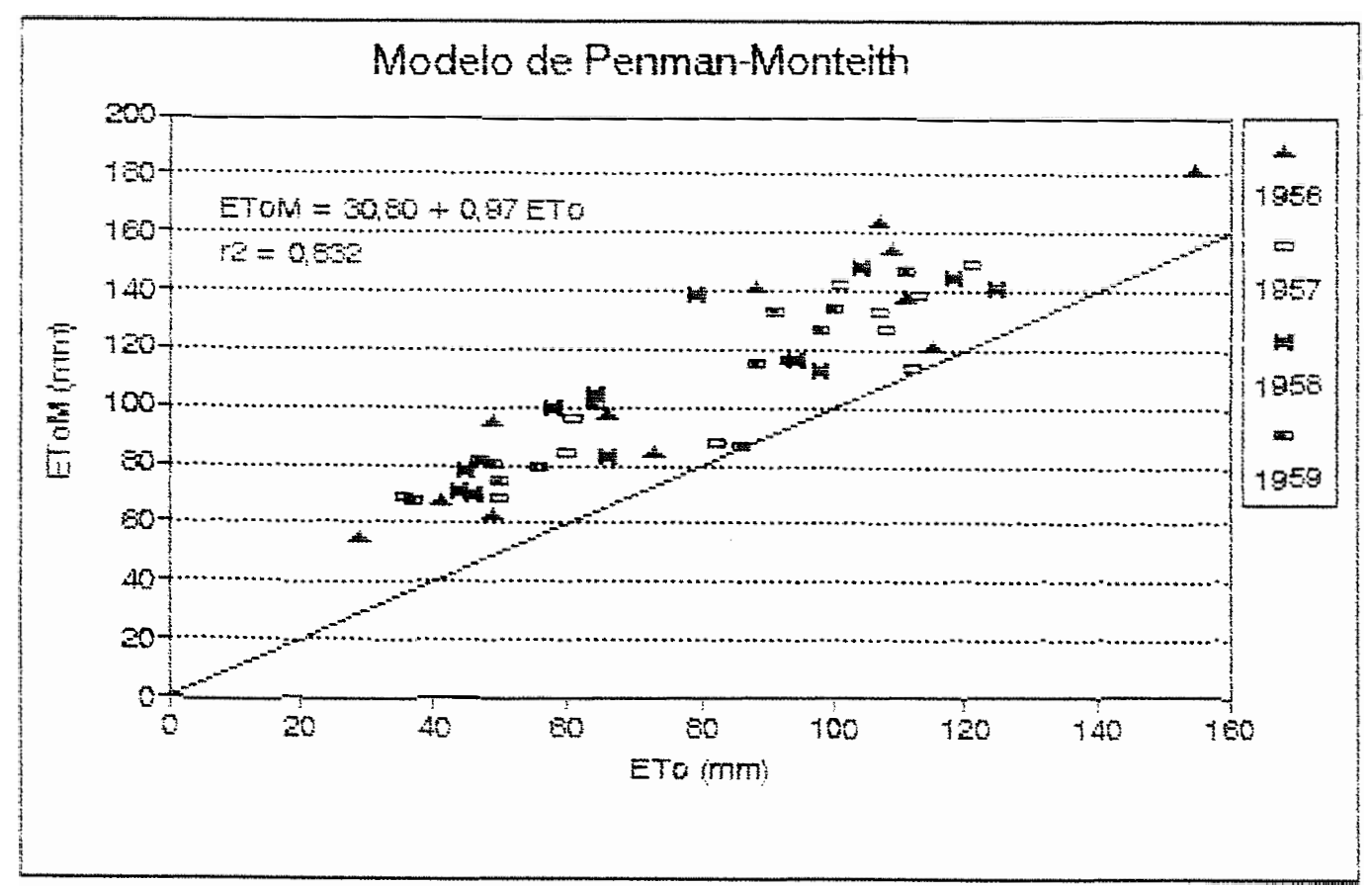

Figura 20: Evapotranspiração de referencia mensal estimada pelo modelo de Penman-Monteith (ETOM ${ }_{\text {oczo }}$ ' versus a medida em evapotranspirómetros de drenagem (ETO) em relação à reta 1:1. Campinas-SP. Periodo de 1956 a 1959 . 
68.

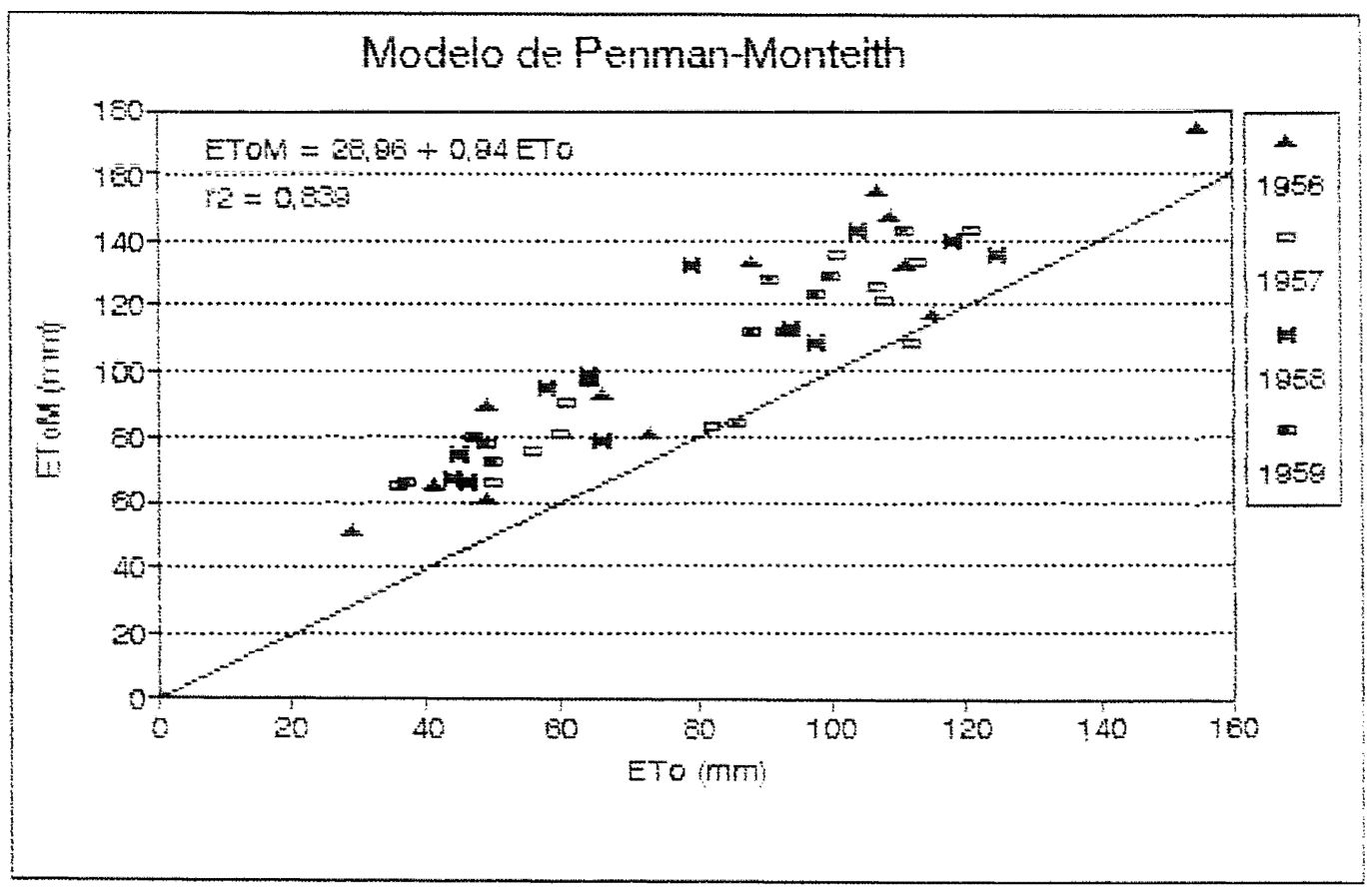

Figura 21: Evapotranspiração de referencia mensal estimada pelo modelo de Penman-Monteith (ETOM ${ }_{0640}$ ' versus a medida em evapotranspirómetros de drenagem (ETO) em relação a reta 1:1. Campinas-SP. Periodo de 1956 a 1959 .

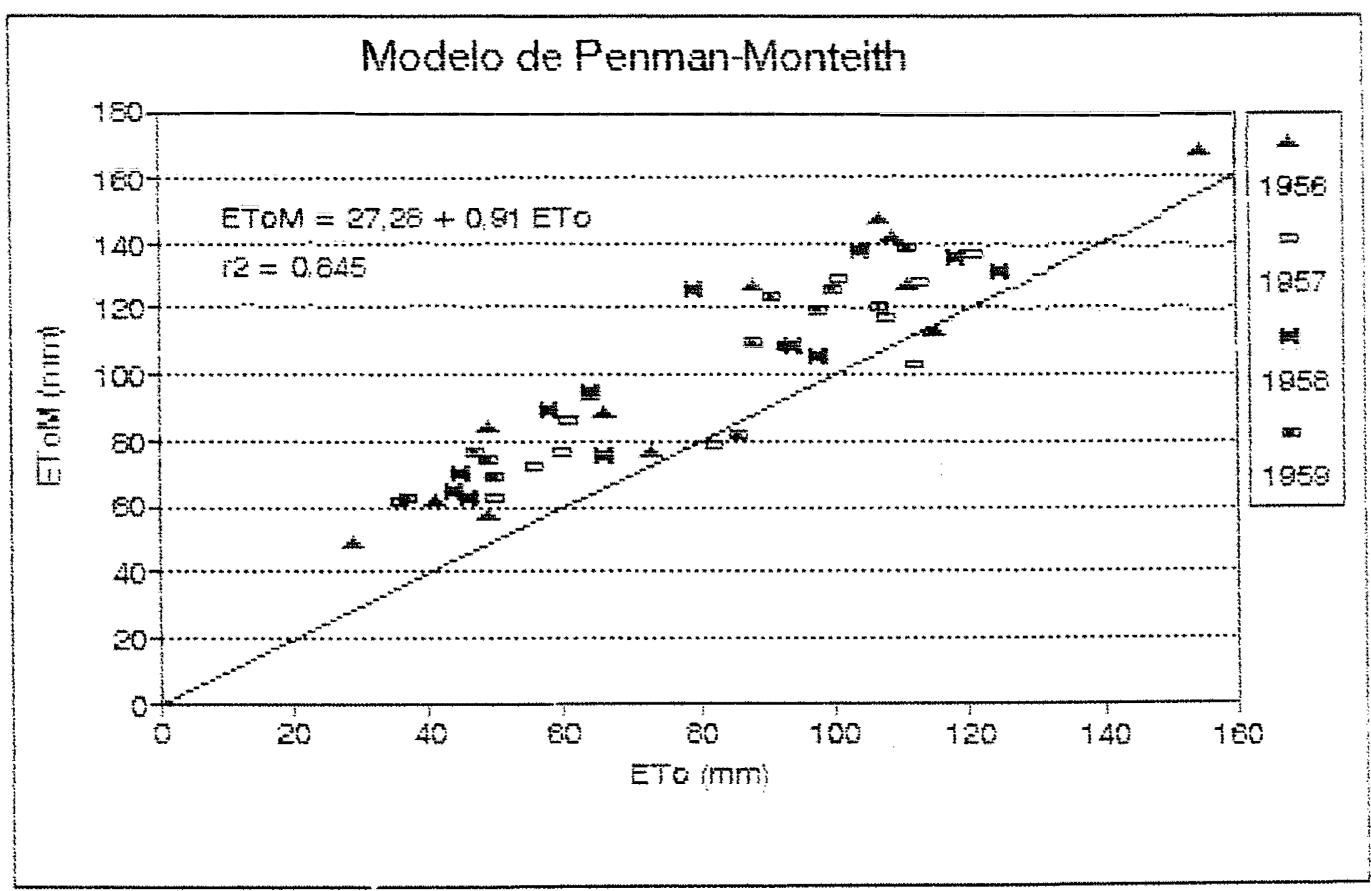

Figura 2e: Evapotranspiração de referencia mensal estimada pelo modelo de Penman-Monteith (ETOM ${ }_{0060}{ }^{2}$ versus a medida em evapotranspirómetros de drenagem (ETO) em relação à reta $1: 1$. Campinas-SP. Periodo de 1956 a 195. 
69.

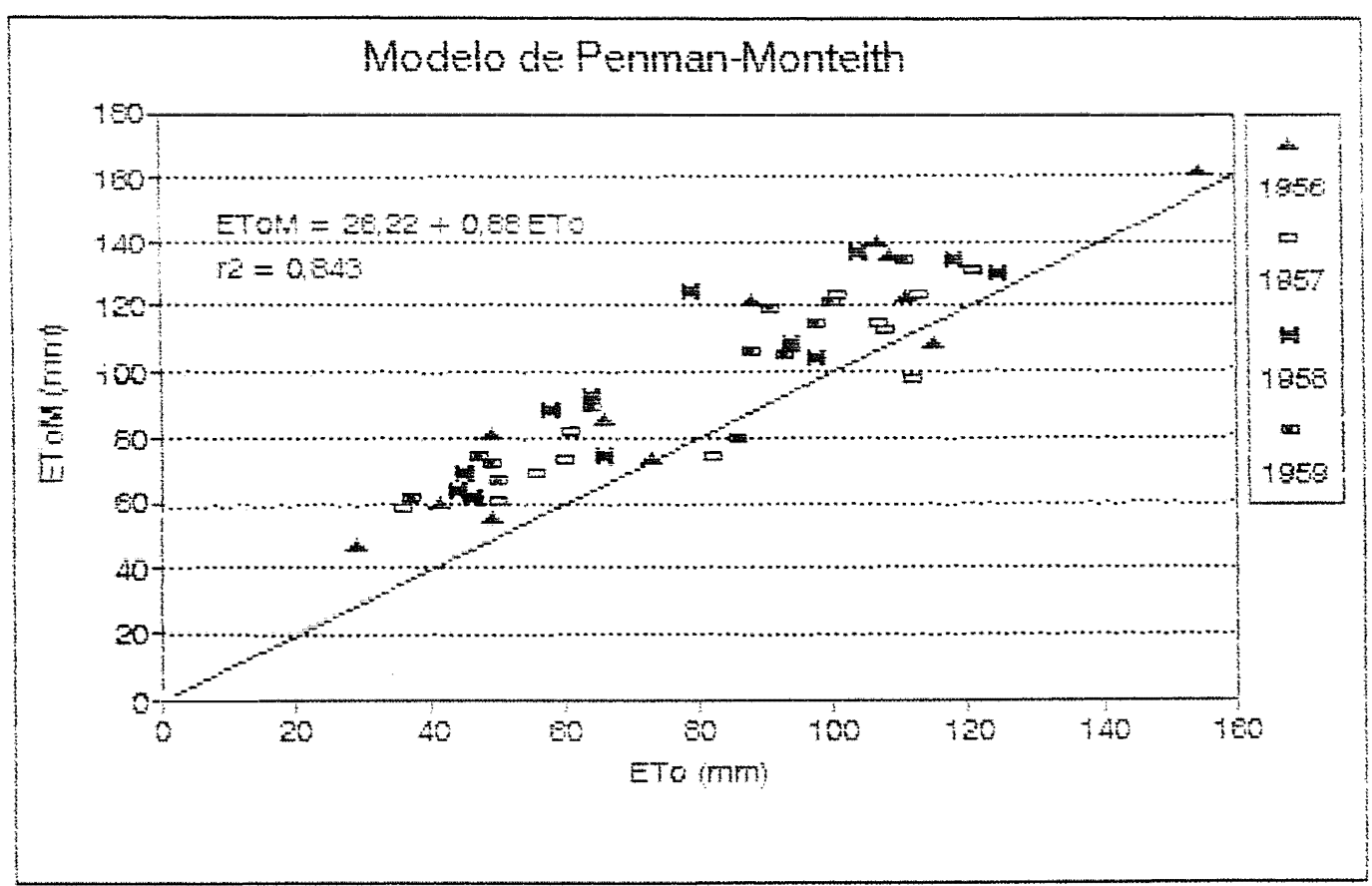

Figura 23: Evapotranspiração de referencia mensal estimada pelo modelo de Penman-Monteith (ETOM ${ }_{0 \sigma 80}$ ' versus a medida em evapotranspirómetros de drenagem (ETO) em relação à reta 1:1. Campinas-SP. Período de 1956 a 1959.

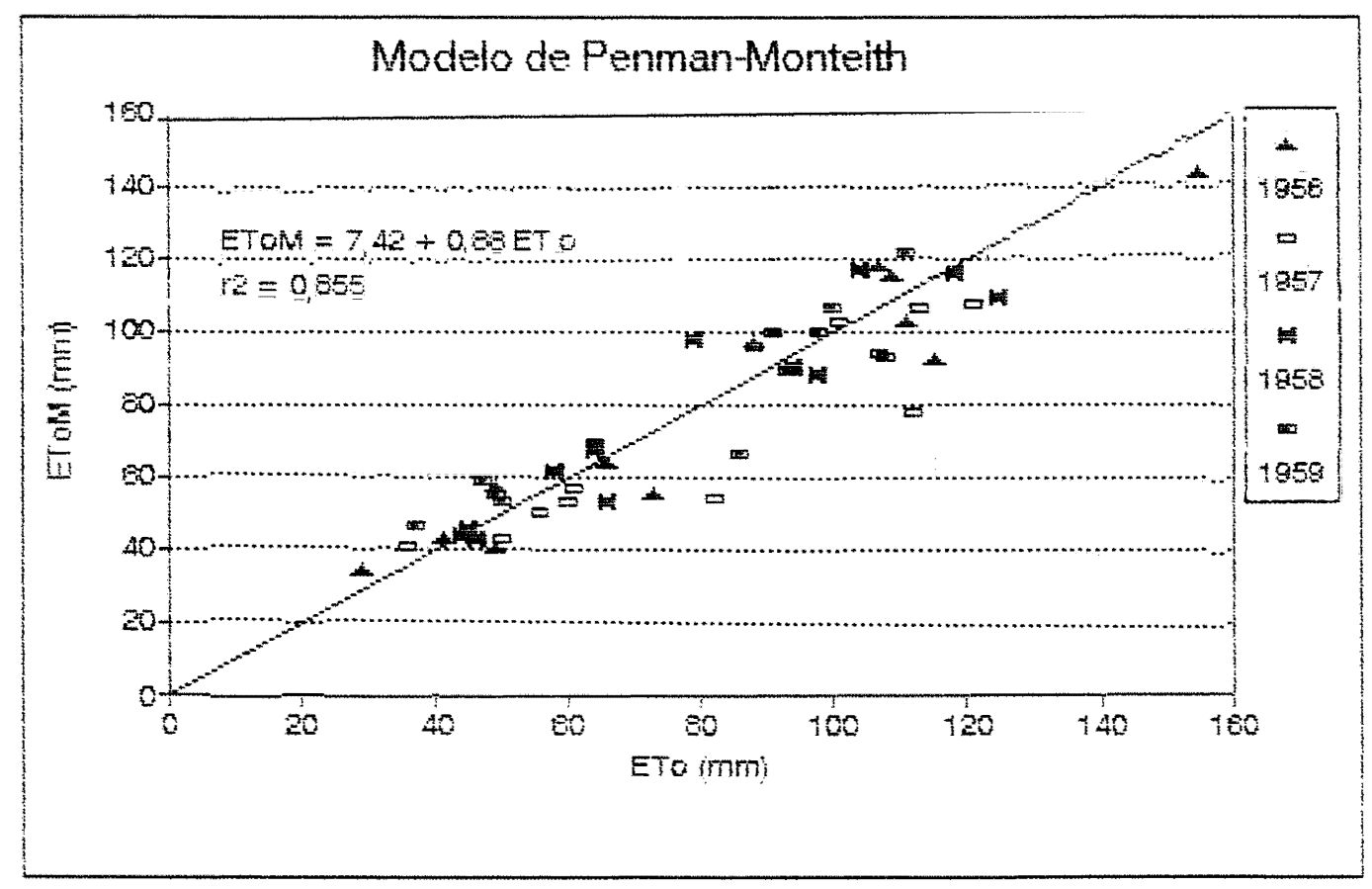

Figura 24: Evapotranspiração de referencia mensal estimada pelo modelo de Penman-Monteith (EToM oovr ${ }^{\text {' versus }}$ a medida em evapotranspirómetros de drenagem (ETO) em relação à reta $1: 1$. Campinas-SP. Período de 1956 a 1959. 
70.

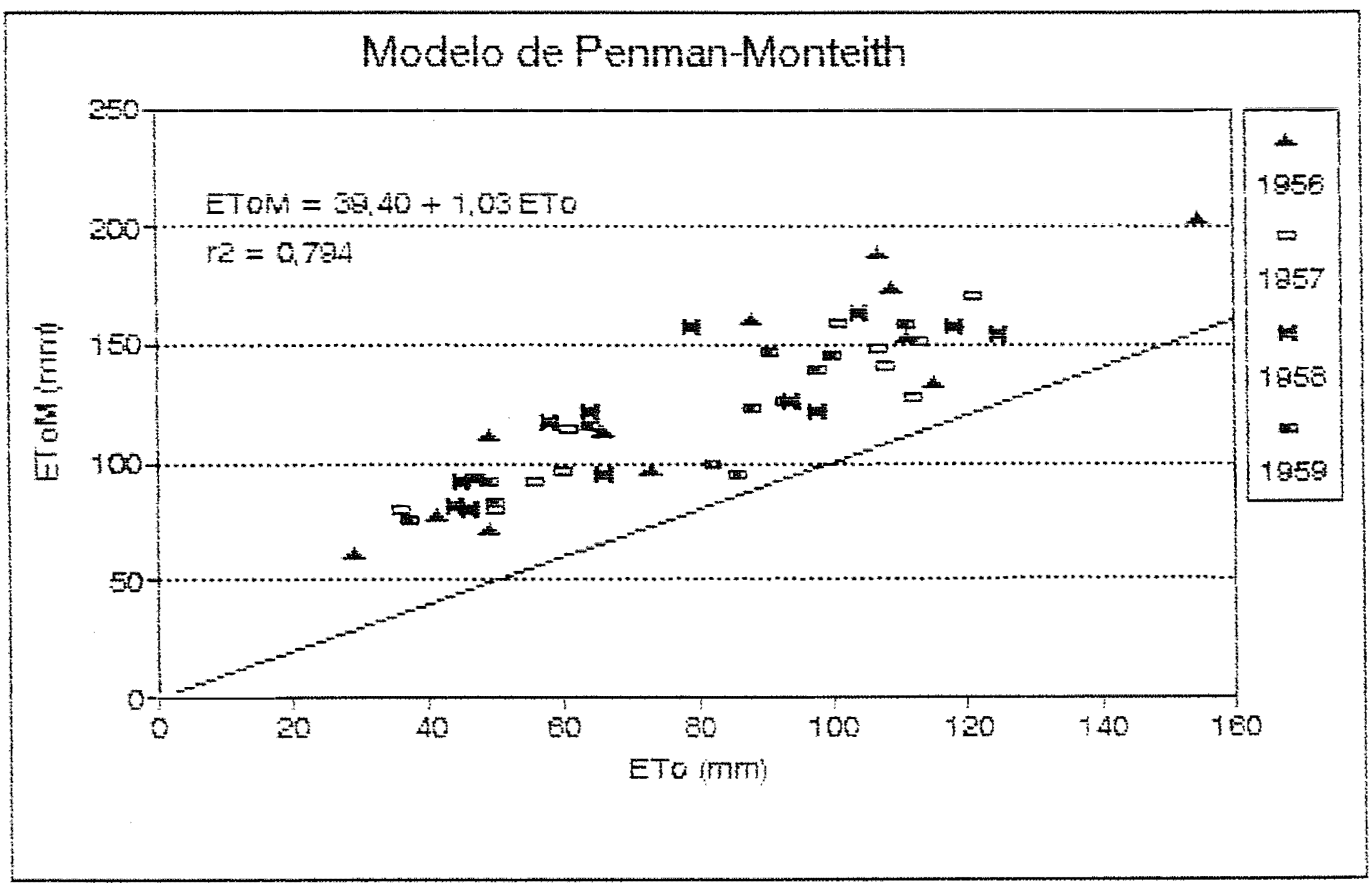

Figura 25: Evapotranspiraçăo de referencia mensal estimada pelo modelo de Penman-Monteith (ETOM ${ }_{1200}$ ) versus a medida em evapotranspirómetros de drenagem (ETO) em relação à reta 1:1. Campinas-SF. Periodo de 1956 a 1959 .

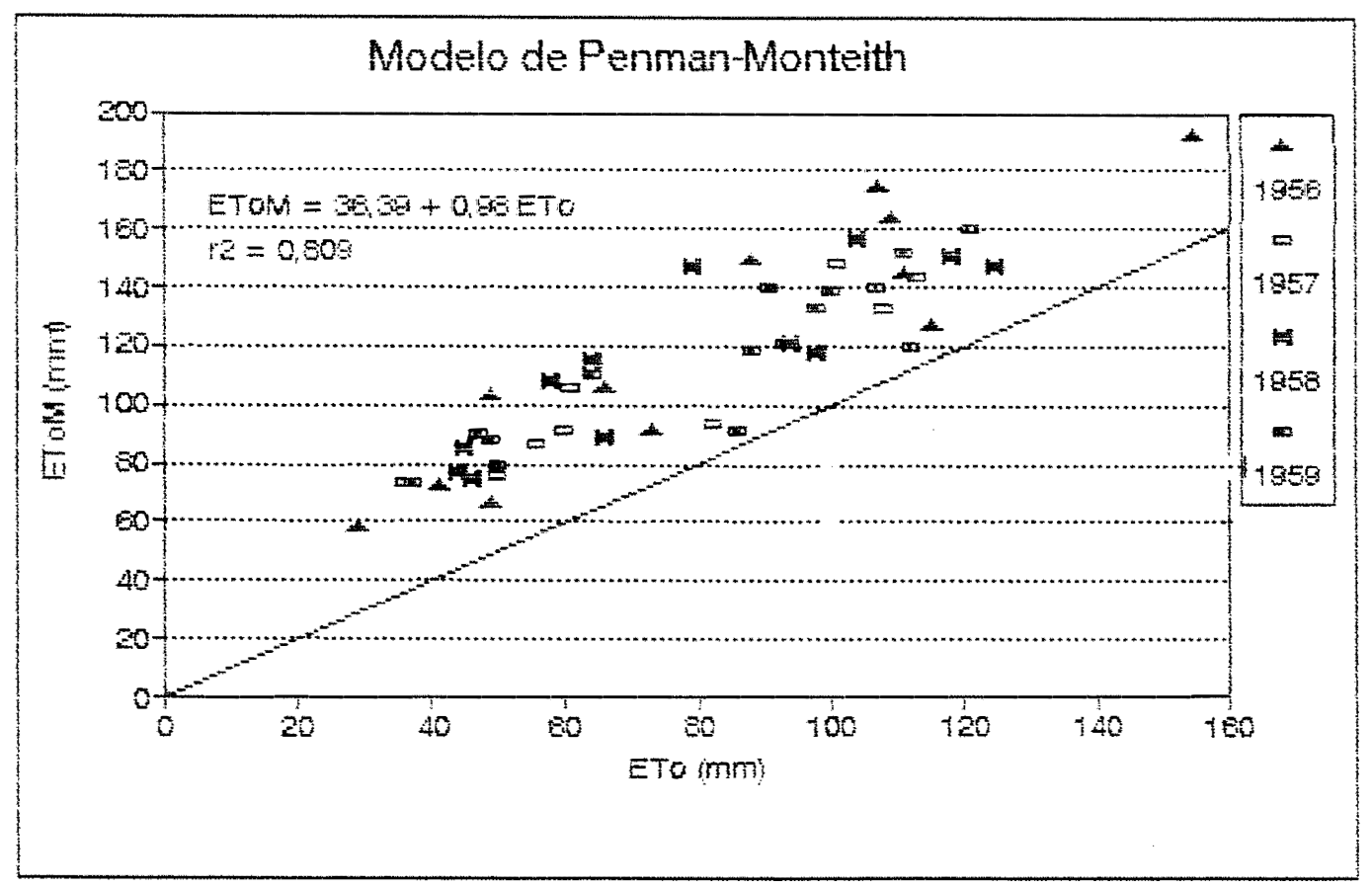

Figura 26: Evapotranspiração de referencia mensal estimada pelo modelo de Penman-Monteith (EToM $\left.{ }_{1220}\right)^{2}$ versus a medida em evapotranspirometros de drenagem (ETO) em relação à reta 1:1. Campinas-SP. Periodo de 1956 a 1959. 


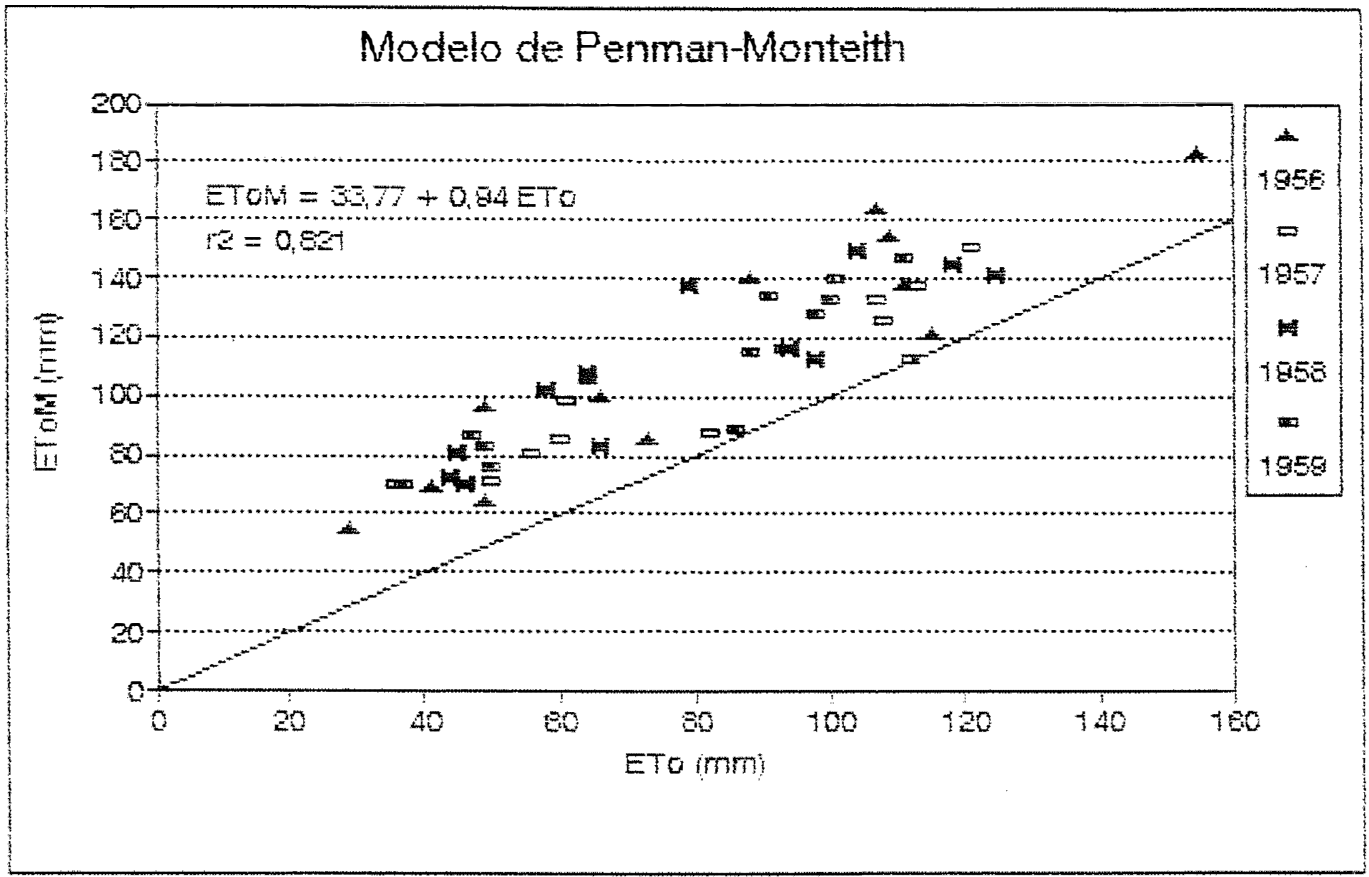

Figura 27: Evapotranspiração de referencia mensal estimada pelo modelo de Penman-Monteith (ETOM ${ }_{1240}$ ' versus a medida em evapotranspirometros de drenagem (ETO) em relação à reta $1: 1$. Campinas-SP. Per 1odo de 1956 a 1959 .

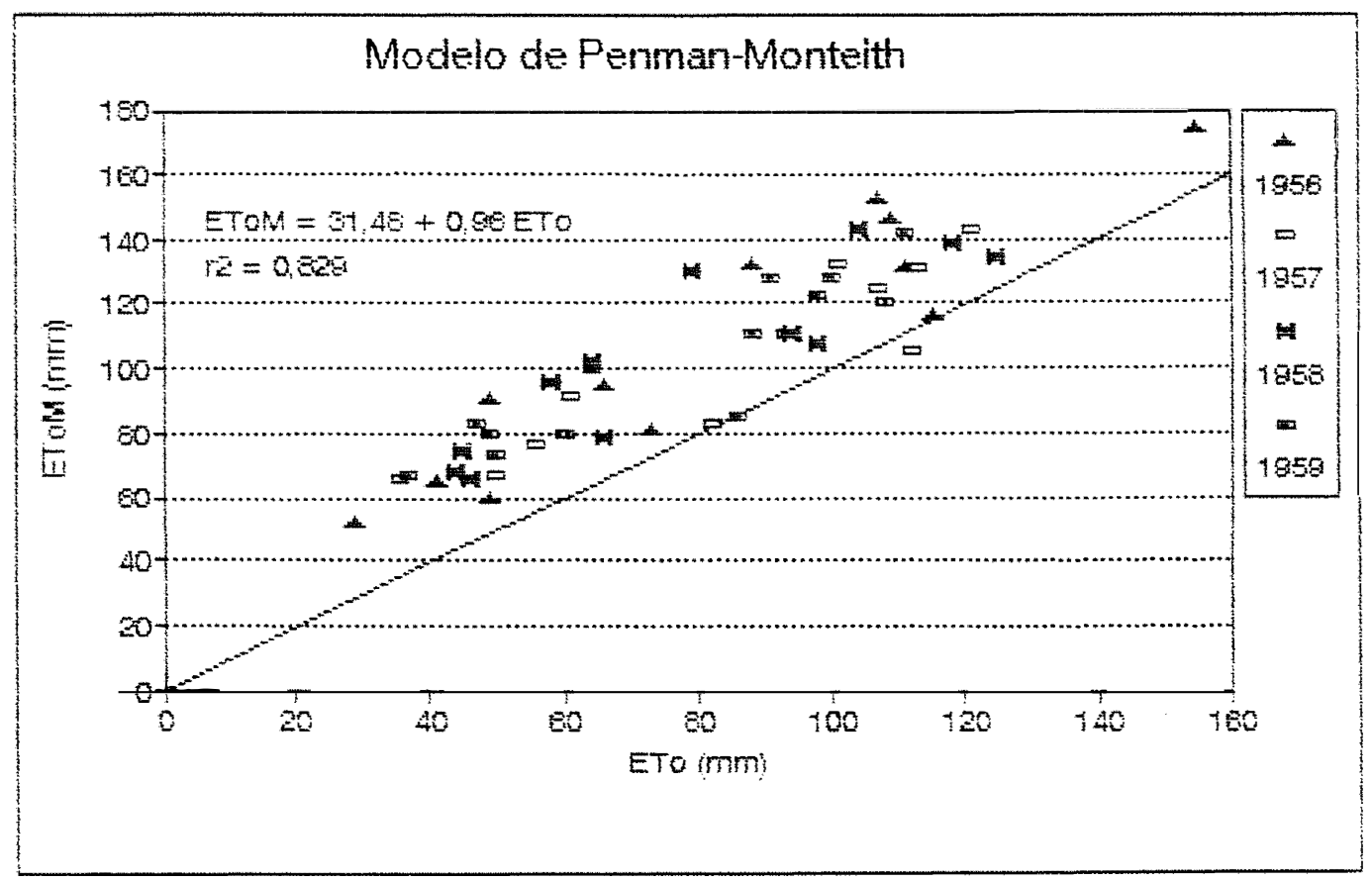

Figura 28: Evapotranspiração de referéncia mensal estimada pelo modelo de Penman-Monteith (EToM ${ }_{1200}{ }^{3}$ versus a medida em evapotranspirometros de drenagem (ETO) em relação à reta 1:1. Campinas-SP. Periodo de 1956 a 1959 . 
72.

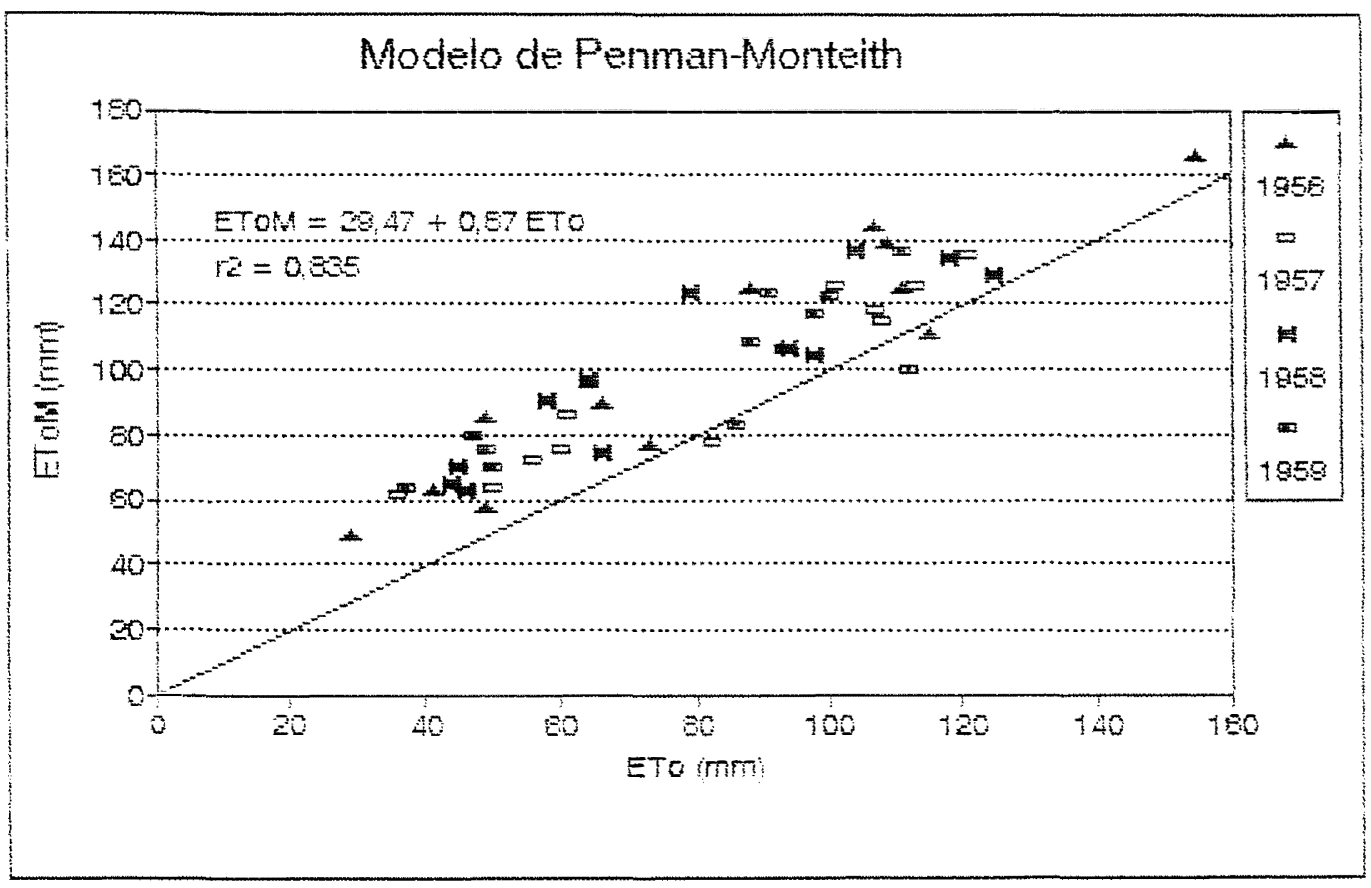

Figura 29: Evapotranspiração de referencia mensal estimada pelo modelo de Penman-Monteith (ETOM ${ }_{1280}$ ' versus a medida em evapotranspirómetros de drenagem (ETO) em relação à reta 1:1. Campinas-SP. Periodo de 1956 a 1959.

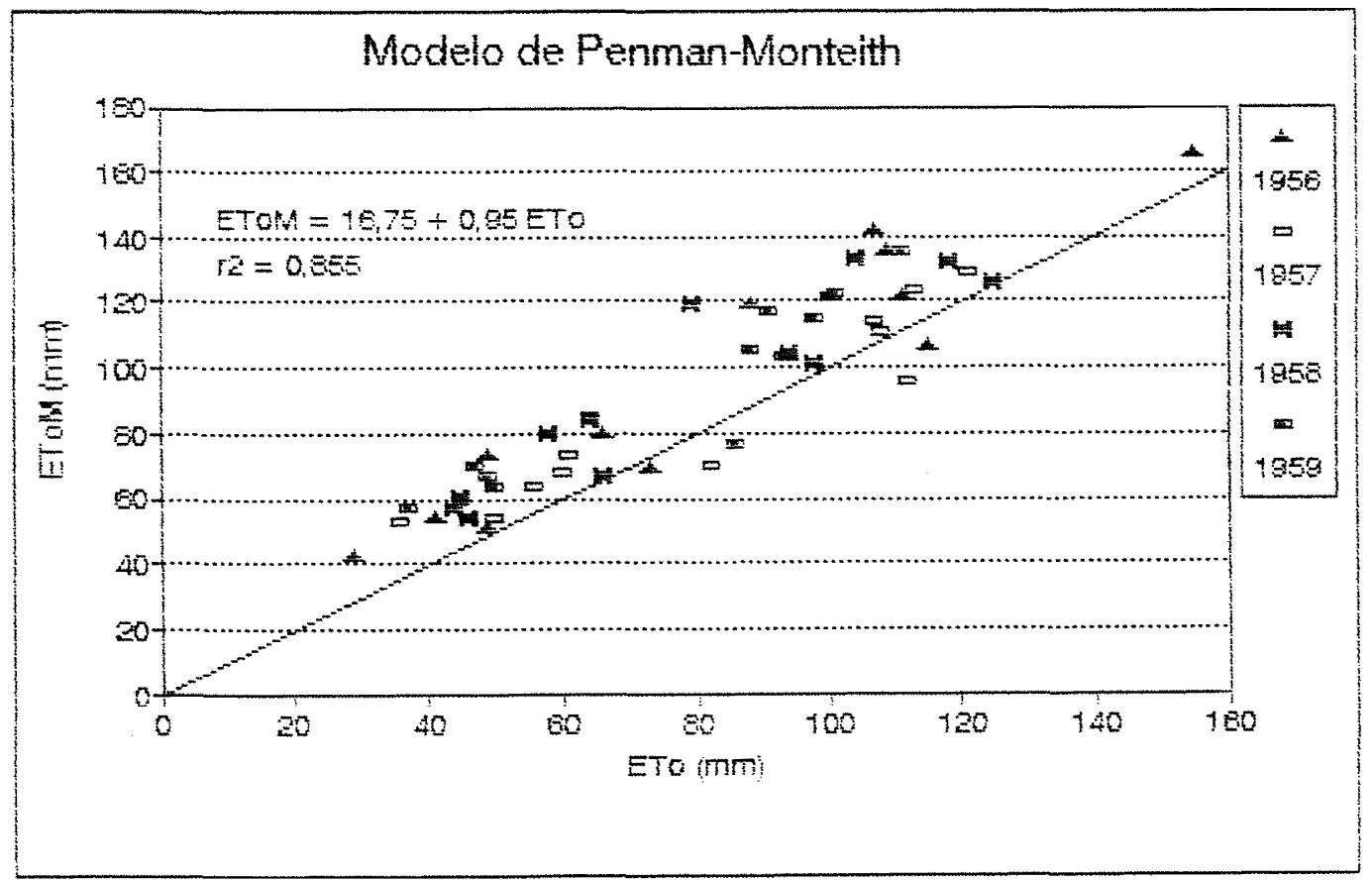

Figura 30: Evapotranspiração de referencia mensal estimada pelo modelo de Penman-Monteith (EToM ${ }_{12 V R}$ ) versus a medida em evapotranspirómetros de drenagem (ETO) em relação à reta 1:1. Campinas-SP. Periodo de 1956 a 1959 . 
As Tabela 17 e 26 permitem observar que todas as combinaçơes, decadiarias e mensais, incorporando a altura da vegetaçăo igual a $0.06 \mathrm{~m}$, correlacionaram a evapotranspiração de referéncia medida de forma mais estreita do que quando se utilizou $h_{c}=0.12 \mathrm{~m}$, como proposto pela FAO.

As Figuras 7 a 11,13 a 17,19 a 23 e 25 a 29 mostram claramente que a altura da vegetação igual a 0, O6 m determina uma menor dispersão das variáveis envolvidas em relação a reta $1: 1$, indicando que ela gera estimativas mais coerentes com os valores medidos, ratificando, assim, o que era sinalizado pelos indicadores estatisticos constantes das Tabelas 17 e 26 . A explicação a esta ocorréncia está no fato do evapotranspirómetros instalados em Campinas-SP terem tido seus gramados aparados com maior frequiencia, resultando em uma vegetação de porte mais baixo e uniforme. Assim sendo, esta evidência experimental ratifica a importancia de se padronizar e manter constante a altura da vegetação nos lisimetros de referéncia, para sua utilização futura na equação de Penman-Monteith.

Outro ponto que deve ser comentado é que todas as combinaçơes incorporando $h_{c}=0.06 \mathrm{~m}$ geram estimativas da evapotranspiração de referéncia mais baixas do que aquelas incorporando $h_{c}=0.12 \mathrm{~m}$. A explicação a esta evidéncia experimental é dada pelo fato da vegetação mais elevada apresentar resistências aerodinâmicas menores do que aquelas de menor porte $e$, por consequéncia, taxas de 
74.

evapotranspiração mais elevadas. Do ponto de vista aerodinâmico, plantas de porte mais alto apresentam comprimentos de rugosidade para transferencia de momento e calor $\mathrm{Cz}_{\text {om }}$ e $Z_{\text {oh }}$ ' maiores, implicando em uma superficie de contato mais extensa, o que facilita a sua difusão turbulenta para a atmosfera.

Pelos numeros apresentados nas Tabelas 17 e 26 pode ser detectado o bom ajustamento entre valores medidos e estimados na escala mensal, muito superior ao verificado na escala decadiária. Em termos médios, o coeficiente de correlação e o erro padrão da estimativa mensal foram da ordem de 0,833 , significativo ao nivel de $1 \%$ de probabilidade, e de $0,42 \mathrm{~mm} \mathrm{dia}^{-1}$, contra os $0,66 \mathrm{z}$ e 0,67 $\mathrm{mm}$ dia ${ }^{-1}$ verificados na escala decadiăria. Estes números são indicativos da necessidade de se tomar cuidados adicionais quando se utiliza do escalas de tempo curtas, especialmente quando se trabalhar com lisimetros de drenagem.

As combinaçióes ETOM ${ }_{0000}$ e ETOM ${ }_{1200}$ que representam as condições de evaporação de uma superficie de água livre, for am aquelas que apresentaram as estimativas de ETo menos correlacionadas com os valores medidos, confirmando os trabalhos de JACKSON et al. (1981), JACKSON (1983) e MONTEITH (1985), donde se conclui que mesmo sob condições ótimas de umidade as plantas ainda apresentam uma resisténcia do dossel mensurável, contrapondo-se, portanto, às conclusões de van BAVEL (1967), van BAVEL \& 
75.

EHRLER (1968), SLABBERS (1977) e JOHNS et al. (1983), que sustentam não haver controle do consumo de água pelas plantas, via estómatos, enquanto o solo estiver bem suprido de água.

Embora HATFIELD (1988) tenha sugerido a adoção de uma resistencia do dossel de $20 \mathrm{~s} \mathrm{~m}^{-1}$ como representativa da evapotranspiração potencial, as combinaçỡes pertinentes (ETOM $_{00020}$ e ETOM ${ }_{1220}{ }^{2}$, has duas escalas de tempo consideradas, foram as que apresentaram a segunda pior correlação entre valores estimados e medidos. Esta evidencia experimental mostra que $20 \mathrm{~s} \mathrm{~m}^{-1}$ e um valor muito baixo para a resistencia do dossel nas condições potenciais, o que está de acordo com MONTEITH (1985), que sugere um valor minimo de $r_{c}=50 \mathrm{~s} \mathrm{~m}^{-1}$ para esta situação.

As Figuras $7,8,13,14,19,20,25$ e 26 mostram que as combinações que incorporam em sua estrutura valores de resistência do dossel entre 0 e $20 \mathrm{~s} \mathrm{~m}^{-1}$ superestimaram a evapotranspiração de referência, apesar da alta correlação verificada, sinalizando que resistencias do dossel tão baixas estimam valores iguais ou próximos à evaporação de uma superficie de água livre.

Observando-se atentamente as Tabelas 17 e 26. nota-se a evidéncia de que foi no intervalo de 40 a 80 $s \mathrm{~m}^{-1}$ onde foram obtidos os melhores indicadores estatisticos relativos à correlação entre valores medidos e estimados. Os acréscimos verificados nestes indicadores são marginais em relação aos acréscimos muito maiores na re- 
sisténcia do dossel, principalmente acima de $60 \mathrm{~s} \mathrm{~m}^{-1}$, sinalizando que a resistencia do dossel, que representa a condição de evapotranspiração potencial, situa-se na faixa de $60-80=\mathrm{m}^{-1}$, o que vem referendar os numeros de BRUIN \& HOLTSLAG (1982), ALLEN (1986), ALLEN et al. (1989) e OKE (1992). Deve ser salientado, no entanto, que os melhores indicadores estatisticos for am obtidos com a combinação ETOM $_{0000}$, I igeiramente superior à ETOM $0060^{\circ}$

A combinação EToM ${ }_{1209}$, que representa a padronização proposta pela FAO (SMITH, 1991), forneceu valores estimativos da evapotranspiração de referéncia altamente correlacionados com os valores medidos, principalmente na escala mensal, onde foram obtidos coeficiente de correlação igual a 0,91 , signifivativo ao nível de $1 \%$ de probabilidade, e erro padrão da estimativa da ordem de $0,40 \mathrm{~mm}$ dia ${ }^{-1}$, valores estes, muito proximos aos citados por ALLEN (1986) e ALLEN et al. (1989). Na escala decadiaria estes números são, respectivamente, 0,81 e $0,64 \mathrm{~mm}$ dia ${ }^{-1}$. Isto posto, pode se afirmar que a proposicão da FAO encontra justificativa técnica nos dados experimentais aqui reproduzidos.

As Figuras $10,11,16,17,22,23,28$ e 29 mostram que ocorre uma melhoria crescente no nivel de concordância dos valores estimados e medidos, à medida que se aumenta o valor da resisténcia do dossel, independentemente da altura da vegetação. Apesar de apresentar indicadores estatisticos bastante elevados, significando al ta cor- 
relação entre valores estimados e medidos, pode se observar que todas as combinações pertinentes às figuras anteriores superestimaram a evapotranspiração de referéncia. o que pode ser explicado pela utilização no modelo de temperaturas anormalmente elevadas, como já explicado anteriormente.

As combinaçơes anteriores utilizam, em sua estrutura, uma resisténcia do dossel constante no tempo, desconsiderando os efeitos da radiação solar na abertura e fechamento dos estómatos e, por consequéncia, na resistencia do dossel. Assim, quando se relaciona a resistência do dossel à disponibilidade de energia, as estimativas obtidas pelas combinaçơes ETo ${ }_{\text {oovr }}$ e ETo 12VR $_{\text {apresentam corre- }}$ lação mais estreita com os valores medidos do que qualquer outra combinação constante das Tabelas 17 e 26. Um fato que deve ser destacado é que, quando se considera a resisténcia do dossel variável com o nivel de energia disponivel, a influencia da altura da vegetação passa a ser desprezivel, como pode ser observado pelos coeficientes de determinação e erros padrões da estimativa das combinaçơes ETOM $_{\text {oovr }}$ e ETOM ${ }_{12 V R}$, considerando-se as duas escalas escalas de tempo. No entanto, a prova mais cabal das vantagens de se parametrizar a resistencia do dossel em função da radiação solar liquida pode ser vista nas figuras 12, 18 , 24 e 30, nas quais nota-se que existe uma concordancia muito grande entre os valores estimados e medidos, caracterizada por um alinhamento bastante próximo da reta 1:1, 
78.

superior a todas as combinaçơes anteriormente avaliadas. Desse modo, dentre todas as combinaçơes analisadas, aquelas que incorporam em sua estrutura resistencias do dossel variáveis são as que fornecem estimativas com correlação mais estreita e de maior concordância com os valores medidos. Embora de forma bastante ligeira, a combinação EToM oovr prové melhor ajustamento das informações estimadas e medidas da evapotranspiração de referencia do que a combinação EToM $_{12 \mathrm{VR}}$.

4. 3. Relativos à resistencia do dossel

Quando se conhece a evapotranspiração e as variáveis ulimáticas envol vidas no processo, a resisténcia do dossel (r) pode ser calculada de forma residual pela aplicação do modelo de Penman-Monteith, o que foi feito nesta pesquisa com base nas informaçơes de evapotranspiração de referéncia medida em Campinas-SP, no periodo de 1956 a 1959 (CAMARGO, 1966). Foi verificado nos cálculos que as diferenças resultantes da aplicação de informações decadiárias ou mensais são irrelevantes, razão pela qual os resultados e comentários a seguir se aplicam indistintamente às duas escalas de tempo.

Tomando-se a resisténcia do dossel como incognita do modelo, observou-se que, para a altura da 
79.

vegetação igual a $0,06 \mathrm{~m}$, seu valor médio no periodo foi da ordem de $300 \mathrm{~s} \mathrm{~m}^{-1}$ para os meses de abril a setembro (outono-inverno); de $202 \mathrm{~s} \mathrm{~m}^{-1}$ de outubro a março (primavera-verão), passando por um valor médio anual de $250 \mathrm{~s} \mathrm{~m}^{-1}$, sendo que, no caso de $h_{c}=0,12 \mathrm{~m}$, estes valores for am, respectivamente, de 365,241 e $303 \mathrm{~s} \mathrm{~m}^{-1}$. Um aspecto que deve ser salientado é a extrema variabilidade temporal da resisténcia do dossel, caracterizada por coeficientes de variação da magnitude de $40 \%$

As Figuras 31 e 32 mostram a variação temporal da resistencia do dossel com a disponibilidade de energia solar, observando-se claramente que esta resistencia apresenta-se mais elevada nos meses de menor insol ação (abril a setembro) e mais baixas nos meses onde esta disponibilidade energética é maior Coutubro a marços.

Os números e figuras anteriores mosiram a evidente influencia da disponibilidade de energia solar sobre o comportamento numérico da resisténcia do dossel, que cresce à medida que a disponibilidade de energia diminui, ratificando, assim, as conclusores de BAYLEY \& DAVIES (1981) MONTEITH (1981; 1985) e HATFIELD (1985). Estas evidencias experimentais sinalizam que a adoção de uma resistencia do dossel única e constante ao longo do tempo, não encontra sustentação nos resultados obtidos nesta pesquisa. 
80.

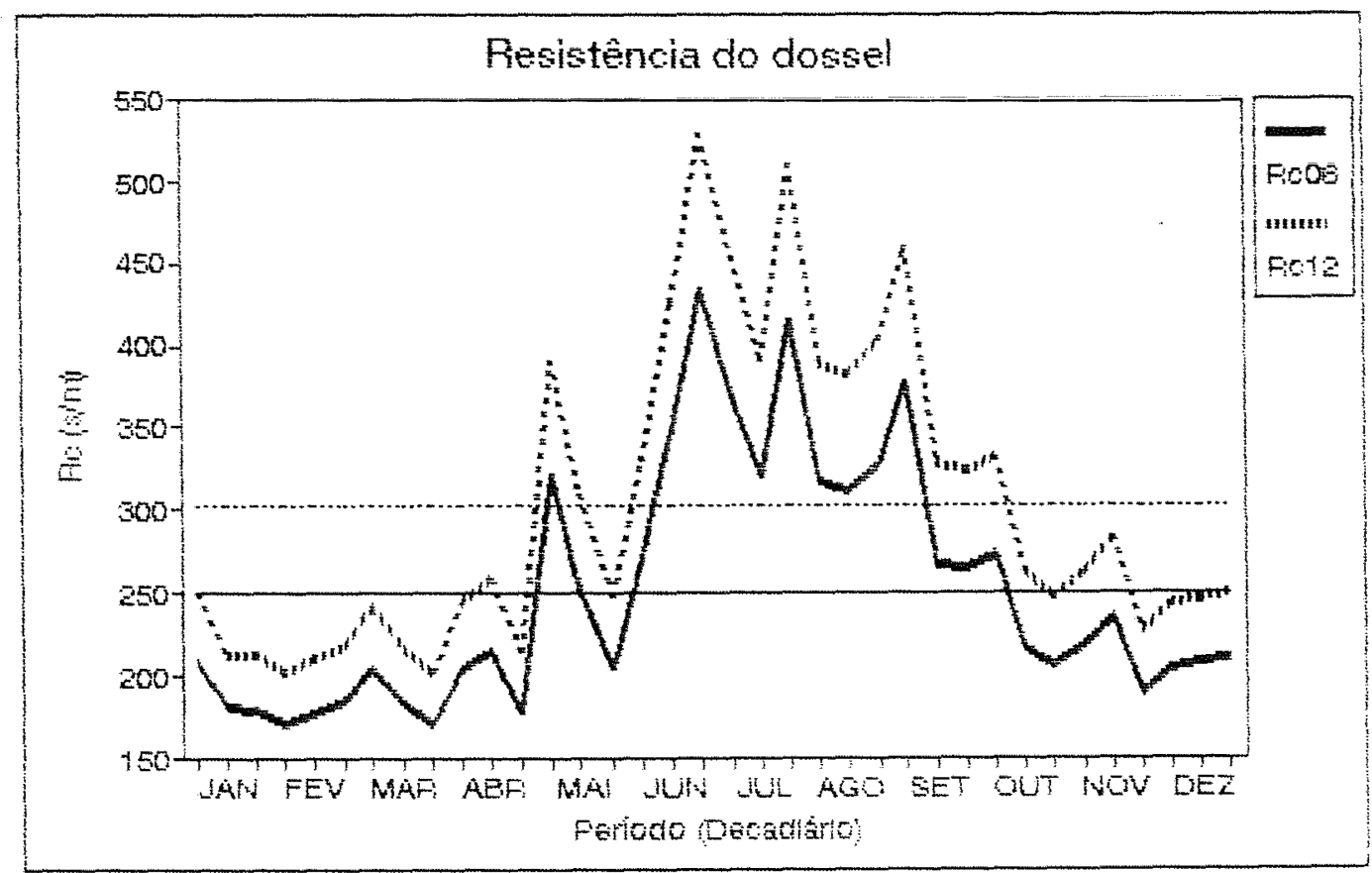

Figura 31 : Variação temporal decadiária média da resistência do dossel, considerando oz alturas de vegetação, obtida a partir da aplicação do modelo de Penman-Monteith aos valores medidos da evapotranspiração de referencia coletados em Campinas-SP, no periodo de 1956 a 1959.

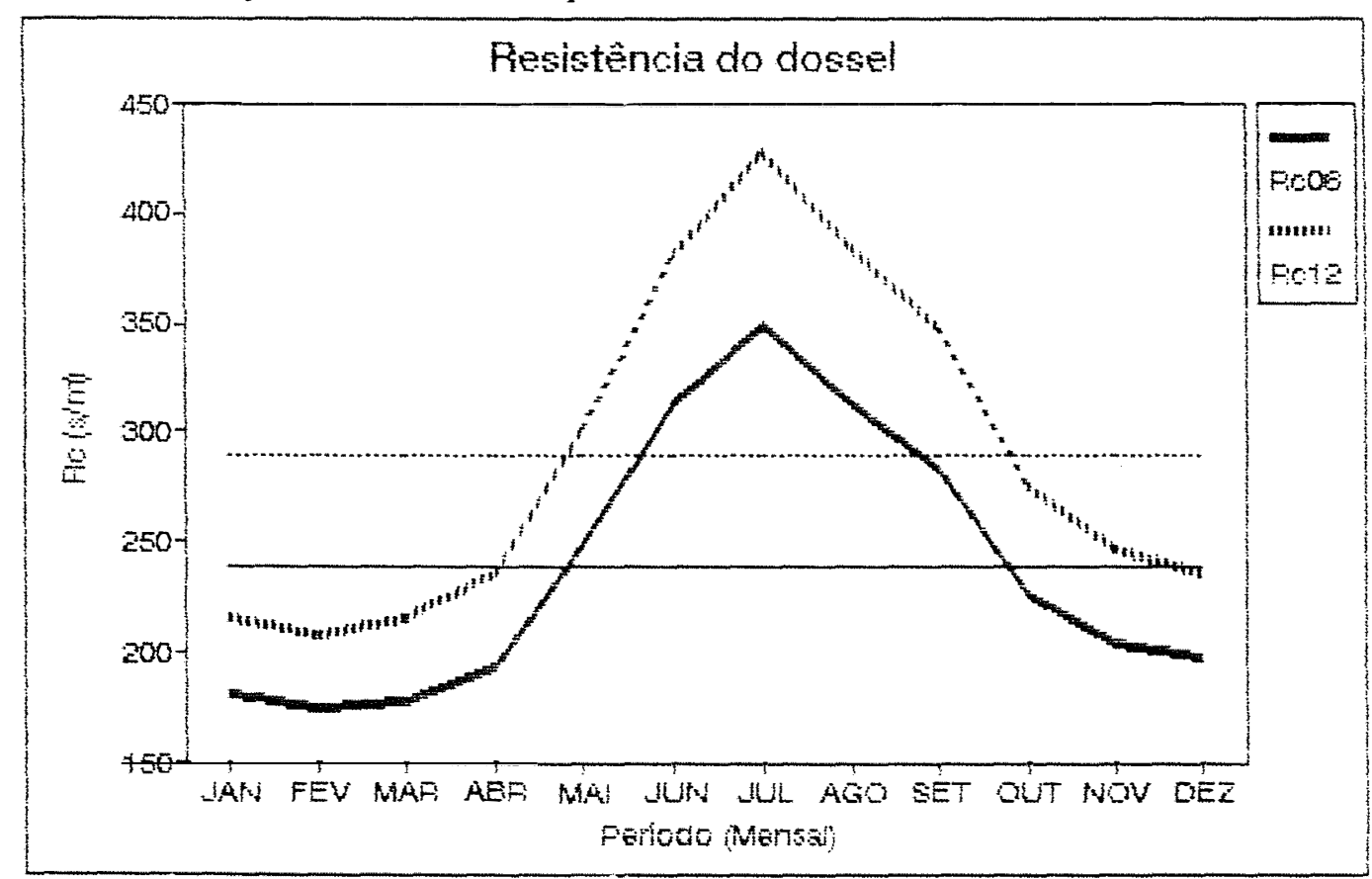

Figura 32: Variação temporal mensal media da resistencia do dossel, considerando oe alturas de vegetação, obtida a partir da aplicação do modelo de Penman-Monteith aos valores medidos da evapotranspiração de referéncia coletados em Campinas-SP, no periodo de 1956 a 1959. 
81.

Quando se trabalhou com a equação 23 para determinação da resistência do dossel, foi verificado que, para $h_{c}=0,06 \mathrm{~m}$, ela assumiu valores médios de $259 \mathrm{~s} \mathrm{~m}^{-1}$ nos meses de abril a setembro (outono-inverno); de $174 \mathrm{~s}$ $\mathrm{m}^{-1}$ no periodo de outubro a março (primavera-verão), que resultaram em um valor médio anual de aproximadamente 219 $s \mathrm{~m}^{-1}$. Para a altura da vegetação igual a $0.12 \mathrm{~m}$, estes valores são exatamente a metade dos anteriores, fato decorrente da estrutura linear da equação utilizada na estimativa da resistência do dossel (eq. 23). Nos mesmos períodos, constatou-se que a radiação solar liquida foi da

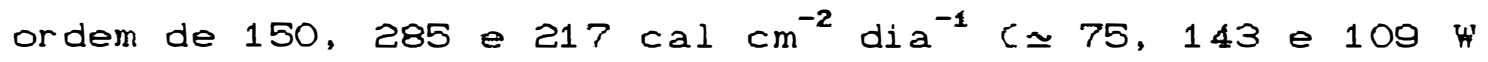
$\mathrm{m}^{-2}$, confirmando numericamente que resistência do dossel aumenta com a diminuição da disponibilidade de radiação solar.

Nas duas situaçỡes anteriormente analisadas, pode ser constatado que a resistencia do dossel assume valores muito mais elevados do que os propostos por MONTEITH (1981, 1985), ALLEN (1986), ALLEN et. al. (1989) e SMI TH (1991), embora números desta ordem de grandeza e variabilidade tenham sido encontrados por RUSSEL (1980), HATFIELD (1981) e BRUIN \& HOLTSLAG (1982).

A extrema variabilidade temporal da resistência do dossel tem sido ressaltada por muitos pesquisadores e, dentre eles, LUCHIARI Jr. \& RIHA (1991) constataram que nas condiçơes edafoclimaticas do Planal to Central brasileiro, ela variou de 15 a $50 \mathrm{~s} \mathrm{~m}^{-1}$, entre 8 h $30^{\circ}$ e 
82.

14h30', até valores superiores a $200 \mathrm{~s} \mathrm{~m}^{-1}$ pelas $16 \mathrm{~h} 30^{\circ}$. no dia imediatamente após a irrigação. Assim sendo, parece não haver sustentação cientifica à tese de que a resistência do dossel para períodos longos de 10 a 30 dias possa ser considerada como uma resisténcia fisiológica, controlada pelos estómatos das plantas. Por isso, como querem BEN-ASHER et al. (1989), a resisténcia do dossel deve ser considerada como um coeficiente de proporcionalidade de determinação empirica, sem nenhum significado fisiológico mais claro. 
83.

5. CONCLUSOES

A partir das informaçőes coletadas, processadas e interpretadas nesta pesquisa, foram obtidas as seguintes conclusões:

a) nas 03 localidades estudadas, 0 modelo de Penman-Monteith, desenvolvido segundo a padronização proposta pela FAO Caltura da vegetação de $0.12 \mathrm{~m}$, resistencia do dossel de $69 \mathrm{~s} \mathrm{~m}^{-1}$ e albedo de $23 \%$ estimou a evapotranspiração de referéncia para grama de forma consistente e bem correlacionada com os valores medidos em evapotranspirómetros, tanto na escala de tempo decadiária quanto na mensal, indicando que este modelo pode ser utilizado com sucesso na determinação das necessidades de agua das culturas;

b) as estimativas mensais obtidas com a aplicação do modelo de Penman-Monteith padronizado são muito mais consistentes do que as decadiárias;

c) o modelo de Penman-Monteith é sensivel a variações da altura da vegetação e da resistência do dossel. A melhor combinação destes fatores para as condições 
84.

desta pesquisa foi a seguinte: altura da vegetação de 0,06 $m$ e resistencia do dossel de $80 \mathrm{~s} \mathrm{~m}^{-1}$;

d) a melhor correlação e concordância entre os valores estimados e medidos da evapotranspiração de referencia foi obtida quando se utilizou no modelo de Penman-Monteith uma resistencia do dossel variável, calculada em função da radiação solar liquida e do indice de area foliar da vegetação;

e) a resistencia do dossel que melhor representa as condiçőes de evapotranspiração potencial situa-se na faixa de 60 a $80 \mathrm{~s} \mathrm{~m}^{-1}$;

f) tomando-se a resistencia do dossel como incognita do modelo, verificou-se que para $h_{c}=0,06 \mathrm{~m}$ seu valor variou entre $300 \mathrm{~s} \mathrm{~m}^{-1}$, no periodo de outonoinverno, e $202 \mathrm{~s} \mathrm{~m}^{-1}$, no periodo de primavera-verão; enquanto que, pa: a $h_{c}=0,12 \mathrm{~m}$, estes valores foram, respectivamente, 365 e $241 \mathrm{~s} \mathrm{~m}^{-1}$; e

g) a resistencia do dossel para periodos de tempo longos comporta-se como um coeficiente empirico de proporcionalidade, sem nenhum significado fisiológico mais claro. 
85.

\section{REFERENCI A BIBLIOGRAFICA}

AGUI AR NETTO, A. O.; BASTOS, E. A.; LUNARDI, D. M. C.; MARTINS, D. Comparação entre métodos de estimativa da evapotranspiração de referencia para Botucatu-SP. In: CONGRESSO BRASILEIRO DE ENGENHARIA AGRICOLA, 22., Ilhéus, 1993. Anais. Ilhéus, SBEA, 1993. v. 4, p. 2285-92.

ALLEN, R. G. Daily reference evapotranspiration in ar 1 d and humid environment. In: NATIONAL CONFERENCE ON ADVANCES IN EVAPOTRANSPIRATION, ChICago, 1985. Proceedings. St. Joseph, ASAE, 1985. p. 4-12.

ALLEN, R. G. A Penman for all seasons. Journal Irrig. Drain. Engineering, New York, $112(4): 348-68,1986$.

ALLEN, R. G.; JENSEN, M. E. ; WRIGHT, I. L.; BURMAN, R. D. Operational estimates of reference evapotranspiration. Agronomy J., Madison, 81:550-62, 1989. 
86.

ALLEN, R. G.; PRUEGER, J. R.; HILL, R. W. Evapotranspiration from isolated stands of hydrophytes: cattail and bulrush. Transactions of the ASAE, St. Joseph, 35( 4):1191-8, 1992.

AZEVEDO, P. V.; RAO, T. U. R.; NETO, M. S. A.; SOBRINHO, J. E.; MACIEL, G. F. Resisténcia aerodinâmica e estomática da cultura do algodão herbáceo. Revista Brasileira de Agrometeorologia, Santa Maria, $1(1): 19-24,1993$.

BAILEY, W. G.; DAVIES, J. A. Bulk stomatal resistance control on evaporation. Boundary Layer Meteor.. Dordrecht, 20:401-15,1981.

BARBIERI, V. Medidas e estimativas ue consumo hidrico em cana-de- açúcar. Piracicaba, 1981. 82p. CMestradoEscola Superior de Agricultura "Luiz de Queiroz"/USP).

BEN-ASHER, J.; MEEK, D. W. ; HUTMACHER, R. B.; PHENE, C. J. Computational approach to assess actual transpiration from aerodynamic and canopy resistance. Agronomy $J$, Madison, 81:776-82, 1989.

BLANEY, H. F. \& CRIDDLE, W. D. Determining water requirements in irrigated areas from climatological and 
irrigation data. Washington, USDA, $1950.48 p$.

BRUIN, H. A. R.; \& HOLTSLAG, A. A. M. A simple parameterization of the surface fluxes of sensible and latent heat during daytime with the Penman-Monteith concept. J. Appl. Meteor., Boston, 21:1610-21, 1982.

BRUTSAERT, W. Evaporation into the atmosphere: Theory, History and Applications. Dordrecht, Kluver Academic, 1982. 299p. (Environmental Fluid Mechanics, 12.

BURMAN, R. D. ; NIXON, P. R.; WRIGHT, I. L. ; PRUITT, W. O. Water requirements. In: JENSEN, M. E., ed. Design and operation of farm irrigation system. St. Joseph, ASAE, 1983. Chap. 6, p. $189-232$.

BURMAN, R. D. Evapotranspiration. In: NATIONAL CONFERENCE ON ADVANCES IN EVAPOTRANSPIRATION, Chicago, 1985. Proceedings. St. Joseph, ASAE, 1985. p. $185-92$

CAMARGO, A. P. Contribuição para determinação da evapotranspiração potencial no Estado de São Paulo. Campinas, Instituto Agronómico, 1960. 60p. CBoletim, 1613. 
CUENGA. F. H. Irrigation system design. An engineering approach. Englewood Cliffs, Frentice-Hall Ine, 1080. 522p.

DOORENBOS, J. \& PRUITT, J. O. Guidelines for predicting crop water requirements. Rome, FAO, 1975. 179p. CFAO Irrigation and Drainage Paper, 243.

FERREIRA, W. A. Utilização da evaporação "Piche" na estimativa da evapotranspiração potencial. Botucatu, 1972. 72p. CDoutorado - Faculdade de Ciencias Médicas e Biológicas de Botucatus.

FOLEGATTI, M. V. Avaliação do desempenho de um "scheduler" na deteç̧ão do estresse hidrico em cultura do feijoeiro (Phaseolus vulgaris, L.) irrigada com diferentes lâminas. Piracicaba, $1988.188 p$. CDoutorado - Escola Superior de Agricultura "Luiz de Queiroz",USF?.

GRANT, D. R. Comparison of evaporation from barley with Penman estimates. Agric. Meteorology. Amsterdam, 15: $49-50,1975$. 
89.

HARGREAVES, G. H. Water requirements manual for irrigated crop and rainfed agriculture. Logan, Utah State University, 1977. $41 \mathrm{p}$.

HATFIELD, J. L. Wheat canopy resistance determined by energy balance techniques. Agronomy J., Madison, $77: 279-83,1985$.

HATFIELD, J. L. Research priorities in ET: evolving methods. Transactions of the ASAE, St. Joseph, $31(2): 491-95,1988$.

JACKSON, R. D. ; IDSO, S. B. ; REGINATO, R. J.; WINTER Jr, P. J. Canopy temperature as a crop water stress indicator. Water Res. Research, 17(4):1133-38, 1981.

JACKSON, R. D. Canopy temperature and crop water stress. In: HILlEL, D. Advances in irrigation. New York, Academic Press, 1983. v.1, p. 43-85.

JENSEN, M. E. \& HAISE, H. R. Estimating evapotranspiration from solar radiation. Journal Irrig and Drain Division, New York, 89:15-41, 1963.

JENSEN, M. E., ed. Consumptive use of water and irrigation water requirements. New York, ASCE, 1973. $215 p$. 
90.

JOHNS, D. ; BEARD, I. B.; van BAVEL, C. H. M. Resistances to evapotranspiration from a st. Augustinegrass tur $f$ canopy. Agronomy J., Madison, 75(3):419-22, 1983.

KROON, L. J. M. \& BRUIN, H. A. R. Atmosphere-vegetation interaction in local advection conditions: efect of lower boundary conditions. Agric. Forest Meteor. Amsterdam, 64:1-28, 1993.

LIMA. S. F. F. Comparação de métodos de estimativa de evapotranspiração potencial para o municipio de Ribeirão Preto (SP). Piracicaba, $1991 . \quad 69 p$. CMestrado - Escola Superior de Agricultura "Luiz de Queiroz"/USPS.

LHOMME, J. P. The concept of canopy resistance: historical survey and comparison of different approaches. Agric. Forest Meteor., Amsterdam, 54: $227-40,1991$

LUCHIARI Jr., A. Measurements and predictions of evapotranspiration rates from irrigated wheat in the Cerrado region of Central Brazil. Ithaca, 1988. $171 \mathrm{p}$. (PhD - Cornell University).

LUCHI ARI Jr., A. \& RIHA, S. J. Bulk surface resistance and its effect on evapotranspiration rates in irrigated 
91.

wheat. Agronomy J., Madison, 83:888-95, 1991.

MONTEITH, J. L. Evaporation and environment. Symp. Soc. Exp. Biolo8y. London, 19:205-34, 1955.

MONTEITH, J. L. The development and extension of Penman's evaporation formula. In: HILLEL, D., ed. Applications of soil physics. New York, Academic Press, 1980. Chap. 10 , p. 247-53.

MONTEITH, J. L. Evaporation from land surfaces: progress in analysis and prediction since 1948. In: National Conference on Advances in Evapotranspiration, Chicago, 1985. Proceedings. St. Joseph, ASAE, 1985. p. 4-12.

MONTEITH, J. L. Evaporation and surface temperature. Quart. 3. R. Met. Society, London, 107(451):1-27, 1981.

MONTEITH, J. L. \& UNSWORTH, M. H. Principles of environmental physics. Zed. London, Routledge, 1990. $191 \mathrm{p}$.

NORMAN, J. M. \& CAMPBELL, G. Application of a plant-environment model to problems in irrigation. In: HILLEL, D. Advances in irrigation. New York, Academic Press, 1983. v. 2, p. 155-88. 
92.

OKE, T. R. Boudary Layer Climates. Zed. London, Routledge, 1992. 435p.

OMETTO, J. C. Bioclimatologia Vegetal. São Paulo, CERES, 1981. 425p.

ORTOLANI, A. A.; CAMARGO, A. P.; VILLA NOVA, N. A. Correlação entre valores decendiais da evapotranspiração potencial calculados segundo métodos de Penman e Thornthwaite e dados de evpotranspirómetros na região de Ribeirão Preto. Bragantia, Campinas, 25: 65-8, 1966. (Nota, 15$).$

O'TOOLE, J.C. \& REAL, J. G. Estimation of aerodynamic and crop resistances from canopy temperature. Agronomy J., Madison, 78: 305-10, 1986.

PENMAN, H. L. Natural evaporation from open water, bare soil and grass. Proc. Royal Society of London, Serie A, London, 193:120-45, 1948.

PENMAN, H. L. The dependence of evapotranspiration on weather and soil conditions. Journal of Soil Science, $1: 74-89,1949$.

PEREIRA, A. R. Análise do modelo de Priestley-Taylor para estimativa da evapotranspiração potencial. Piracicaba, 
93.

1990. 68p. CLivre docéncia - Escola Superior de Agricultura "Luiz de Queiroz"/USPJ.

PEREIRA, A. R. Evapo(transpi)ração. Piracicaba, ESALQ-Departamento de Física e Meteorologia, 1992. $51 \mathrm{p}$

PEREIRA, A. R. \& CAMARGO, A. P. Analysis of the criticism of Thornthwaite's equation for estinating potential evapotranspiration. Agric. Forest Meteor., Amsterdam, $46: 149-57,1989$.

PERES, J. G. \& SCARDUA, R. Estudo de métodos agroclimatológicos para estimativa da evapotranpiração potencial de referéncia (ETO), segundo DOORENBOS \& PRUITT. Engenharia Rural, Piracicaba, 2(2):46-63, 1991.

PRIESTLEY, C. H. B. \& TAYLOR, R. I. On the assessment of surface heat $f l u x$ and evaporation using large-scale parameters. Monthly Weather Rev., Washington, 100:81-92, 1972.

RUSSELL, G. Crop evaporation, surface resistance and soil water status. Agric. Meteor., Amsterdam, 21:213-26, 1980. 
94.

SANTOS, R. Z. \& ANDRE, R. G. B. Relações energéticas e aerodinâmicas em uma cultura de feijão. Revista Brasileira de Agrometeorologia, Santa Maria, 1(1):11-8, 1993.

SEDIYAMA, G. C. Necessidade de água para os cultivos. Brasilia, ABEAS, 1987. 143p.

SHARMA, M. L. Estimating evapotranspiration. In: HILLEL, D. Advances in irrigation. New York, Academic Press, 1983. v. 3, p. $213-81$

SILVA. A. A. G. Avaliação da eficiência de métodos de estimativa da evapotranspiração de referéncia para o municipio de Parnalba-PI. Piracicaba, 1989. $81 \mathrm{p}$. CMestrado - Escola Superior de Agricultura "Luiz de Queiroz"/USP?.

SLABBERS, P. J. Surface roughness of crops and potential evapotranspiration. J. Hydrolo8y, Amsterdam, 34:181-91, 1977.

SMITH, M., ed. Report on the expert consultation on procedures for revision of $F A O$ guidelines for predictions of crop water requirements. Rome, FAO, 1991. 45p. 
95.

TANNER, C. B. Evaporation of water from plants and soil. In: KOZLOHSKI, T. T. Water deficits and plant growth. New York, Academic Press, 1968. v.1, Chap. 4, p. $73-106$.

THOM, A. S. Momentum, mass and heat exchange pf plant. communities. In: MONTEITH, J. L., ed. Vegetation and the atmosphere. London, Academic Press, 1975. v.1, Chap. 3, p. 57-109.

THOM, A. S. \& OLIVER, H. R. On Penman's equation for estimating regional evaporation. Quart. I. R. Met. Society, London, 103:345-57, 1977.

THORNTWAITE, G. W. An approach toward a rational classification of climate. Geographycal Rev., New York, $38(1): 55-94,1948$

Van BAVEL, C. H. M. Changes in canopy resistances to water loss from alfalfa induced by soil water deplection. Agric. Meteor. Amsterdam, 4:165-76, 1967.

Van BAVEL, C. H. M. \& EHRLER, W. L. Water loss from a sorghum field and stomatal control. Agronomy $J$ Madison, 60:84-6, 1968. 
96.

Van ZYL, H. H. \& JAGER, J. M. Accuracy of the Penman-Monteith equation adjusted for atmospheric stability. Agric. Forest Meteor., Amsterdam, $41: 57-64,1987$.

VILLA NOVA, N. A. A estimativa da evaporação potencial no Estado de São Paulo. Piracicaba, 1967. 66p. CDoutorado - Escola Superior de Agricultura "Luiz de Queiroz"/USP).

VILLA NOVA, N. A. \& OMETTO, J. C. Adaptação e simplificação do método de Penman às condições climáticas do Estado de São Paulo. In: SIMPOSIO BRASILEIRO DE HIDROLOGIA E RECURSOS HIDRICOS, IV, Fortaleza, 1981. Anais. Să Paulo, ABRH, 1981. v. 3 , p. $281-99$.

VILLA NOVA, N. A. \& REICHARDT, K. Evaporação e evapotranspiração. In: RAMOS, F.; CCHIPINTI, A. G.; VILLA NOVA, N. A. \& REICHARDT, K.; MAGALHAES, P. C.; CLEARY, R. W. Engenharia Hidrologica, Rio de Janeiro, ABRH, 1989. Cap. 3, p. 145-97. CColeção ABRH de Recursos Hidricos, 2).

WRIGHT, J. L. New evapotranspiration crop coefficients. Journal Irrig and Drain Division, New York, ASCE, $108(2): 57-74,1982$. 
ZHANG, L. \& LEMEUR, R. Effect of aerodynamic resistance on energy balance and Penman-Monteith estimates of evapotranspiration in greenhouse conditions. Agric. Forest Meteor., Amsterdam, 58:209-28, 1992. 
98.

$A P E N D I C E 1$ 
88.

Tabela 1: Valores decadiários da evapotranspiração de referéncia medida (ETO) e estimada pelo modelo de Penman-Monteith CETOMD, em Campinas-SP. Periodo de 1956 a 1959 . Valores em $\mathrm{mm}$ de água.

\begin{tabular}{|c|c|c|c|c|c|c|c|c|c|}
\hline \multirow{2}{*}{\multicolumn{2}{|c|}{ Período }} & \multicolumn{2}{|c|}{1956} & \multicolumn{2}{|c|}{1957} & \multicolumn{2}{|c|}{1958} & \multicolumn{2}{|c|}{1959} \\
\hline & & ETO & ETOM & ETo & ETOM & ETo & ETOM & ETo & ETOM \\
\hline \multirow{3}{*}{ JAN } & 1 & 44 & 56 & 43 & 47 & 50 & 57 & 21 & 40 \\
\hline & 2 & 59 & 52 & 21 & 34 & 28 & 39 & 40 & 34 \\
\hline & 3 & 52 & 61 & 37 & 49 & 47 & 36 & 39 & 52 \\
\hline \multirow{3}{*}{ FEV } & 1 & 59 & 57 & 42 & 35 & 32 & 38 & 25 & 34 \\
\hline & 2 & 33 & 30 & 34 & 40 & 44 & 50 & 35 & 40 \\
\hline & 3 & 23 & 29 & 36 & 28 & 22 & 21 & 26 & 34 \\
\hline \multirow{3}{*}{ MAR } & 1 & 34 & 44 & 43 & 42 & 25 & 36 & 30 & 43 \\
\hline & 2 & 38 & 41 & 29 & 42 & 31 & 32 & 31 & 32 \\
\hline & 3 & 39 & 43 & 36 & 34 & 38 & 43 & 32 & 34 \\
\hline \multirow{3}{*}{$A B R$} & 1 & 29 & 29 & 27 & 27 & 24 & 27 & 26 & 30 \\
\hline & 2 & 21 & 28 & 30 & 28 & 19 & 23 & 29 & 30 \\
\hline & 3 & 23 & 23 & 25 & 25 & 23 & 27 & 31 & 24 \\
\hline \multirow{3}{*}{ MAI } & 1 & 13 & 18 & 12 & 24 & 14 & 23 & 15 & 27 \\
\hline & 2 & 17 & 24 & 17 & 23 & 15 & 25 & 21 & 23 \\
\hline & 3 & 19 & 17 & 27 & 28 & 17 & 17 & 14 & 23 \\
\hline \multirow{3}{*}{ JUN } & 1 & 10 & 16 & 12 & 21 & 19 & 24 & 18 & 20 \\
\hline & 2 & 11 & 15 & 21 & 24 & 16 & 19 & 6 & 22 \\
\hline & 3 & 8 & 20 & 17 & 21 & 9 & 24 & 13 & 23 \\
\hline \multirow{3}{*}{ JUL } & 1 & 11 & 22 & 11 & 19 & 17 & 26 & 13 & 26 \\
\hline & 2 & 14 & 22 & 17 & 17 & 11 & 19 & 16 & 26 \\
\hline & 3 & 16 & 20 & 8 & 28 & 17 & 29 & 18 & 29 \\
\hline \multirow{3}{*}{$A G O$} & 1 & 11 & 21 & 21 & 30 & 16 & 28 & 12 & 20 \\
\hline & 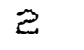 & 17 & 31 & 14 & 23 & 21 & 35 & 18 & 23 \\
\hline & 3 & 21 & 36 & 26 & 38 & 27 & 37 & 19 & 37 \\
\hline \multirow{3}{*}{ SET } & 1 & -- & 30 & 15 & 23 & 20 & 31 & 15 & 27 \\
\hline & 2 & -- & 28 & 20 & 28 & 15 & 27 & 22 & 35 \\
\hline & 3 & 25 & 34 & 25 & 28 & 23 & 34 & 27 & 36 \\
\hline \multirow{3}{*}{ OUT } & 1 & 31 & 49 & 34 & 51 & 33 & 47 & 25 & 47 \\
\hline & 2 & 27 & 40 & 43 & 49 & 23 & 44 & 32 & 35 \\
\hline & 3 & 30 & 41 & 44 & 39 & 23 & 36 & 34 & 45 \\
\hline \multirow{3}{*}{ NOV } & 1 & 33 & 44 & 36 & 42 & 44 & 50 & 31 & 40 \\
\hline & 2 & 41 & 56 & 32 & 35 & 26 & 45 & 23 & 42 \\
\hline & 3 & 33 & 48 & 39 & 45 & 34 & 45 & 44 & 38 \\
\hline \multirow{3}{*}{ DEZ } & 1 & 28 & 48 & 44 & 40 & 42 & 52 & 40 & 40 \\
\hline & 2 & 49 & 45 & 27 & 35 & 35 & 34 & 31 & 52 \\
\hline & 3 & 32 & 51 & 42 & 55 & 41 & 52 & 40 & 46 \\
\hline
\end{tabular}


100.

Tabela 2: Valores decadiarios da evapotranspiração de referência medida (ETO) e estimada pelo modelo de Penman-Monteith CETOM, em Ribeirăo Preto-SF. Periodo de 1956 a 1959 . Valores em $\mathrm{mm}$ de água.

\begin{tabular}{|c|c|c|c|c|c|c|c|c|c|}
\hline \multirow{2}{*}{\multicolumn{2}{|c|}{ Periodo }} & \multicolumn{2}{|c|}{1956} & \multicolumn{2}{|c|}{1957} & \multicolumn{2}{|c|}{1958} & \multicolumn{2}{|c|}{1959} \\
\hline & & ETo & ETOM & ETo & ETOM & ETo & ETOM & ETo & ETOM \\
\hline \multirow{3}{*}{ JAN } & 1 & 41 & 49 & 59 & 45 & 62 & 51 & 55 & 35 \\
\hline & 2 & 40 & 53 & 29 & 33 & 49 & 34 & 26 & 29 \\
\hline & 3 & 38 & 60 & 39 & 43 & 35 & 33 & 31 & 41 \\
\hline \multirow{3}{*}{ FEV } & 1 & 51 & 65 & 53 & 34 & 35 & 34 & 30 & 39 \\
\hline & 2 & 46 & 37 & 31 & 43 & 36 & 46 & 45 & 43 \\
\hline & 3 & 28 & 35 & 41 & 25 & 51 & 26 & 58 & 31 \\
\hline \multirow{3}{*}{ MAR } & 1 & 27 & 47 & 44 & 43 & 39 & 38 & 36 & 34 \\
\hline & 2 & 40 & 44 & 28 & 41 & 45 & 35 & 31 & 32 \\
\hline & 3 & 30 & 45 & 52 & 31 & 52 & 45 & 26 & 33 \\
\hline \multirow{3}{*}{$\mathrm{ABR}$} & 1 & 32 & 28 & 23 & 24 & 22 & 25 & 27 & 28 \\
\hline & $z$ & 27 & 35 & 33 & 31 & 29 & 21 & 27 & 31 \\
\hline & 3 & 26 & 25 & 38 & 25 & 22 & 26 & 40 & 25 \\
\hline \multirow{3}{*}{ MAI } & 1 & 24 & 20 & 17 & 26 & 26 & 23 & 32 & 28 \\
\hline & 2 & 21 & 25 & 15 & 26 & 17 & 26 & 24 & 23 \\
\hline & 3 & 10 & 21 & 25 & 30 & 45 & 17 & 26 & 28 \\
\hline \multirow{3}{*}{ JUN } & 1 & 21 & 17 & 14 & 23 & 21 & 21 & 15 & 21 \\
\hline & 2 & 6 & 16 & 17 & 27 & 22 & 19 & 12 & 24 \\
\hline & 3 & 12 & 24 & 21 & 27 & 16 & 23 & 17 & 27 \\
\hline \multirow{3}{*}{ JUL } & 1 & 12 & 23 & 23 & 23 & 17 & 24 & 21 & 29 \\
\hline & 2 & 14 & 28 & 27 & 16 & 16 & 17 & 27 & 30 \\
\hline & 3 & 22 & 25 & 9 & 36 & 24 & 27 & 40 & 33 \\
\hline \multirow{3}{*}{$A G O$} & 1 & 13 & 23 & 28 & 32 & 19 & 26 & 28 & 20 \\
\hline & 2 & 16 & 38 & 31 & 24 & 37 & 31 & 22 & 29 \\
\hline & 3 & 24 & 48 & 27 & 41 & 29 & 36 & 38 & 42 \\
\hline \multirow{3}{*}{ SET } & 1 & 30 & 42 & 31 & 25 & 22 & 32 & 35 & 33 \\
\hline & 2 & -- & 33 & 36 & 32 & 23 & 30 & 35 & 42 \\
\hline & 3 & 28 & 43 & 29 & 31 & 35 & 35 & 57 & 43 \\
\hline \multirow{3}{*}{ OUT } & 1 & 25 & 58 & 46 & 51 & 52 & 44 & 51 & 58 \\
\hline & 2 & 57 & 48 & 41 & 51 & 37 & 44 & 20 & 34 \\
\hline & 3 & 36 & 42 & 61 & 44 & 37 & 36 & 49 & 47 \\
\hline \multirow{3}{*}{ NOV } & 1 & 25 & 54 & 41 & 41 & 34 & 49 & -- & 46 \\
\hline & 2 & 67 & 66 & 42 & 36 & 45 & 49 & -- & 46 \\
\hline & 3 & 46 & 49 & 40 & 46 & 56 & 48 & -- & 38 \\
\hline \multirow{3}{*}{ DEZ } & 1 & 63 & 53 & 35 & 38 & 44 & 51 & 58 & 38 \\
\hline & 2 & 42 & 45 & 50 & 35 & -- & 32 & 35 & 46 \\
\hline & 3 & 38 & 48 & 49 & 57 & -- & 52 & 37 & 46 \\
\hline
\end{tabular}


101.

abela 3: Valores decadiários da evapotranspiração de referéncia medida (ETO) e estimada pelo modelo de Perman-Monteith CETOM, em Pindamonhangaba-SP. Periodo de 1954 a 1956 . Valores em $\mathrm{mm}$ de água.

\begin{tabular}{|c|c|c|c|c|c|c|c|}
\hline \multirow{2}{*}{\multicolumn{2}{|c|}{ Periodo }} & \multicolumn{2}{|c|}{1954} & \multicolumn{2}{|c|}{1955} & \multicolumn{2}{|c|}{1956} \\
\hline & & ETo & ETOM & ETo & ETOM & ETO & ETOM \\
\hline \multirow{3}{*}{ JAN } & 1 & -- & 34 & 32 & 37 & 33 & 45 \\
\hline & 2 & -- & 43 & 49 & 36 & 57 & 47 \\
\hline & 3 & -- & 51 & 48 & 43 & 57 & 49 \\
\hline \multirow{3}{*}{ FEV } & 1 & -- & 32 & 26 & 44 & 55 & 47 \\
\hline & 2 & -- & 33 & 48 & 45 & 40 & 28 \\
\hline & 3 & -- & 34 & 31 & 24 & 33 & 28 \\
\hline \multirow{3}{*}{ MAR } & 1 & 40 & 36 & 36 & 34 & 34 & 34 \\
\hline & 2 & 31 & 36 & 38 & 33 & 43 & 32 \\
\hline & 3 & 43 & 35 & 50 & 37 & 46 & 37 \\
\hline \multirow{3}{*}{$A B R$} & 1 & 29 & 25 & 14 & 22 & 48 & 25 \\
\hline & 2 & 30 & 23 & 48 & 20 & 23 & 19 \\
\hline & 3 & 29 & 22 & 28 & 21 & 14 & 19 \\
\hline \multirow{3}{*}{ MAI } & 1 & 8 & 18 & 24 & 19 & 20 & 17 \\
\hline & 2 & 18 & 16 & 29 & 18 & 23 & 17 \\
\hline & 3 & 14 & 18 & 17 & 18 & 16 & 15 \\
\hline \multirow{3}{*}{ JUN } & 1 & 10 & 16 & 17 & 16 & 17 & 16 \\
\hline & 2 & 5 & 18 & 11 & 18 & 12 & 12 \\
\hline & 3 & 13 & 17 & 22 & 16 & 16 & 15 \\
\hline \multirow{3}{*}{ JUL } & 1 & 27 & 20 & 19 & 18 & 19 & 15 \\
\hline & 2 & 18 & 22 & 24 & 20 & 16 & 17 \\
\hline & 3 & 18 & 23 & 23 & 19 & 24 & 17 \\
\hline \multirow{3}{*}{$A G O$} & 1 & 22 & 25 & 18 & 19 & -- & 15 \\
\hline & 2 & 33 & 24 & 31 & 22 & -- & 21 \\
\hline & 3 & 15 & 28 & 25 & 22 & -- & 22 \\
\hline \multirow{3}{*}{ SET } & 1 & 28 & 26 & 24 & 20 & 34 & 23 \\
\hline & 2 & 38 & 27 & 25 & 26 & 12 & 19 \\
\hline & 3 & 29 & 23 & 36 & 24 & 43 & 24 \\
\hline \multirow{3}{*}{ OUT } & 1 & 19 & 36 & 48 & 26 & 25 & 40 \\
\hline & 2 & 35 & 27 & 30 & 25 & 33 & 29 \\
\hline & 3 & 42 & 42 & 47 & 30 & 41 & 33 \\
\hline \multirow{3}{*}{ NOV } & 1 & 38 & 44 & 37 & 27 & 43 & 36 \\
\hline & 2 & 25 & 38 & 36 & 33 & 41 & 41 \\
\hline & 3 & 36 & 41 & 26 & 40 & 37 & 35 \\
\hline \multirow{3}{*}{ DEZ } & 1 & 40 & 41 & 37 & 36 & 35 & 36 \\
\hline & 2 & 37 & 39 & 40 & 38 & 37 & 39 \\
\hline & 3 & 27 & 43 & 54 & 35 & 46 & 40 \\
\hline
\end{tabular}


102.

abela 5: Valores mensais da evapotranspiração de referéncia medida (ETO) e estimada pelo modelo de Penman-Monteith (ETOM em Campinas-SP. Periodo de 1956 a 1959. Valores em mm de água.

\begin{tabular}{lrrrrrrrr}
\hline \multirow{2}{*}{ Periodo } & \multicolumn{2}{c}{1956} & \multicolumn{2}{c}{1957} & \multicolumn{2}{c}{1958} & \multicolumn{2}{c}{1959} \\
& ETo & EToM & ETo & EToM & ETo & EToM & ETo & EToM \\
\hline JAN & 155 & 170 & 101 & 129 & 125 & 132 & 100 & 126 \\
FEV & 115 & 114 & 112 & 103 & 98 & 107 & 88 & 110 \\
MAR & 111 & 128 & 108 & 118 & 94 & 110 & 93 & 109 \\
ABR & 73 & 79 & 82 & 81 & 6 & 77 & 86 & 84 \\
MAI & 49 & 59 & 56 & 75 & 46 & 64 & 50 & 72 \\
JUN & 29 & 51 & 50 & 66 & 44 & 67 & 37 & 66 \\
JUL & 41 & 64 & 36 & 64 & 45 & 73 & 47 & 81 \\
AGO & 49 & 88 & 61 & 90 & 64 & 100 & 49 & 78 \\
SET & 66 & 92 & 60 & 78 & 58 & 93 & 64 & 98 \\
OUT & 88 & 129 & 121 & 140 & 79 & 127 & 91 & 126 \\
NOV & 107 & 149 & 107 & 122 & 104 & 140 & 98 & 120 \\
DEZ & 109 & 143 & 113 & 129 & 118 & 137 & 111 & 139 \\
\hline
\end{tabular}

Tabela 6: Valores mensais da evapotranspiração de referencia medida (ETO) e estimada pelo modelo de Penman-Monteith (ETOM), em Ribeirão Preto-SP. Periodo de 1956 a 1959. Valores em $\mathrm{mm}$ de água.

\begin{tabular}{lrrrrrrrr}
\hline \multirow{2}{*}{ Periodo } & \multicolumn{2}{c}{1956} & \multicolumn{2}{c}{1957} & \multicolumn{2}{c}{1958} & \multicolumn{2}{c}{1959} \\
& ETo & EToM & ETo & EToM & ETo & ETOM & ETo & EToM \\
\hline JAN & 119 & 162 & 127 & 121 & 146 & 121 & 112 & 105 \\
FEV & 125 & 135 & 125 & 101 & 122 & 105 & 133 & 113 \\
MAR & 97 & 136 & 124 & 114 & 136 & 118 & 95 & 99 \\
ABR & 85 & 88 & 94 & 80 & 73 & 72 & 94 & 84 \\
MAI & 55 & 66 & 57 & 84 & 88 & 66 & 84 & 80 \\
JUN & 39 & 57 & 52 & 76 & 59 & 63 & 44 & 72 \\
JUL & 48 & 76 & 59 & 75 & 57 & 67 & 88 & 91 \\
AGO & 53 & 108 & 86 & 96 & 85 & 93 & 88 & 90 \\
SET & 64 & 117 & 96 & 87 & 80 & 98 & 127 & 118 \\
OUT & 118 & 148 & 148 & 148 & 126 & 125 & 120 & 137 \\
NOV & 138 & 169 & 123 & 123 & 135 & 146 & 141 & 130 \\
DEZ & 143 & 145 & 134 & 129 & 108 & 134 & 130 & 131 \\
\hline
\end{tabular}


103.

abela 7: Valores mensais da evapotranspiração de referéncia medida (ETO) e estimada pelo modelo de Penman-Monteith (ETOM, em Pindamonhangaba-SP. Período de 1954 a 1950 . Valores em $\mathrm{mm}$ de água.

\begin{tabular}{lrrrrrr}
\hline Periodo & \multicolumn{2}{c}{1954} & \multicolumn{2}{c}{1955} & \multicolumn{2}{c}{1956} \\
& ETo & ETOM & ETo & EToM & ETo & EToM \\
\hline JAN & -- & 129 & 129 & 117 & 147 & 140 \\
FEV & -- & 101 & 105 & 111 & 128 & 103 \\
MAR & 114 & 107 & 124 & 105 & 123 & 102 \\
ABR & 88 & 69 & 70 & 63 & 85 & 62 \\
MAI & 40 & 52 & 70 & 55 & 59 & 49 \\
JUN & 28 & 51 & 50 & 50 & 45 & 42 \\
JUL & 63 & 64 & 66 & 57 & 59 & 49 \\
AGO & 70 & 77 & 74 & 63 & -- & 58 \\
SET & 95 & 77 & 85 & 70 & 89 & 66 \\
OUT & 96 & 103 & 125 & 82 & 99 & 102 \\
NOV & 99 & 123 & 99 & 102 & 121 & 112 \\
DEZ & 104 & 122 & 131 & 110 & 118 & 115 \\
\hline
\end{tabular}


104.

A P E N D C E Z 
105.

abela 9: Valores decadiários da evapotranspiração de referéncia medida (ETO) e estimada pelo modelo de Penman-Monteith CETOMD, considerando diferentes resistencias do dossel e altura de vegetação igual a $0.06 \mathrm{~m}$, em Campinas-SP, ano de 1956. Valores em $\mathrm{mm}$ de água.

\begin{tabular}{|c|c|c|c|c|c|c|c|c|}
\hline \multicolumn{2}{|c|}{ Periodo } & \multirow{2}{*}{$\frac{\text { ETO }}{44}$} & \multirow{2}{*}{$\frac{\text { ETOM }_{0000}}{65}$} & \multirow{2}{*}{$\frac{\text { ETOM }_{0020}}{62}$} & \multirow{2}{*}{$\frac{\text { ETOM }_{0640}}{58}$} & \multirow{2}{*}{$\frac{\text { ETOM }_{0000}}{55}$} & \multirow{2}{*}{$\frac{\text { ETOM }_{0000}}{53}$} & \multirow{2}{*}{$\frac{\text { ETOM }_{\text {OoVR }}}{46}$} \\
\hline & 1 & & & & & & & \\
\hline JAN & 2 & 59 & 56 & 54 & 53 & 51 & 50 & 45 \\
\hline & 3 & 52 & 68 & 65 & 62 & 60 & 58 & 52 \\
\hline \multirow{3}{*}{ FEV } & 1 & 59 & 62 & 60 & 58 & 56 & 54 & 49 \\
\hline & 2 & 33 & 34 & 33 & 31 & 30 & 29 & 24 \\
\hline & 3 & 23 & 32 & 31 & 30 & 29 & 28 & 23 \\
\hline \multirow{3}{*}{ MAR } & 1 & 34 & 50 & 48 & 46 & 44 & 42 & 36 \\
\hline & 2 & 38 & 45 & 43 & 42 & 40 & 39 & 33 \\
\hline & 3 & 39 & 48 & 46 & 44 & 43 & 41 & 39 \\
\hline \multirow{3}{*}{$A B R$} & 1 & 29 & 31 & 30 & 29 & 28 & 27 & 22 \\
\hline & 2 & 21 & 32 & 30 & 28 & 27 & 26 & 18 \\
\hline & 3 & 23 & 26 & 25 & 24 & 23 & 22 & 16 \\
\hline \multirow{3}{*}{ MAI } & 1 & 13 & 19 & 19 & 18 & 17 & 17 & 13 \\
\hline & 2 & 17 & 28 & 26 & 25 & 24 & 23 & 16 \\
\hline & 3 & 19 & 19 & 18 & 17 & 17 & 16 & 11 \\
\hline \multirow{3}{*}{ JUN } & 1 & 10 & 18 & 17 & 16 & 15 & 15 & 10 \\
\hline & 2 & 11 & 17 & 16 & 16 & 15 & 14 & 10 \\
\hline & 3 & 8 & ટ2 & 21 & 20 & 19 & 19 & 14 \\
\hline \multirow{3}{*}{ JUL } & 1 & 11 & 25 & 24 & 22 & 21 & 20 & 14 \\
\hline & 2 & 14 & 24 & 23 & 22 & 21 & 21 & 16 \\
\hline & 3 & 16 & 22 & 21 & 20 & 19 & 19 & 14 \\
\hline \multirow{3}{*}{$A G O$} & 1 & 11 & 25 & 24 & 22 & 21 & 20 & 13 \\
\hline & 2 & 17 & 35 & 33 & 31 & 30 & 28 & 20 \\
\hline & 3 & 21 & 41 & 38 & 36 & 35 & 33 & 24 \\
\hline \multirow{3}{*}{ SET } & 1 & -- & 33 & 31 & 30 & 29 & 28 & 22 \\
\hline & 2 & -- & 31 & 30 & 28 & 27 & 26 & 19 \\
\hline & 3 & 25 & 38 & 36 & 34 & 33 & 31 & 23 \\
\hline \multirow{3}{*}{ OUT } & 1 & 31 & 57 & 53 & 50 & 48 & 45 & 36 \\
\hline & 2 & 27 & 48 & 45 & 42 & 39 & 37 & 28 \\
\hline & 3 & 30 & 45 & 43 & 42 & 40 & 39 & 33 \\
\hline \multirow{3}{*}{ NOV } & 1 & 33 & 48 & 46 & 45 & 43 & 42 & 37 \\
\hline & 2 & 41 & 70 & 64 & 60 & 56 & 52 & 44 \\
\hline & 3 & 33 & 57 & 53 & 50 & 48 & 45 & 37 \\
\hline \multirow{3}{*}{$D E Z$} & 1 & 28 & 55 & 52 & 50 & 47 & 45 & 38 \\
\hline & 2 & 49 & 50 & 48 & 46 & 44 & 42 & 36 \\
\hline & 3 & 32 & 57 & 55 & 52 & 50 & 48 & 42 \\
\hline
\end{tabular}


106.

Tabela 10: Valores decadiarios da evapotranspiração de referencia medida (ETO) estimada pelo modelo de Penman-Monteith CETOMD, considerando diferentes resistencias do dossel e altura de vegetação i gual a $0,06 \mathrm{~m}$, em Campinas-SP, ano de 1957. Valores em $\mathrm{mm}$ de água.

\begin{tabular}{|c|c|c|c|c|c|c|c|c|}
\hline \multicolumn{2}{|c|}{ Periodo } & \multirow{2}{*}{$\frac{\text { ETo }}{43}$} & \multirow{2}{*}{$\frac{\text { ETOM }_{0600}}{53}$} & \multirow{2}{*}{$\frac{\text { ETOM }_{0020}}{51}$} & \multirow{2}{*}{$\frac{\text { ETOM }_{0640}}{48}$} & \multirow{2}{*}{$\frac{\text { ETOM }_{0000}}{46}$} & \multirow{2}{*}{$\frac{\text { ETOM }_{0600}}{44}$} & \multirow{2}{*}{$\frac{\text { ETOM }_{\text {OGVR }}}{38}$} \\
\hline & 1 & & & & & & & \\
\hline JAN & 2 & 21 & 40 & 38 & 36 & 34 & 33 & 26 \\
\hline & 3 & 37 & 56 & 54 & 51 & 49 & 47 & 40 \\
\hline \multirow{3}{*}{ FEV } & 1 & 42 & 41 & 36 & 37 & 35 & 33 & 28 \\
\hline & 2 & 34 & 47 & 45 & 42 & 40 & 38 & 31 \\
\hline & 3 & 36 & 33 & 31 & 30 & 28 & 27 & 21 \\
\hline \multirow{3}{*}{ MAR } & 1 & 43 & 47 & 45 & 43 & 42 & 40 & 35 \\
\hline & 2 & 29 & 48 & 45 & 43 & 41 & 40 & 33 \\
\hline & 3 & 36 & 38 & 36 & 35 & 34 & 32 & 26 \\
\hline \multirow{3}{*}{$A B R$} & 1 & 27 & 32 & 30 & 28 & 27 & 25 & 18 \\
\hline & 2 & 30 & 32 & 30 & 29 & 28 & 26 & 19 \\
\hline & 3 & 25 & 28 & 27 & 26 & 25 & 24 & 17 \\
\hline \multirow{3}{*}{ MAI } & 1 & 12 & 28 & 26 & 25 & 23 & 22 & 15 \\
\hline & 2 & 17 & 25 & 24 & 24 & 23 & 22 & 17 \\
\hline & 3 & 27 & 31 & 29 & 28 & 27 & 25 & 18 \\
\hline \multirow{3}{*}{ JUN } & 1 & 12 & 23 & 22 & 21 & 20 & 19 & 13 \\
\hline & 2 & 21 & 27 & 25 & 24 & 23 & 22 & 15 \\
\hline & 3 & 17 & 23 & 22 & 21 & 20 & 20 & 15 \\
\hline \multirow{3}{*}{ JUL } & 1 & 11 & 21 & 20 & 19 & 19 & 18 & 13 \\
\hline & 2 & 17 & 20 & 19 & 18 & 17 & 16 & 11 \\
\hline & 3 & 8 & 32 & 30 & 28 & 27 & 26 & 18 \\
\hline \multirow{3}{*}{$A G O$} & 1 & 21 & 33 & 31 & 30 & 28 & 27 & 19 \\
\hline & 2 & 14 & 26 & 24 & 23 & 22 & 21 & 15 \\
\hline & 3 & 26 & 45 & 41 & 39 & 36 & 34 & 23 \\
\hline \multirow{3}{*}{ SET } & 1 & 15 & 26 & 24 & 23 & 22 & 21 & 15 \\
\hline & 2 & 20 & 32 & 30 & 29 & 27 & 26 & 19 \\
\hline & 3 & 25 & 33 & 31 & 29 & 28 & 26 & 19 \\
\hline \multirow{3}{*}{ OUT } & 1 & 34 & 58 & 55 & 52 & 50 & 47 & 40 \\
\hline & 2 & 43 & 54 & 52 & 50 & 48 & 46 & 39 \\
\hline & 3 & 44 & 44 & 42 & 40 & 38 & 36 & 28 \\
\hline \multirow{3}{*}{ NOV } & 1 & 36 & 46 & 45 & 43 & 41 & 39 & 31 \\
\hline & 2 & 32 & 40 & 38 & 37 & 35 & 34 & 28 \\
\hline & 3 & 39 & 51 & 49 & 47 & 45 & 43 & 36 \\
\hline \multirow{3}{*}{$\mathrm{DEZ}$} & 1 & 44 & 46 & 44 & 42 & 40 & 38 & 32 \\
\hline & 2 & 27 & 39 & 38 & 36 & 35 & 34 & 29 \\
\hline & 3 & 42 & 50 & 58 & 56 & 54 & 53 & 48 \\
\hline
\end{tabular}


107.

abela 11: Valores decadiários da evapotranspiração de referencia medida (ETO) e estimada pelo modelo de Penmam-Monteith CETOMD, considerando diferentes resistências do dossel e altura de vegetação igual a $0,06 \mathrm{~m}$, em Campinas-SP, ano de 1958. Valores em $\mathrm{mm}$ de água.

\begin{tabular}{|c|c|c|c|c|c|c|c|c|}
\hline \multicolumn{2}{|c|}{ Período } & \multirow{2}{*}{ ETo } & \multirow{2}{*}{$\frac{\text { ETOM }_{0000}}{62}$} & \multirow{2}{*}{$\frac{\text { ETOM }_{0020}}{60}$} & \multirow{2}{*}{$\frac{\text { ETOM }_{0040}}{58}$} & \multirow{2}{*}{$\frac{\text { ETOM }_{0000}}{56}$} & \multirow{2}{*}{$\frac{\text { ETOM }_{0000}}{54}$} & \multirow{2}{*}{$\frac{\text { ETOM }_{\text {OOVR }}}{50}$} \\
\hline & 1 & & & & & & & \\
\hline JAN & 2 & 28 & 43 & 42 & 40 & 39 & 39 & 32 \\
\hline & 3 & 47 & 41 & 39 & 37 & 36 & 36 & 28 \\
\hline \multirow{3}{*}{ FEV } & 1 & 32 & 42 & 41 & 39 & 38 & 27 & 30 \\
\hline & 2 & 44 & 54 & 52 & 51 & 49 & 49 & 44 \\
\hline & 3 & ट己 & 23 & 22 & 22 & 21 & 21 & 17 \\
\hline \multirow{3}{*}{ MAR } & 1 & 25 & 39 & 38 & 37 & 36 & 36 & 30 \\
\hline & 2 & 31 & 34 & 33 & 32 & 32 & 32 & 27 \\
\hline & 3 & 38 & 49 & 47 & 45 & 43 & 42 & 33 \\
\hline \multirow{3}{*}{$\mathrm{ABR}$} & 1 & 24 & 30 & 29 & 27 & 26 & 26 & 19 \\
\hline & 2 & 19 & 26 & 25 & 24 & 23 & 23 & 16 \\
\hline & 3 & 23 & 31 & 29 & 28 & 27 & 26 & 18 \\
\hline \multirow{3}{*}{ MAI } & 1 & 14 & 25 & 24 & 23 & 22 & 22 & 16 \\
\hline & 2 & 15 & 28 & 27 & 25 & 24 & 24 & 16 \\
\hline & 3 & 17 & 20 & 18 & 18 & 17 & 16 & 11 \\
\hline \multirow{3}{*}{ JUN } & 1 & 19 & 26 & 25 & 24 & 23 & 23 & 17 \\
\hline & 2 & 16 & 21 & 20 & 19 & 18 & 18 & 12 \\
\hline & 3 & 9 & 27 & 26 & 25 & 23 & 23 & 16 \\
\hline \multirow{3}{*}{ JUL } & 1 & 17 & 29 & 27 & 26 & 24 & 24 & 16 \\
\hline & 2 & 11 & 22 & 21 & 20 & 19 & 19 & 12 \\
\hline & 3 & 17 & 33 & 31 & 29 & 28 & 27 & 19 \\
\hline \multirow{3}{*}{$A G O$} & 1 & 16 & 30 & 29 & 28 & 27 & 26 & 19 \\
\hline & 2 & 21 & 38 & 36 & 34 & 33 & 32 & 24 \\
\hline & 3 & 27 & $4 己$ & 40 & 38 & 36 & 35 & 24 \\
\hline \multirow{3}{*}{ SET } & 1 & 20 & 34 & 32 & 31 & 30 & 29 & 21 \\
\hline & 2 & 15 & 33 & 31 & 29 & 27 & 26 & 17 \\
\hline & 3 & 23 & 37 & 36 & 34 & 33 & 32 & 24 \\
\hline \multirow{3}{*}{ OUT } & 1 & 33 & 54 & 51 & 49 & 47 & 46 & 37 \\
\hline & 2 & 23 & 52 & 49 & 46 & 44 & 43 & 34 \\
\hline & 3 & 23 & 40 & 38 & 37 & 35 & 35 & 28 \\
\hline \multirow{3}{*}{ NOV } & 1 & 44 & 56 & 53 & 51 & 49 & 49 & 41 \\
\hline & $\hat{z}$ & 20 & 48 & 47 & 45 & 44 & 44 & 37 \\
\hline & 3 & 34 & 50 & 48 & 46 & 44 & 44 & 38 \\
\hline \multirow{3}{*}{$\mathrm{DEZ}$} & 1 & 42 & 56 & 54 & 53 & 51 & 51 & 45 \\
\hline & 2 & 35 & 36 & 35 & 35 & 34 & 34 & 30 \\
\hline & 3 & 41 & 59 & 57 & 54 & 51 & 51 & 42 \\
\hline
\end{tabular}


108.

Tabela 12: Valores decadiários da evapotranspiração de referéncia medida (ETo) e estimada pelo modelo de Penman-Monteith CETOMD, considerando diferentes resistencias do dossel e altura de vegetação igual a $0.06 \mathrm{~m}$, em Campinas-SP, ano de 1959. Valores em $\mathrm{mm}$ de água.

\begin{tabular}{|c|c|c|c|c|c|c|c|c|}
\hline \multicolumn{2}{|c|}{ Período } & \multirow{2}{*}{$\frac{\text { ETo }}{21}$} & \multirow{2}{*}{$\frac{\text { ETOM }_{0000}}{45}$} & ETOM $_{0020}$ & \multirow{2}{*}{$\frac{\text { ETOM }_{0040}}{41}$} & \multirow{2}{*}{$\frac{\text { ETOM }_{0600}}{40}$} & \multirow{2}{*}{$\frac{\text { ETOM }_{0600}}{39}$} & \multirow{2}{*}{$\frac{\text { ETOM }_{\text {OGVR }}}{33}$} \\
\hline & 1 & & & 43 & & & & \\
\hline JAN & 2 & 40 & 38 & 37 & 35 & 34 & 33 & 28 \\
\hline & 3 & 39 & 56 & 55 & 53 & 52 & 50 & 46 \\
\hline \multirow{3}{*}{ FEV } & 1 & 25 & 37 & 36 & 35 & 34 & 33 & 29 \\
\hline & 2 & 35 & 44 & 42 & 41 & 40 & 39 & 35 \\
\hline & 3 & 26 & 36 & 36 & 35 & 34 & 33 & 31 \\
\hline \multirow{3}{*}{ MAR } & 1 & 30 & 47 & 46 & 44 & 43 & 41 & 36 \\
\hline & 2 & 31 & 36 & 35 & 33 & 32 & 31 & 25 \\
\hline & 3 & 32 & 37 & 36 & 35 & 34 & 34 & 30 \\
\hline \multirow{3}{*}{$\mathrm{ABR}$} & 1 & 26 & 31 & 30 & 30 & 29 & 28 & 24 \\
\hline & 2 & 29 & 31 & 31 & 30 & 29 & 29 & 15 \\
\hline & 3 & 31 & 26 & 25 & 25 & 24 & 23 & 18 \\
\hline \multirow{3}{*}{ MAI } & 1 & 15 & 28 & 28 & 27 & 26 & 25 & 21 \\
\hline & 2 & 21 & 25 & 24 & 23 & 22 & 21 & 16 \\
\hline & 3 & 14 & 24 & 23 & 23 & 22 & 21 & 17 \\
\hline \multirow{3}{*}{ JUN } & 1 & 18 & 22 & 21 & 20 & 20 & 19 & 14 \\
\hline & 2 & 6 & 25 & 24 & 23 & 22 & 21 & 16 \\
\hline & 3 & 13 & 24 & 23 & 23 & 22 & 22 & 17 \\
\hline \multirow{3}{*}{ JUL } & 1 & 13 & 28 & 26 & 25 & 24 & 24 & 18 \\
\hline & 2 & 16 & 27 & 27 & 26 & 25 & 24 & 20 \\
\hline & 3 & 18 & 29 & 29 & 28 & 27 & 26 & 22 \\
\hline \multirow{3}{*}{$A G O$} & 1 & 12 & 21 & 20 & 20 & 19 & 18 & 14 \\
\hline & 2 & 18 & 26 & 25 & 24 & 23 & 22 & 16 \\
\hline & 3 & 19 & 39 & 38 & 36 & 35 & 34 & 26 \\
\hline \multirow{3}{*}{ SET } & 1 & 15 & 27 & 26 & 26 & 25 & 25 & 21 \\
\hline & 2 & $2 己$ & 40 & 37 & 35 & 34 & 32 & 23 \\
\hline & 3 & 27 & 39 & 37 & 36 & 34 & 33 & 26 \\
\hline \multirow{3}{*}{ OUT } & 1 & 25 & 51 & 49 & 47 & 45 & 44 & 36 \\
\hline & z & 32 & 38 & 37 & 36 & 35 & 34 & 20 \\
\hline & 3 & 34 & 50 & 48 & 46 & 44 & 42 & 35 \\
\hline \multirow{3}{*}{ NOV } & 1 & 31 & 43 & 42 & 41 & 40 & 39 & 35 \\
\hline & 2 & 23 & 48 & 46 & 44 & 42 & 40 & 34 \\
\hline & 3 & 44 & 41 & 40 & 39 & 38 & 36 & 31 \\
\hline \multirow{3}{*}{$D E Z$} & 1 & 40 & 43 & 41 & 40 & 39 & 38 & 34 \\
\hline & 2 & 31 & 57 & 55 & 53 & 52 & 50 & 46 \\
\hline & 3 & 40 & 53 & 51 & 50 & 48 & 47 & 43 \\
\hline
\end{tabular}


109.

abela 13: Valores decadiarios da evapotranspiraçăo de referencia medida (ETO) e estimada pelo modelo de Penman-Monteith CETOMD, considerando diferentes resistencias do dossel e altura de vegetação igual a $0.12 \mathrm{~m}$, em Campinas-SP, ano de 1956. Valores em $\mathrm{mm}$ de água.

\begin{tabular}{|c|c|c|c|c|c|c|c|c|}
\hline \multicolumn{2}{|c|}{ Periodo } & \multirow{2}{*}{$\frac{\text { ETo }}{44}$} & \multirow{2}{*}{$\frac{\text { ETOM }_{1200}}{71}$} & \multirow{2}{*}{$\frac{\text { EToM }_{1220}}{56}$} & \multirow{2}{*}{$\frac{\text { ETOM }_{1240}}{61}$} & \multirow{2}{*}{$\frac{\text { ETOM }_{1260}}{57}$} & \multirow{2}{*}{$\frac{\text { ETOM }_{1200}}{54}$} & \multirow{2}{*}{$\frac{\text { ETOM }_{12 \mathrm{VR}}}{54}$} \\
\hline & 1 & & & & & & & \\
\hline \multirow{2}{*}{ JAN } & 2 & 59 & 59 & 57 & 55 & 53 & 51 & 50 \\
\hline & 3 & 52 & 72 & 69 & 65 & 62 & 59 & 59 \\
\hline \multirow{3}{*}{ FEV } & 1 & 59 & 68 & 63 & 60 & 58 & 55 & 55 \\
\hline & 2 & 33 & 35 & 34 & 32 & 31 & 29 & 28 \\
\hline & 3 & 23 & 34 & 32 & 31 & 30 & 28 & 27 \\
\hline \multirow{3}{*}{ MAR } & 1 & 34 & 54 & 51 & 48 & 45 & 43 & 42 \\
\hline & 2 & 38 & 48 & 45 & 43 & 42 & 40 & 39 \\
\hline & 3 & 39 & 51 & 48 & 46 & 44 & 42 & 40 \\
\hline \multirow{3}{*}{$\mathrm{ABR}$} & 1 & 29 & 33 & 32 & 30 & 29 & 28 & 26 \\
\hline & 2 & 21 & 35 & 33 & 31 & 29 & 27 & 23 \\
\hline & 3 & 23 & 28 & 27 & 25 & 24 & 22 & 20 \\
\hline \multirow{3}{*}{ MAI } & 1 & 13 & 21 & 20 & 19 & 18 & 17 & 16 \\
\hline & 2 & 17 & 30 & 28 & 26 & 25 & 24 & 21 \\
\hline & 3 & 19 & 20 & 19 & 18 & 17 & 16 & 14 \\
\hline \multirow{3}{*}{ JUN } & 1 & 10 & 19 & 18 & 17 & 16 & 15 & 13 \\
\hline & 2 & 11 & 19 & 17 & 16 & 15 & 15 & 13 \\
\hline & 3 & 8 & 24 & 23 & 21 & 20 & 20 & 17 \\
\hline \multirow{3}{*}{ JUL } & 1 & 11 & 27 & 26 & 24 & 23 & 21 & 18 \\
\hline & 2 & 14 & 26 & 25 & 24 & 23 & 22 & 19 \\
\hline & 3 & 16 & 23 & 22 & 21 & 20 & 19 & 17 \\
\hline \multirow{3}{*}{$A G O$} & 1 & 11 & 28 & 26 & 24 & 22 & 21 & 18 \\
\hline & 2 & 17 & 39 & 36 & 34 & 32 & 30 & 26 \\
\hline & 3 & 21 & 45 & 42 & 39 & 37 & 35 & 31 \\
\hline \multirow{3}{*}{ SET } & 1 & -- & 36 & 34 & 32 & 31 & 29 & 26 \\
\hline & 2 & -- & 34 & 32 & 30 & 29 & 27 & 24 \\
\hline & 3 & 25 & 42 & 39 & 37 & 35 & 33 & 29 \\
\hline \multirow{3}{*}{ OUT } & 1 & 31 & 62 & 57 & 53 & 50 & 47 & 45 \\
\hline & 2 & 27 & 52 & 48 & 44 & 41 & 38 & 36 \\
\hline & 3 & 30 & 47 & 45 & 43 & 41 & 40 & 39 \\
\hline \multirow{3}{*}{ NOV } & 1 & 33 & 51 & 48 & 46 & 45 & 43 & 42 \\
\hline & 2 & 41 & 77 & 69 & 63 & 58 & 54 & 55 \\
\hline & 3 & 33 & 62 & 57 & 53 & 50 & 47 & 45 \\
\hline \multirow{3}{*}{$D E Z$} & 1 & 28 & 60 & 56 & 53 & 50 & 47 & 45 \\
\hline & 2 & 49 & 53 & 50 & 48 & 46 & $4 \pi$ & 43 \\
\hline & 3 & 32 & 61 & 57 & 54 & 52 & 49 & 49 \\
\hline
\end{tabular}


110.

Tabela 14: Valores decadiários da evapotranspiração de referência medida (ETO) e estimada pelo modelo de Penman-Monteith CETOMD, considerando diferentes resistencias do dossel e altura de vegetação igual a $0,12 \mathrm{~m}$, em Campinas-SP, ano de 1957. Valores em $\mathrm{mm}$ de água.

\begin{tabular}{|c|c|c|c|c|c|c|c|c|}
\hline \multicolumn{2}{|c|}{ Período } & \multirow{2}{*}{ ETo } & \multirow{2}{*}{$\frac{\text { ETOM }_{1200}}{57}$} & \multirow{2}{*}{$\frac{\text { ETOM }_{1220}}{54}$} & \multirow{2}{*}{$\frac{\text { ETOM }_{1240}}{50}$} & \multirow{2}{*}{$\frac{\text { ETOM }_{1260}}{48}$} & \multirow{2}{*}{$\frac{\text { ETOM }_{1280}}{45}$} & \multirow{2}{*}{$\frac{\text { ETOM }_{\text {12VR }}}{45}$} \\
\hline \multirow{3}{*}{ JAN } & 1 & & & & & & & \\
\hline & 2 & 21 & 42 & 39 & 37 & 35 & 33 & 32 \\
\hline & 3 & 37 & 60 & 56 & 53 & 50 & 48 & 47 \\
\hline \multirow{3}{*}{ FEV } & 1 & 42 & 43 & 40 & 38 & 36 & 34 & 32 \\
\hline & 2 & 34 & 50 & 47 & 44 & 41 & 39 & 38 \\
\hline & 3 & 36 & 35 & 33 & 31 & 29 & 27 & 26 \\
\hline \multirow{3}{*}{ MAR } & 1 & 43 & 49 & 47 & 45 & 43 & 41 & 40 \\
\hline & 2 & 29 & 51 & 48 & 45 & 43 & 41 & 39 \\
\hline & 3 & 36 & 40 & 38 & 36 & 34 & 33 & 31 \\
\hline \multirow{3}{*}{ ABR } & 1 & 27 & 35 & 32 & 30 & 28 & 26 & 23 \\
\hline & 己 & 30 & 35 & 32 & 31 & 29 & 27 & 25 \\
\hline & 3 & 25 & 31 & 29 & 27 & 26 & 24 & 22 \\
\hline \multirow{3}{*}{ MAI } & 1 & 12 & 31 & 29 & 27 & 25 & 23 & 20 \\
\hline & 2 & 17 & 27 & 26 & 25 & 24 & 23 & 21 \\
\hline & 3 & 27 & 34 & 32 & 30 & 28 & 27 & 23 \\
\hline \multirow{3}{*}{ JUN } & 1 & 12 & 26 & 24 & 23 & 21 & 20 & 17 \\
\hline & 2 & 21 & 30 & 28 & 26 & 25 & 23 & 20 \\
\hline & 3 & 17 & 25 & 24 & 23 & 21 & 21 & 18 \\
\hline \multirow{3}{*}{ JUL } & 1 & 11 & 23 & e己 & 21 & 20 & 19 & 16 \\
\hline & 2 & 17 & 22 & 20 & 19 & 18 & 17 & 14 \\
\hline & 3 & 8 & 35 & 33 & 31 & 29 & 27 & 23 \\
\hline \multirow{3}{*}{$A G O$} & 1 & 21 & 37 & 35 & 32 & 30 & 29 & 25 \\
\hline & 2 & 14 & 28 & 26 & 25 & 23 & 22 & 19 \\
\hline & 3 & 26 & 50 & 46 & 42 & 39 & 37 & 31 \\
\hline \multirow{3}{*}{ SET } & 1 & 15 & 28 & 26 & 24 & 23 & 22 & 20 \\
\hline & 2 & 20 & 34 & 32 & 30 & 29 & 27 & 24 \\
\hline & 3 & 25 & 36 & 33 & 31 & 29 & 27 & 24 \\
\hline \multirow{3}{*}{ OUT } & 1 & 34 & 63 & 59 & 55 & 52 & 48 & 48 \\
\hline & $z$ & 43 & 59 & 56 & 53 & 50 & 48 & 46 \\
\hline & 3 & 44 & 47 & 44 & 42 & 40 & 37 & 35 \\
\hline \multirow{3}{*}{ NOV } & 1 & 36 & 52 & 48 & 45 & 43 & 40 & 38 \\
\hline & 2 & 32 & 42 & 40 & 38 & 36 & 34 & 33 \\
\hline & 3 & 39 & 55 & 52 & 49 & 46 & 44 & 42 \\
\hline \multirow{3}{*}{$D E Z$} & 1 & 44 & 49 & 46 & 43 & 41 & 39 & 38 \\
\hline & 2 & 27 & 41 & 39 & 37 & 36 & 34 & 34 \\
\hline & 3 & 42 & 63 & 60 & 58 & 56 & 54 & 53 \\
\hline
\end{tabular}


111.

abela 15: Valores decadiários da evapotranspiração de referéncia medida (ETO) e estimada pelo modelo de Penman-Monteith CETOM, considerando diferentes resistencias do dossel e altura de vegetação igual a $0.12 \mathrm{~m}$, em Campinas-SP, ano de 1958. Valores em $\mathrm{mm}$ de água.

\begin{tabular}{|c|c|c|c|c|c|c|c|c|}
\hline \multicolumn{2}{|c|}{ Período } & \multirow{2}{*}{$\frac{\text { ETo }}{50}$} & \multirow{2}{*}{$\frac{\text { ETOM }_{1200}}{66}$} & \multirow{2}{*}{$\frac{E_{1220}}{63}$} & \multirow{2}{*}{$\frac{\text { ETOM }_{1240}}{60}$} & \multirow{2}{*}{$\frac{\text { ETOM }_{1260}}{58}$} & \multirow{2}{*}{$\frac{\text { ETOM }_{1200}}{56}$} & \multirow{2}{*}{$\frac{\text { ETOM }_{12 \mathrm{VR}}}{55}$} \\
\hline & 1 & & & & & & & \\
\hline \multirow[t]{2}{*}{ JAN } & 2 & 28 & 45 & 43 & 42 & 40 & 38 & 37 \\
\hline & 3 & 47 & 42 & 40 & 38 & 37 & 35 & 34 \\
\hline \multirow{3}{*}{ FEV } & 1 & 32 & 44 & 42 & 40 & 38 & 37 & 36 \\
\hline & 2 & 44 & 56 & 54 & 52 & 51 & 49 & 49 \\
\hline & 3 & 22 & 24 & 23 & 2ટ & 22 & 21 & 20 \\
\hline \multirow{3}{*}{ MAR } & 1 & 25 & 41 & 39 & 38 & 37 & 35 & 34 \\
\hline & 2 & 31 & 35 & 34 & 33 & 32 & 31 & 30 \\
\hline & 3 & 38 & 52 & 49 & 46 & 44 & 42 & 40 \\
\hline \multirow{3}{*}{$A B R$} & 1 & 24 & 32 & 30 & 29 & 27 & 26 & 24 \\
\hline & 2 & 19 & 29 & 27 & 25 & 24 & 23 & 20 \\
\hline & 3 & 23 & 34 & 32 & 30 & 28 & 27 & 23 \\
\hline \multirow{3}{*}{ MAI } & 1 & 14 & 27 & 26 & 25 & 23 & 22 & 20 \\
\hline & 2 & 15 & 31 & 29 & 27 & 25 & 24 & 21 \\
\hline & 3 & 17 & 21 & 20 & 18 & 17 & 16 & 14 \\
\hline \multirow{3}{*}{ JUN } & 1 & 19 & 28 & 27 & 26 & 24 & 23 & 21 \\
\hline & 2 & 16 & 23 & 22 & 20 & 19 & 18 & 16 \\
\hline & 3 & 9 & 30 & 28 & 26 & 25 & 24 & 20 \\
\hline \multirow{3}{*}{ JUL } & 1 & 17 & 33 & 30 & 28 & 26 & 25 & 21 \\
\hline & 2 & 11 & 24 & 23 & 21 & 20 & 19 & 16 \\
\hline & 3 & 17 & 36 & 34 & 32 & 30 & 28 & 24 \\
\hline \multirow{3}{*}{$A G O$} & 1 & 16 & 33 & 32 & 30 & 28 & 27 & 24 \\
\hline & 2 & 21 & 42 & 40 & 37 & 36 & 34 & 30 \\
\hline & 3 & 27 & 47 & 44 & 41 & 38 & 36 & 31 \\
\hline \multirow{3}{*}{ SET } & 1 & 20 & 37 & 35 & 33 & 32 & 30 & 27 \\
\hline & 2 & 15 & 37 & 33 & 31 & 28 & 26 & 23 \\
\hline & 3 & 23 & 41 & 39 & 37 & 35 & 33 & 30 \\
\hline \multirow{3}{*}{ OUT } & 1 & 33 & 59 & 55 & 52 & 49 & 46 & 45 \\
\hline & 2 & 23 & 56 & 52 & 48 & 45 & 42 & 42 \\
\hline & 3 & 23 & 42 & 40 & 38 & 36 & 35 & 33 \\
\hline \multirow{3}{*}{ NOV } & 1 & 44 & 60 & 57 & 54 & 51 & 49 & 48 \\
\hline & 2 & 26 & 51 & 49 & 47 & 45 & 44 & 43 \\
\hline & 3 & 34 & 53 & 50 & 48 & 46 & 44 & 43 \\
\hline \multirow{3}{*}{$D E Z$} & 1 & 42 & 59 & 57 & 55 & 53 & 51 & 51 \\
\hline & 2 & 35 & 37 & 36 & 35 & 34 & 34 & 33 \\
\hline & 3 & 41 & 64 & 50 & 56 & 53 & 50 & 50 \\
\hline
\end{tabular}


112.

Tabela 16: Valores decadiários da evapotranspiração de referência medida (ETO) e estimada pelo modelo de Penman-Monteith CETOMD, considerando diferentes resistencias do dossel e altura de vegetação igual a $0.12 \mathrm{~m}$, em Campinas-SP, ano de 1959. Valores em $\mathrm{mm}$ de água.

\begin{tabular}{|c|c|c|c|c|c|c|c|c|}
\hline \multicolumn{2}{|c|}{ Periodo } & \multirow{2}{*}{ ETo } & \multirow{2}{*}{$\frac{\text { ETOM }_{1200}}{47}$} & \multirow{2}{*}{$\frac{\text { ETOM }_{1220}}{45}$} & \multirow{2}{*}{$\frac{\text { ETOM }_{1240}}{43}$} & \multirow{2}{*}{$\frac{\text { ETOM }_{1260}}{41}$} & \multirow{2}{*}{$\frac{\text { ETOM }_{1280}}{39}$} & \multirow{2}{*}{$\frac{\text { ETOM }_{12 \mathrm{VR}}}{38}$} \\
\hline & 1 & & & & & & & \\
\hline JAN & 2 & 40 & 40 & 38 & 37 & 35 & 33 & 32 \\
\hline & 3 & 39 & 59 & 57 & 55 & 53 & 51 & 51 \\
\hline \multirow{3}{*}{ FEV } & 1 & 25 & 38 & 37 & 36 & 35 & 33 & 33 \\
\hline & 2 & 35 & 45 & 44 & 42 & 41 & 40 & 39 \\
\hline & 3 & 26 & 38 & 37 & 36 & 35 & 34 & 33 \\
\hline \multirow{3}{*}{ MAR } & 1 & 30 & 50 & 48 & 46 & 44 & 42 & 41 \\
\hline & 2 & 31 & 39 & 36 & 35 & 33 & 31 & 30 \\
\hline & 3 & 32 & 38 & 37 & 36 & 35 & 34 & 33 \\
\hline \multirow{3}{*}{ ABR } & 1 & 26 & 33 & 32 & 31 & 30 & 29 & 28 \\
\hline & 2 & 29 & 33 & 32 & 31 & 31 & 30 & 28 \\
\hline & 3 & 31 & 28 & 27 & 26 & 25 & 24 & 21 \\
\hline \multirow{3}{*}{ MAI } & 1 & 15 & 30 & 29 & 28 & 27 & 26 & 24 \\
\hline & 2 & 21 & 27 & 25 & 24 & 23 & 22 & 19 \\
\hline & 3 & 14 & 26 & 25 & 24 & 23 & 22 & 20 \\
\hline \multirow{3}{*}{ JUN } & 1 & 18 & 23 & 22 & 21 & 21 & 20 & 18 \\
\hline & 2 & 6 & 27 & 25 & 24 & 23 & 22 & 19 \\
\hline & 3 & 13 & 26 & 25 & 24 & 23 & 23 & 20 \\
\hline \multirow{3}{*}{ JUL } & 1 & 13 & 31 & 29 & 28 & 26 & 25 & 22 \\
\hline & 2 & 16 & 30 & 29 & 28 & 27 & 26 & 23 \\
\hline & 3 & 18 & 32 & 31 & 30 & 28 & 28 & 25 \\
\hline \multirow{3}{*}{$A G O$} & 1 & 12 & 23 & 22 & 21 & 20 & 19 & 17 \\
\hline & 2 & 18 & 38 & 26 & 25 & 24 & 23 & 20 \\
\hline & 3 & 19 & 43 & 41 & 39 & 38 & 36 & 32 \\
\hline \multirow{3}{*}{ SET } & 1 & 15 & 29 & 28 & 28 & 27 & 26 & 24 \\
\hline & 2 & 22 & 44 & 41 & 39 & 36 & 34 & 30 \\
\hline & 3 & 27 & 43 & 41 & 39 & 37 & 35 & 31 \\
\hline \multirow{3}{*}{ OUT } & 1 & 25 & 56 & 53 & 50 & 48 & 46 & 43 \\
\hline & 2 & 32 & 40 & 39 & 38 & 37 & 35 & 33 \\
\hline & 3 & 34 & 53 & 50 & 48 & 46 & 44 & 42 \\
\hline \multirow{3}{*}{ NOV } & 1 & 31 & 44 & 43 & 42 & 41 & 40 & 39 \\
\hline & 2 & 23 & 51 & 48 & 46 & 43 & 41 & 40 \\
\hline & 3 & 44 & 43 & 42 & 40 & 38 & 37 & 36 \\
\hline \multirow{3}{*}{$D E Z$} & 1 & 40 & 45 & 43 & 41 & 40 & 39 & 38 \\
\hline & 2 & 31 & 60 & 57 & 55 & 53 & 51 & 51 \\
\hline & 3 & 40 & 54 & 52 & 51 & 49 & 47 & 48 \\
\hline
\end{tabular}


113.

abela 18: Valores mensais da evapotranspiração de referéncia medida (ETO) e estimada pelo modelo de Penman-Monteith (ETOM. considerando diferentes resistencias do dossel e uma altura da vegetação de $0,06 \mathrm{~m}$, em Campinas-SP, ano de 1956 . Valores em $\mathrm{mm}$ de àgua.

\begin{tabular}{|c|c|c|c|c|c|c|c|}
\hline Período & ETo & ETOM $_{0000}$ & ETOM $_{0020}$ & ETOM $_{0640}$ & ETOM $_{0000}$ & ETOM $_{0680}$ & ETOM $_{\text {OGVR }}$ \\
\hline JAN & 155 & 190 & 182 & 174 & 167 & 151 & 143 \\
\hline FEV & 115 & 126 & 121 & 117 & 113 & 109 & 92 \\
\hline MAR & 111 & 143 & 138 & 132 & 127 & 122 & 103 \\
\hline$\triangle B R$ & 73 & 89 & 84 & 81 & 77 & 74 & 55 \\
\hline MAI & 49 & 66 & 63 & 60 & 58 & 55 & 40 \\
\hline JUN & 29 & 57 & 54 & 52 & 49 & 47 & 34 \\
\hline JUL & 41 & 71 & 68 & 65 & 62 & 60 & 43 \\
\hline$A G O$ & 49 & 100 & 94 & 89 & 85 & 81 & 57 \\
\hline SET & 66 & 102 & 97 & 93 & 89 & 85 & 64 \\
\hline OUT & 88 & 149 & 141 & 133 & 127 & 121 & 97 \\
\hline NOV & 107 & 174 & 164 & 155 & 147 & 140 & 118 \\
\hline$D E Z$ & 100 & 162 & 154 & 148 & 141 & 136 & 115 \\
\hline
\end{tabular}

abela 19: Valores mensais da evapotranspiração de referéncia medida (ETO) e estimada pelo modelo de Penman-Monteith (ETOMD, considerando diferentes resistencias do dossel e altura de vegetação igual a $0.06 \mathrm{~m}$, em Campinas-SP, ano de 1957 . valores em $\mathrm{mm}$ de água.

\begin{tabular}{|c|c|c|c|c|c|c|c|}
\hline Periodo & ETO & ETOM $_{0000}$ & ETOM $_{0020}$ & ETOM $_{0040}$ & ETOM $_{0000}$ & ETOM $_{O \varnothing 00}$ & ETOM OOVR \\
\hline JAN & 101 & 149 & 142 & 135 & 129 & 124 & 103 \\
\hline FEV & 112 & 120 & 114 & 108 & 103 & 98 & 78 \\
\hline MAR & 108 & 133 & 127 & 122 & 117 & 113 & 93 \\
\hline$A B R$ & 82 & 92 & 87 & 83 & 79 & 75 & 54 \\
\hline MAI & 56 & 84 & 80 & 76 & 72 & 69 & 50 \\
\hline JUN & 50 & 73 & 69 & 66 & 63 & 60 & 43 \\
\hline JUL & 36 & 72 & 68 & 65 & 62 & 59 & 41 \\
\hline$A G O$ & 61 & 102 & 96 & 91 & 86 & 82 & 57 \\
\hline SET & 60 & 89 & 85 & 80 & 77 & 73 & 53 \\
\hline OUT & 121 & 157 & 150 & 143 & 137 & 131 & 107 \\
\hline NOV & 107 & 139 & 132 & 126 & 121 & 115 & 94 \\
\hline$D E Z$ & 113 & 144 & 138 & 133 & 128 & 124 & 106 \\
\hline
\end{tabular}


114.

Tabela 20: Valores mensais da evapotranspiração de referencia medida (ETO) estimada pelo modelo de Penman-Monteith (ETOM), considerando diferentes resistencias do dossel e altura de vegetação igual a $0.06 \mathrm{~m}$, em Campinas-SP, ano de 1958. Valores em $\mathrm{mm}$ de água.

\begin{tabular}{lrrrrrrrr}
\hline Periodo & ETO & ETOM $_{\text {OoOO }}$ & ETOM $_{\text {OOZO }}$ & ETOM $_{\text {OOKO }}$ & ETOM $_{\text {OOCOO }}$ & ETOM $_{\text {OOBO }}$ & ETOM $_{\text {OOVR }}$ \\
\hline JAN & 125 & 146 & 141 & 136 & 131 & 130 & 109 \\
FEV & 98 & 116 & 112 & 109 & 106 & 105 & 88 \\
MAR & 94 & 121 & 117 & 113 & 109 & 109 & 90 \\
ABR & 66 & 87 & 83 & 79 & 76 & 75 & 53 \\
MAI & 46 & 73 & 70 & 66 & 63 & 62 & 43 \\
JUN & 44 & 75 & 71 & 68 & 65 & 64 & 44 \\
JUL & 45 & 83 & 78 & 74 & 71 & 69 & 46 \\
AGO & 64 & 110 & 104 & 99 & 95 & 93 & 67 \\
SET & 58 & 106 & 100 & 95 & 90 & 88 & 62 \\
OUT & 79 & 146 & 139 & 132 & 126 & 124 & 98 \\
NOV & 104 & 154 & 148 & 143 & 138 & 137 & 117 \\
DEZ & 118 & 149 & 145 & 140 & 136 & 135 & 116 \\
\hline
\end{tabular}

Tabela 21: Valores mensais de evapotranspiração de referencia medida (ETO) e estimada pelo modelo de Penman-Monteith (ETOM. considerando diferentes resistencias do dossel e altura de vegetação igual a $0.06 \mathrm{~m}$, em Campinas-SP, ano de 1959 . Valores em $\mathrm{mm}$ de água.

\begin{tabular}{|c|c|c|c|c|c|c|c|}
\hline Periodo & ETo & ETOM $_{0000}$ & ETOM $_{0020}$ & ETOM $_{0640}$ & ETOM $_{0000}$ & ETOM $_{0680}$ & ETOM $_{\text {OOVR }}$ \\
\hline JAN & 100 & 139 & 134 & 130 & 125 & 121 & 100 \\
\hline FEV & 88 & 118 & 115 & 112 & 110 & 107 & 96 \\
\hline MAR & 93 & 120 & 116 & 112 & 109 & 105 & 89 \\
\hline$A B R$ & 86 & 89 & 86 & 84 & 82 & 80 & 60 \\
\hline MAI & 50 & 77 & 75 & 72 & 70 & 68 & 53 \\
\hline JUN & 37 & 70 & 68 & 66 & 63 & 61 & 47 \\
\hline JUL & 47 & 85 & 82 & 80 & 77 & 75 & 59 \\
\hline$A G O$ & 49 & 84 & 81 & 78 & 75 & 72 & 55 \\
\hline SET & 64 & 105 & 101 & 97 & 94 & 90 & 68 \\
\hline OUT & 91 & 138 & 133 & 128 & 123 & 119 & 100 \\
\hline NOV & 98 & 132 & 127 & 123 & 119 & 116 & 100 \\
\hline$D E Z$ & 111 & 152 & 147 & 143 & 139 & 135 & 122 \\
\hline
\end{tabular}


115.

Tabela 22: Valores mensais de evapotranspiração de referencia medida (ETO) e estimada pelo modelo de Penman-Monteith (ETOM. considerando diferentes resistencias do dossel e altura de vegetação igual a $0.1 \mathrm{em}$, em Campinas-SP, ano de 1956. Valores em $\mathrm{mm}$ de água.

\begin{tabular}{lrrrrrrr}
\hline Periodo & ETo & ETOM $_{\mathbf{1 2 0 0}}$ & ETOM $_{\mathbf{1 2 2 0}}$ & ETOM $_{\mathbf{1 2 4 0}}$ & ETOM $_{\mathbf{1 2 6 0}}$ & ETOM $_{\mathbf{1 2 8 0}}$ & ETOM $_{\mathbf{1 2 V R}}$ \\
\hline JAN & 155 & 203 & 192 & 182 & 174 & 165 & 165 \\
FEV & 115 & 133 & 127 & 121 & 116 & 111 & 107 \\
MAR & 111 & 152 & 144 & 137 & 131 & 125 & 121 \\
ABR & 73 & 96 & 91 & 86 & 81 & 77 & 69 \\
MAI & 49 & 71 & 67 & 63 & 60 & 57 & 51 \\
JUN & 29 & 61 & 58 & 55 & 52 & 49 & 43 \\
JUL & 41 & 77 & 73 & 69 & 66 & 62 & 55 \\
AGO & 49 & 111 & 103 & 96 & 90 & 85 & 74 \\
SET & 66 & 112 & 106 & 101 & 95 & 90 & 80 \\
OUT & 88 & 160 & 150 & 140 & 132 & 125 & 119 \\
NOV & 107 & 188 & 175 & 163 & 153 & 141 & 142 \\
DEZ & 109 & 173 & 163 & 154 & 146 & 139 & 136 \\
\hline
\end{tabular}

Cabela 23: Valores mensais de evapotranspiração de referencia medida (ETO) e estimada pelo modelo de Penman-Monteith (EiOM, considerando diferentes resistencias do dossel e altura de vegetação igual a $0.12 \mathrm{~m}$, em Campinas-SP, ano de 1957. valores em $\mathrm{mm}$ de água.

\begin{tabular}{lrrrrrrr}
\hline Periodo & ETo & ETOM $_{\mathbf{1 2 0 0}}$ & ETOM $_{\mathbf{1 2 2 0}}$ & ETOM $_{\mathbf{1 2 4 0}}$ & ETOM $_{\mathbf{1 2 6 0}}$ & ETOM $_{\mathbf{1 2 8 0}}$ & ETOM $_{\mathbf{1 2 V R}}$ \\
\hline JAN & 101 & 158 & 149 & 140 & 133 & 126 & 123 \\
FEV & 112 & 128 & 120 & 112 & 106 & 100 & 96 \\
MAR & 108 & 140 & 133 & 126 & 120 & 115 & 111 \\
ABR & 82 & 100 & 93 & 88 & 83 & 78 & 70 \\
MAI & 56 & 92 & 86 & 81 & 77 & 73 & 64 \\
JUN & 50 & 80 & 75 & 71 & 67 & 64 & 55 \\
JUL & 36 & 79 & 74 & 70 & 66 & 62 & 53 \\
AGO & 61 & 114 & 106 & 98 & 92 & 87 & 74 \\
SET & 50 & 97 & 91 & 85 & 80 & 76 & 68 \\
OUT & 121 & 170 & 160 & 151 & 143 & 136 & 129 \\
NOV & 107 & 149 & 140 & 132 & 125 & 119 & 114 \\
DEZ & 113 & 151 & 144 & 137 & 131 & 126 & 124 \\
\hline
\end{tabular}


116.

Tabela 24: Valores mensais de evapotranspiraça de referéncia medida (ETO) e estimada pelo modelo de Penman-Monteith (ETOM. considerando diferentes resistencias do dossel e altura de vegetação igual a $0.1 \mathrm{Zm}$, em Campinas-SP, ano de 1958. Valores em $\mathrm{mm}$ de água.

\begin{tabular}{lrrrrrrr}
\hline Per IOdO & ETO & ETOM $_{\mathbf{1 2 0 0}}$ & ETOM $_{\mathbf{1 2 2 0}}$ & ETOM $_{\mathbf{1 2 4 0}}$ & ETOM $_{\mathbf{1 2 0 0}}$ & ETOM $_{\mathbf{1 2 8 0}}$ & ETOM $_{\mathbf{1 2 V R}}$ \\
\hline JAN & 125 & 154 & 147 & 141 & 135 & 129 & 126 \\
FEV & 98 & 122 & 117 & 112 & 198 & 104 & 101 \\
MAR & 94 & 126 & 121 & 116 & 111 & 107 & 104 \\
ABR & 66 & 94 & 89 & 84 & 79 & 75 & 67 \\
MAI & 46 & 79 & 74 & 70 & 66 & 63 & 55 \\
JUN & 44 & 82 & 77 & 72 & 69 & 65 & 57 \\
JUL & 45 & 92 & 86 & 80 & 75 & 71 & 61 \\
AGO & 64 & 122 & 115 & 108 & 102 & 97 & 84 \\
SET & 58 & 116 & 109 & 102 & 96 & 90 & 80 \\
OUT & 79 & 156 & 147 & 138 & 130 & 123 & 119 \\
NOV & 104 & 164 & 156 & 149 & 143 & 137 & 134 \\
DEZ & 118 & 157 & 151 & 145 & 139 & 134 & 132 \\
\hline
\end{tabular}

Tabela 25: Valores mensais de evapotranspiração de referencia medida (ETO) e estimada pelo modelo de Penman-Monteith (ETOM, considerando diferentes resistencias do dossel e altura de vegetação igual a $0.1 \mathrm{Zm}$, em Campinas-SP, ano de 1959. Valores em $\mathrm{mm}$ de água.

\begin{tabular}{lrrrrrrr}
\hline Periodo & ETo & ETOM $_{\mathbf{1 2 0 0}}$ & ETOM $_{\mathbf{1 2 2 0}}$ & ETOM $_{\mathbf{1 2 4 0}}$ & ETOM $_{\mathbf{1 2 0 0}}$ & ETOM $_{\mathbf{1 2 8 0}}$ & ETOM $_{\mathbf{1 2 V R}}$ \\
\hline JAN & 100 & 145 & 139 & 133 & 128 & 123 & 121 \\
FEV & 88 & 122 & 119 & 115 & 112 & 108 & 106 \\
MAR & 93 & 126 & 121 & 116 & 111 & 107 & 103 \\
ABR & 86 & 94 & 91 & 88 & 85 & 83 & 77 \\
MAI & 50 & 83 & 79 & 76 & 73 & 71 & 64 \\
JUN & 37 & 76 & 73 & 70 & 57 & 64 & 57 \\
JUL & 47 & 93 & 90 & 86 & 83 & 80 & 70 \\
AGO & 49 & 92 & 87 & 83 & 80 & 76 & 67 \\
SET & 64 & 116 & 110 & 105 & 100 & 96 & 85 \\
OUT & 91 & 147 & 140 & 134 & 128 & 123 & 117 \\
NOV & 98 & 139 & 133 & 128 & 123 & 118 & 115 \\
DEZ & 111 & 158 & 152 & 147 & 142 & 137 & 136 \\
\hline
\end{tabular}

